\title{
Spatially Resolved Production of Platinum Nanoparticles in Metallosupramolecular Polymers
}

\section{Supporting Information}

Luis M. Olaechea, ${ }^{1}$ Lucas Montero de Espinosa,${ }^{1}$ Emad Oveisi, ${ }^{2}$ Sandor Balog, ${ }^{1}$ Preston Sutton, ${ }^{1}$

Stephen Schrettl, ${ }^{1, *}$ Christoph Weder ${ }^{1, *}$

1 Adolphe Merkle Institute, University of Fribourg

Chemin des Verdiers 4, 1700 Fribourg, Switzerland

2 Interdisciplinary Centre for Electron Microscopy

EPFL, 1015 Lausanne, Switzerland

* To whom correspondence should be addressed:

stephen.schrettl@unifr.ch

christoph.weder@unifr.ch 


\section{Table of Contents}

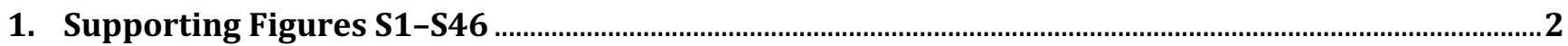

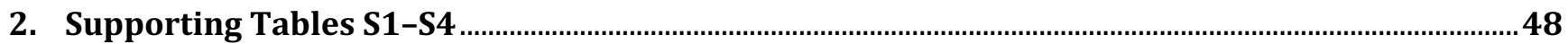

3. Captions for Supporting Movies S1-S8

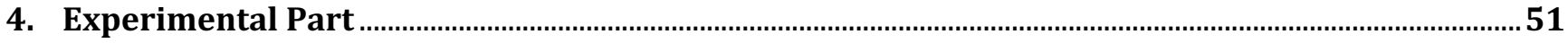

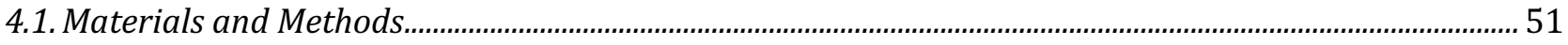

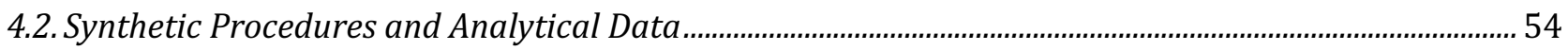

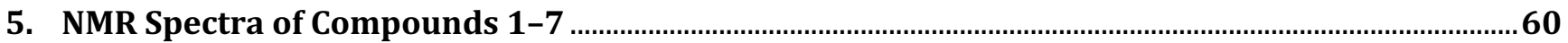

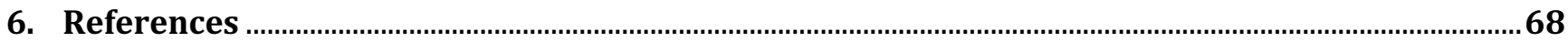




\section{Supporting Figures S1-S46}

A
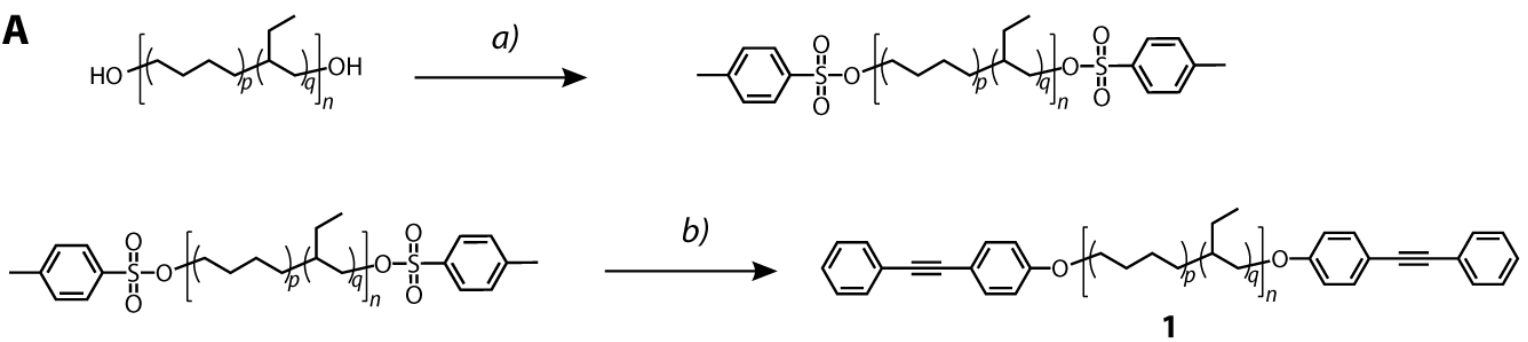

B

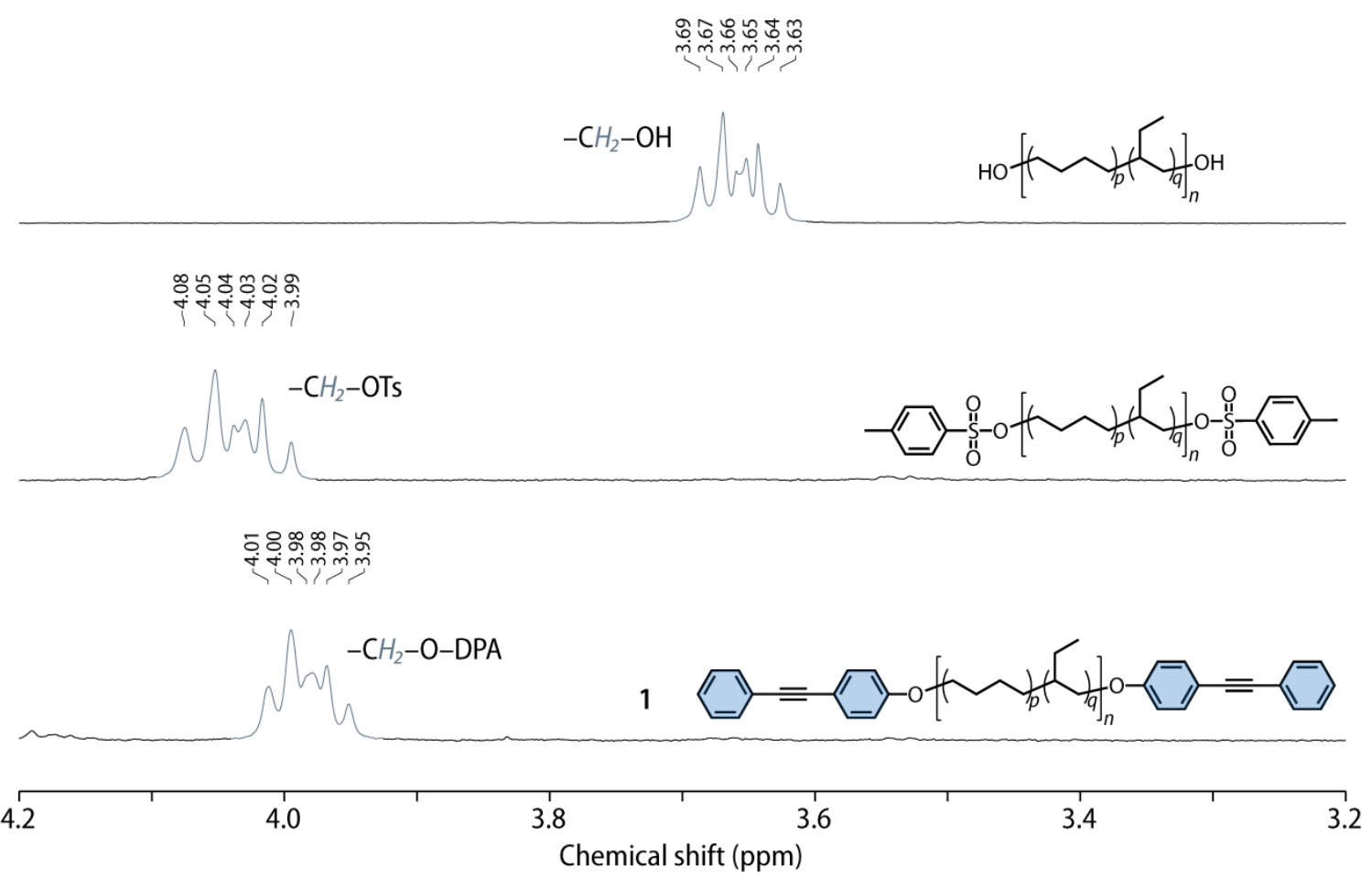

Supporting Figure S1. (A) Scheme depicting the synthesis of the telechelic diphenylacetylene-functionalized poly(ethylene-co-butylene) (PEB) 1 that was prepared from hydroxyl-terminated PEB having a number-average molecular weight $\left(M_{\mathrm{n}}\right)$ of $3100 \mathrm{~g} \mathrm{~mol}^{-1}$ (with $p \approx 0.36, q \approx 0.64, n \approx 55$ ). Reagents and conditions: $a$ ) $p$-toluenesulfonyl chloride, pyridine, DCM, $73 \%$; b) 4-(phenylethynyl)phenol, $\mathrm{K}_{2} \mathrm{CO}_{3}, \mathrm{DMF} /$ Toluene $(1: 1), 100{ }^{\circ} \mathrm{C}, 78 \%$. (B) Comparison of the sections of the ${ }^{1} \mathrm{H}-\mathrm{NMR}$ spectra $\left(400 \mathrm{MHz}, 297.2 \mathrm{~K}, \mathrm{CDCl}_{3}\right)$ of the bis-hydroxyl-terminated PEB (top), the bis-tosyl-terminated PEB (center), and the bis-diphenylacetylene (DPA) terminated macromonomer 1 (bottom) that show the signals associated with the methylene groups $\left(-\mathrm{O}-\mathrm{CH}_{2}-\right)$. The shift of the signals indicates full conversion (within the limits of ${ }^{1} \mathrm{H}-\mathrm{NMR}$ spectroscopy). 


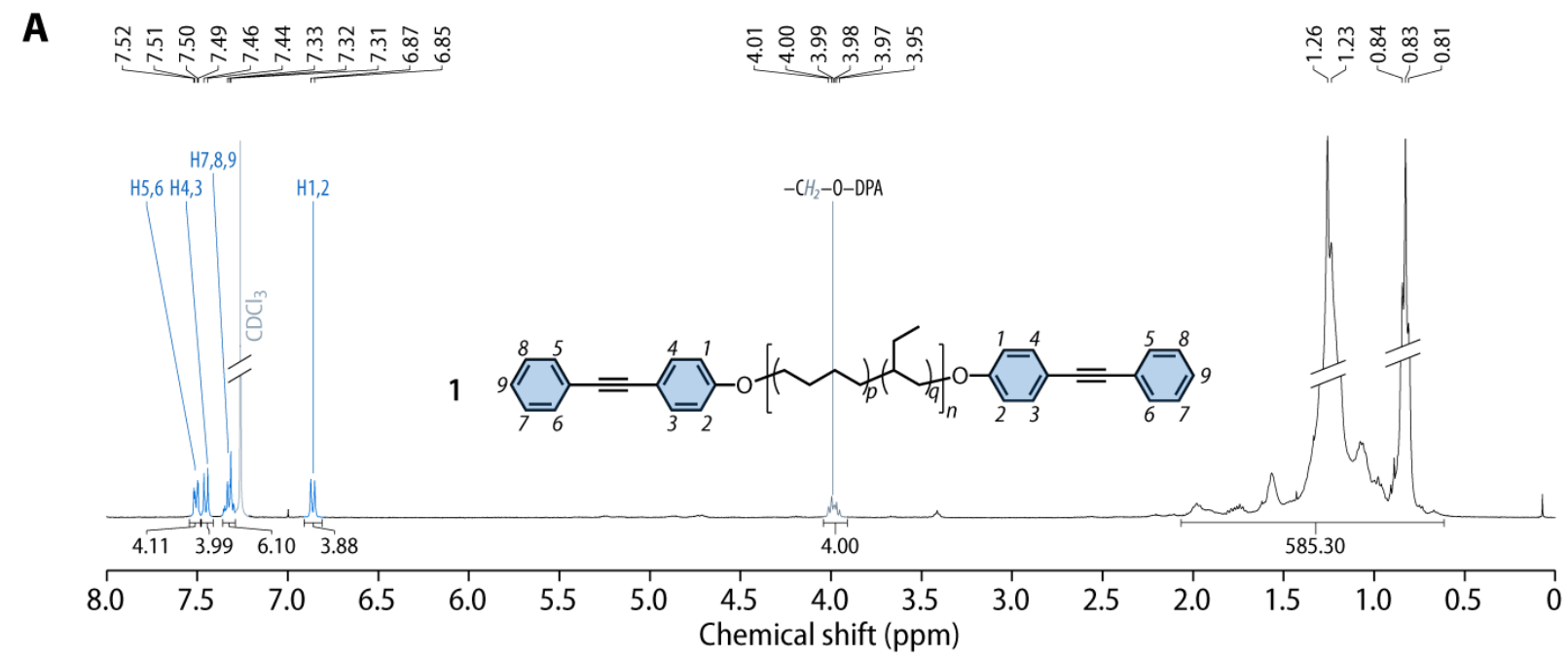

B

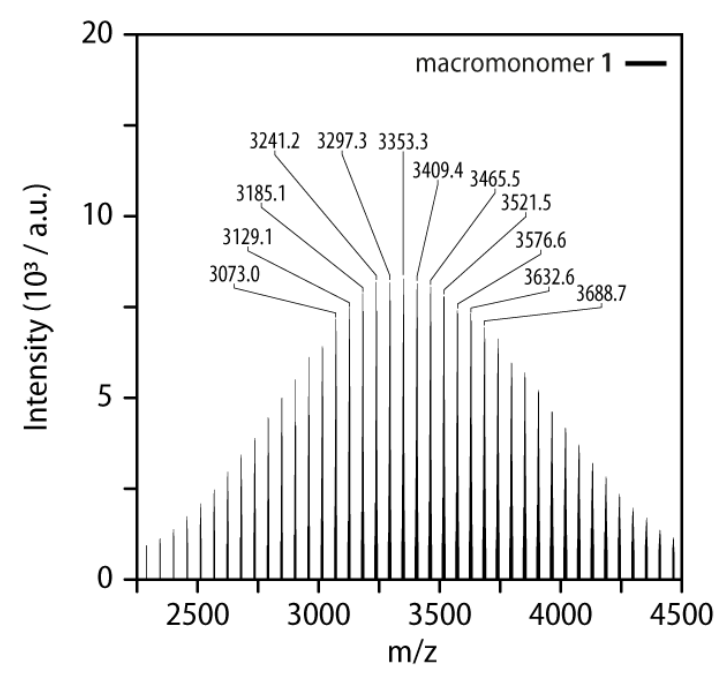

C

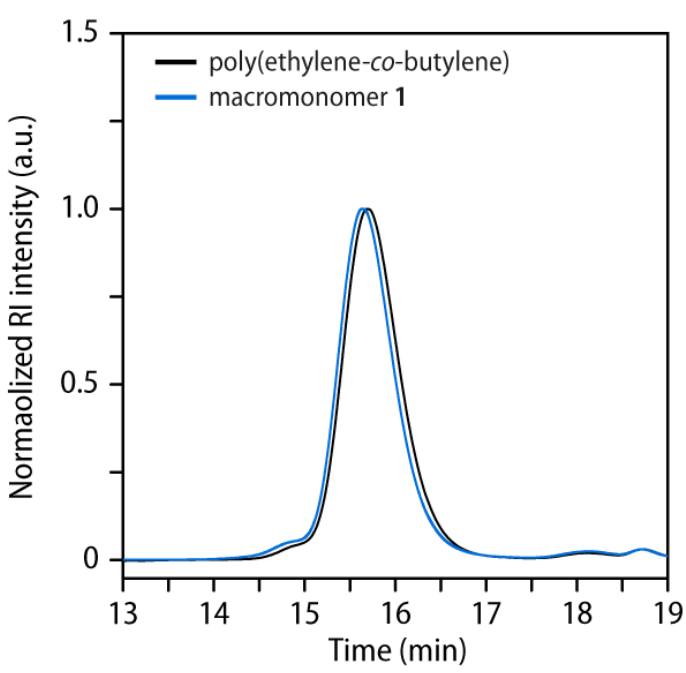

Supporting Figure S2. (A) ${ }^{1} \mathrm{H}-\mathrm{NMR}$ spectrum $\left(400 \mathrm{MHz}, 297.2 \mathrm{~K}, \mathrm{CDCl}_{3}\right)$ of macromonomer 1 in $\mathrm{CDCl}_{3}(c=$ $0.001 \mathrm{mmol} \mathrm{L}^{-1}$ ). (B) Matrix-assisted laser desorption/ionization (MALDI) time-of-flight (TOF) mass spectrum of macromonomer 1 (DCTB matrix). (C) Comparison of the size exclusion chromatography (SEC) traces of the hydroxyl-terminated poly(ethylene-co-butylene) starting material (black) and the prepared macromonomer 1 (blue). 


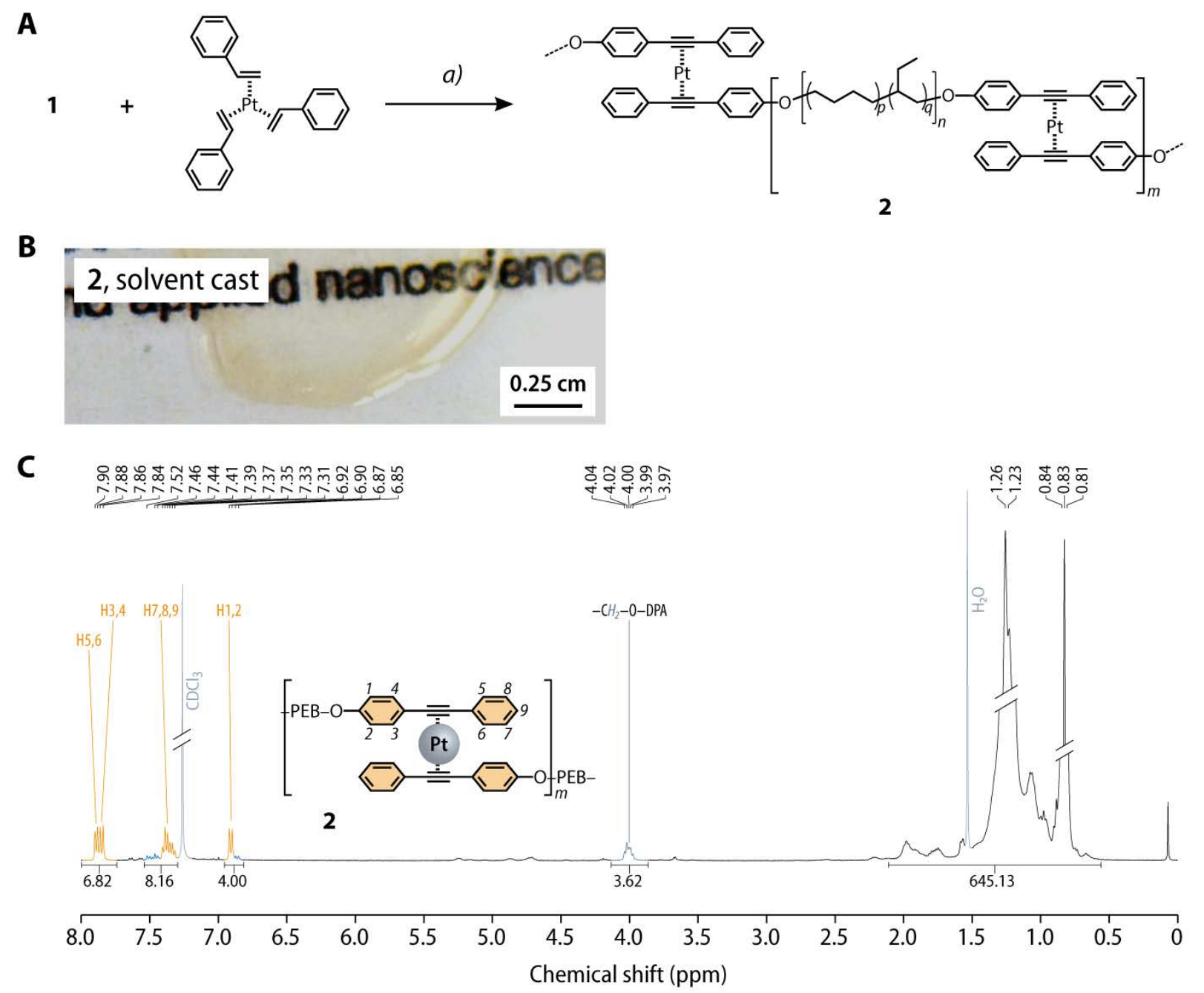

Supporting Figure S3. (A) Scheme depicting the synthesis of the metallosupramolecular polymer 2 from the telechelic diphenylacetylene-functionalized poly(ethylene-co-butylene) 1 (with $p \approx 0.36, q \approx 0.64, n \approx 55$ ). Reagents and conditions: a) chain extension by ligand exchange-driven polymerization, $1 \mathrm{~h}$, room temperature. (B) Picture of a film of MSP 2 that was obtained by preparing solutions with a stoichiometric 1:2 metal-to-ligand ratio by spectrophotometric titrations, subsequent casting onto a glass substrate, and drying. (C) ${ }^{1} \mathrm{H}-\mathrm{NMR}$ spectrum (400 MHz, 297.2 $\left.\mathrm{K}, \mathrm{CDCl}_{3}\right)$ of the MSP 2 prepared as described for (B) after re-dissolving the solid MSP 2 in $\mathrm{CDCl}_{3}(c \approx 1 \mu \mathrm{mol} \mathrm{L}-1)$. The spectrum corroborates the formation of the $\operatorname{bis}\left(\eta^{2}\right.$-alkyne $) \mathrm{Pt}^{0}$ complexes and also reveals a small fraction of free ligands. As observed for the MSP 2 (Figure S4) as well as the molecular complex 4 (Figure S11), the fraction of free ligand increases with time, suggesting a dissociation of the ML complexes in solution, likely under formation of Pt clusters. 

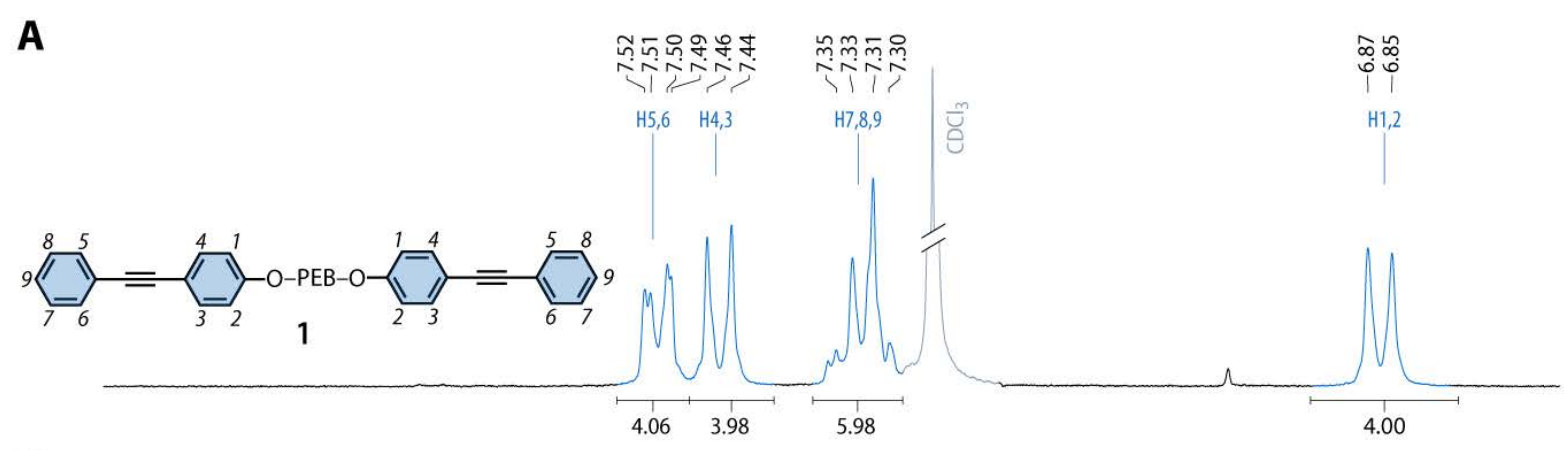

B
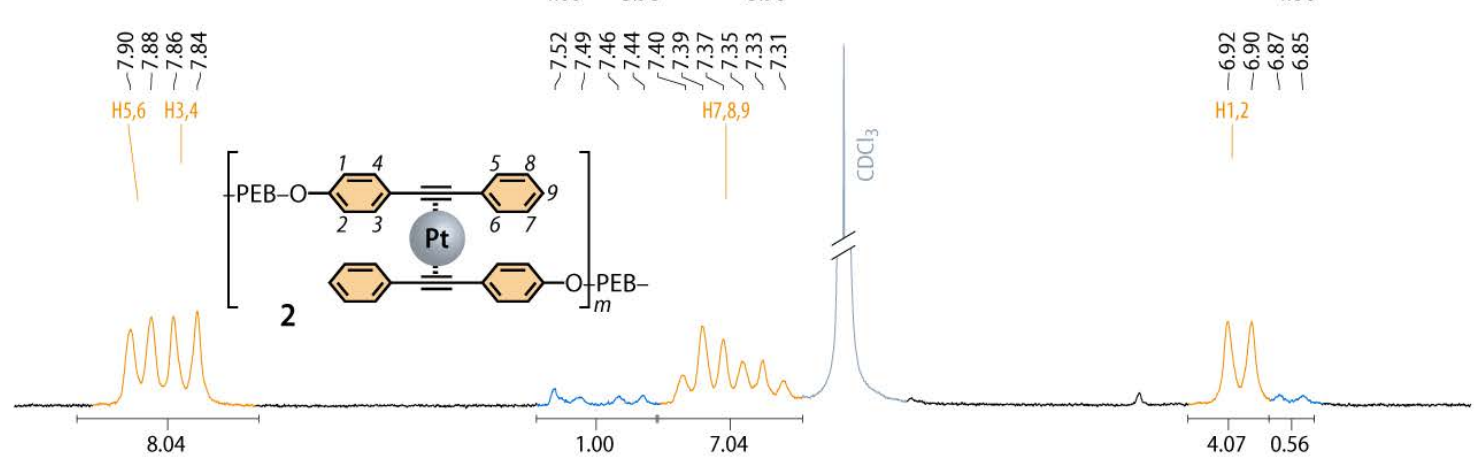

C

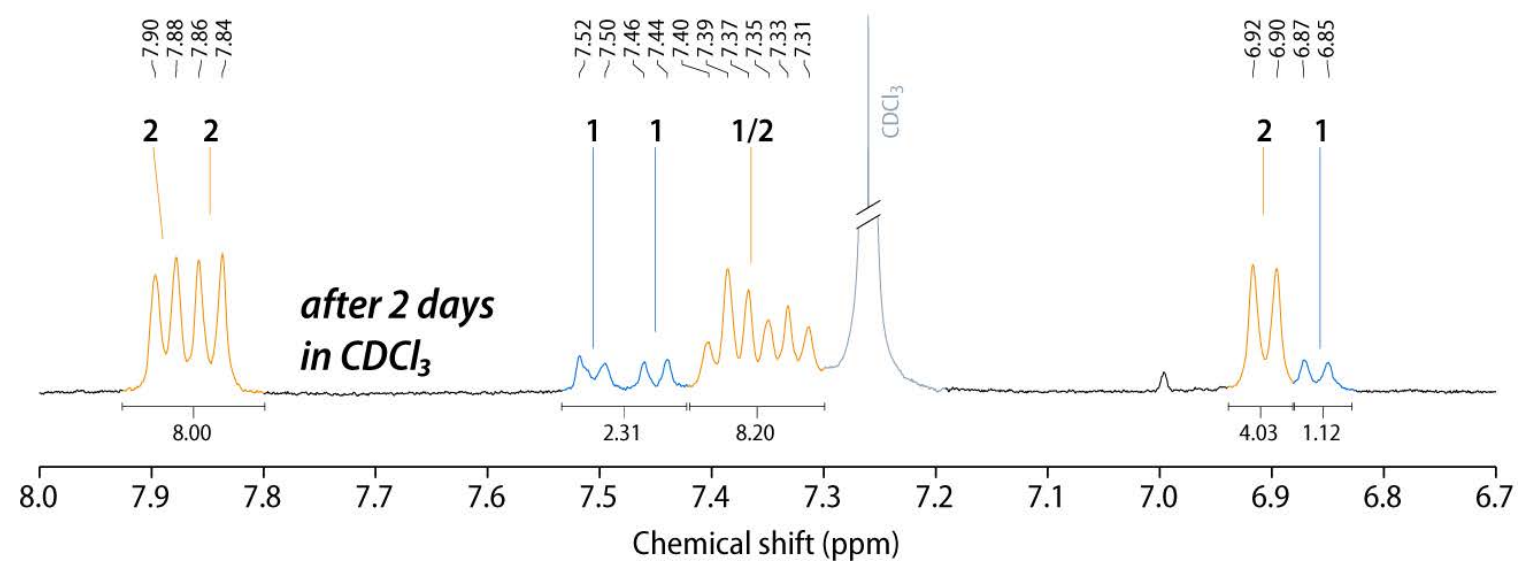

Supporting Figure S4. Comparison of the aromatic region of the ${ }^{1} \mathrm{H}$ NMR spectra $\left(400 \mathrm{MHz}, 297.2 \mathrm{~K}, \mathrm{CDCl}_{3}\right)$ of $(\mathbf{A})$ macromonomer 1, (B) the spectrum recorded just after re-dissolving the solvent-cast MSP $\mathbf{2}$ in $\mathrm{CDCl}_{3}$, as well as (C) the spectrum after MSP 2 was kept in ambient conditions in $\mathrm{CDCl}_{3}$ solution for $48 \mathrm{~h}$. The fraction of free ligand after dissolution of MSP 2 is estimated to be on the order of ca. $13 \%$, while it is observed to increase to ca. $28 \%$ after $48 \mathrm{~h}$ in $\mathrm{CDCl}_{3}$ solution in ambient conditions. 
A

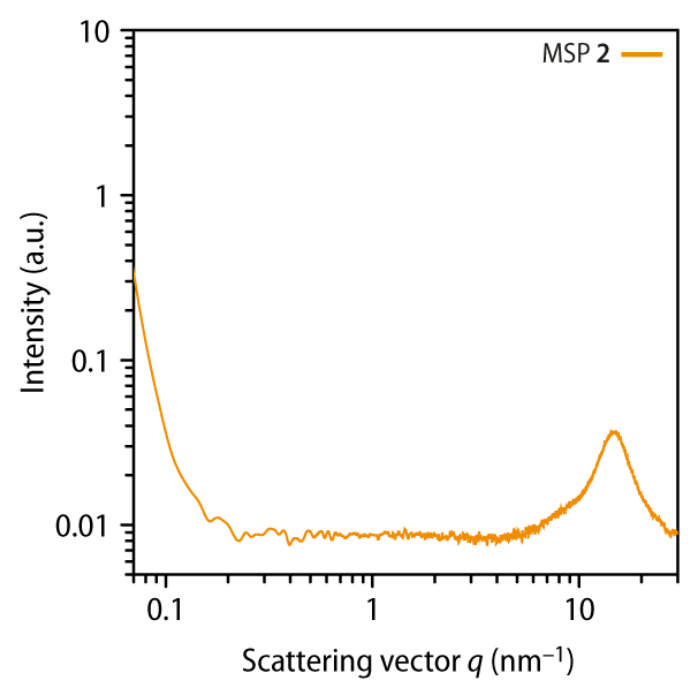

B

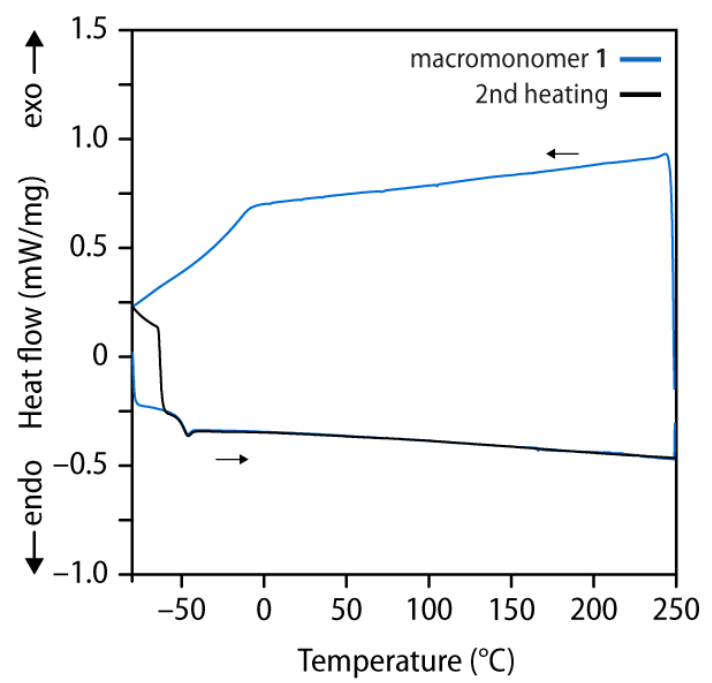

Supporting Figure S5. (A) Small angle X-ray scattering (SAXS) spectrum of a film of MSP 2. The featureless spectrum suggests the absence of a microphase separation between the metal-ligand complexes and the poly(ethylene-co-butylene) backbone. Samples for characterization by SAXS were prepared from solutions in which a stoichiometric 1:2 metal-to-ligand ratio had been established by spectrophotometric titrations that were then solvent-cast onto a poly(tetrafluoroethylene) substrate and dried. The resulting tacky, transparent film of MSP 2 was transferred onto a polyimide (Kapton) substrate for the SAXS measurements. The maximum at ca. $15 \mathrm{~nm}^{-1}$ corresponds to the so-called amorphous halo and the background of the Kapton substrate. (B) Differential scanning calorimetry (DSC) traces of macromonomer 1. Shown are first heating and cooling (blue) and second (black) heating scans $\left(10^{\circ} \mathrm{C} \mathrm{min}-1\right)$. A glass transition $\left(T_{\mathrm{g}}\right)$ is observed at ca. $-42{ }^{\circ} \mathrm{C}$ that is associated with the poly(ethylene-co-butylene) core. The absence of any additional transition suggests the absence of microphase separation and crystallization of the diphenylacetylene ligands in the macromonomer. 


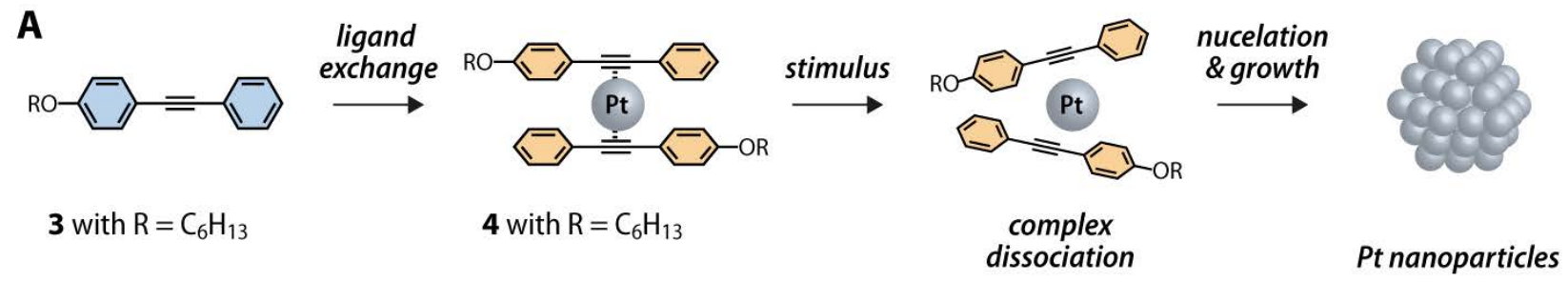

B

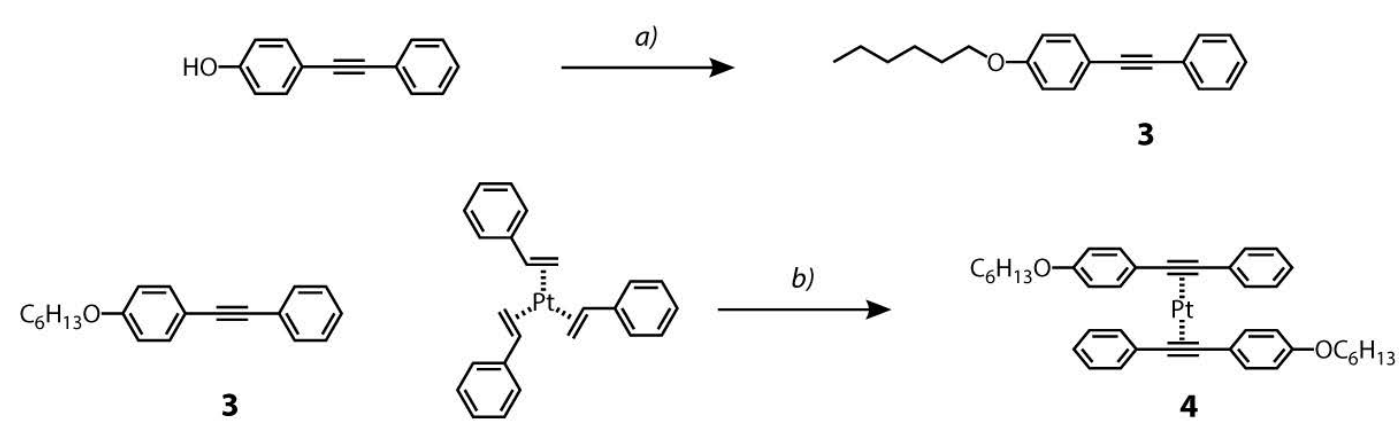

Supporting Figure S6. (A) Schematic depiction of the low-molecular-weight bis $\left(\eta^{2}\right.$-alkyne $) \mathrm{Pt}^{0}$ model complex 4 that was prepared by the ligand-exchange reaction between $\mathrm{Pt}$ (styrene) 3 and 1-(hexyloxy)-4-(phenylethynyl)-benzene 3 ( $\left.\mathrm{R}=n \mathrm{C}_{6} \mathrm{H}_{13}\right)$. The model complex 4 was used to investigate the stability and dissociation behavior of the zerovalent Pt-complexes utilized in this study. (B) Scheme depicting the synthesis of the $\operatorname{bis}\left(\eta^{2}\right.$-alkyne $) \mathrm{Pt}^{0}$ model complex 4. Reagents and conditions: a) Hexyl $p$-toluenesulfonate, $\mathrm{K}_{2} \mathrm{CO}_{3}, \mathrm{DMF}, 40{ }^{\circ} \mathrm{C}, 82 \%$; $\left.b\right)$ room temperature, $69 \%$. 
A

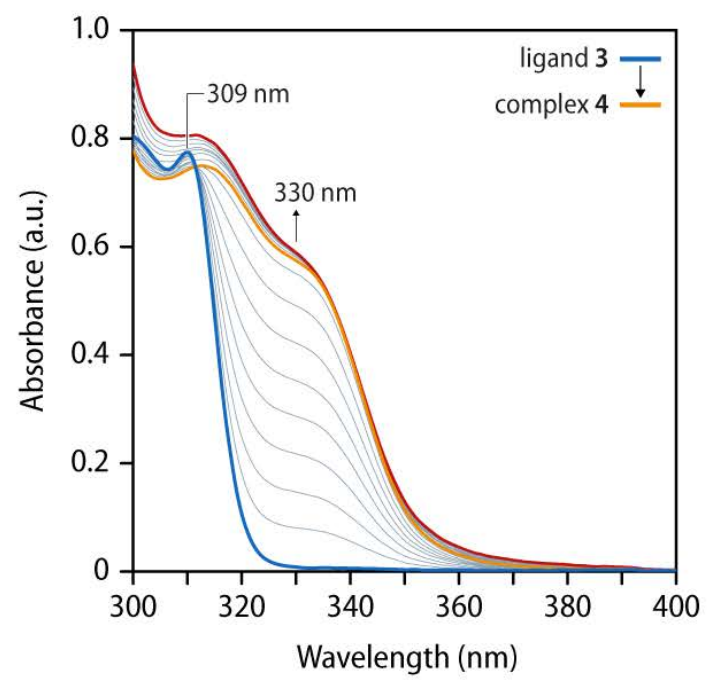

B

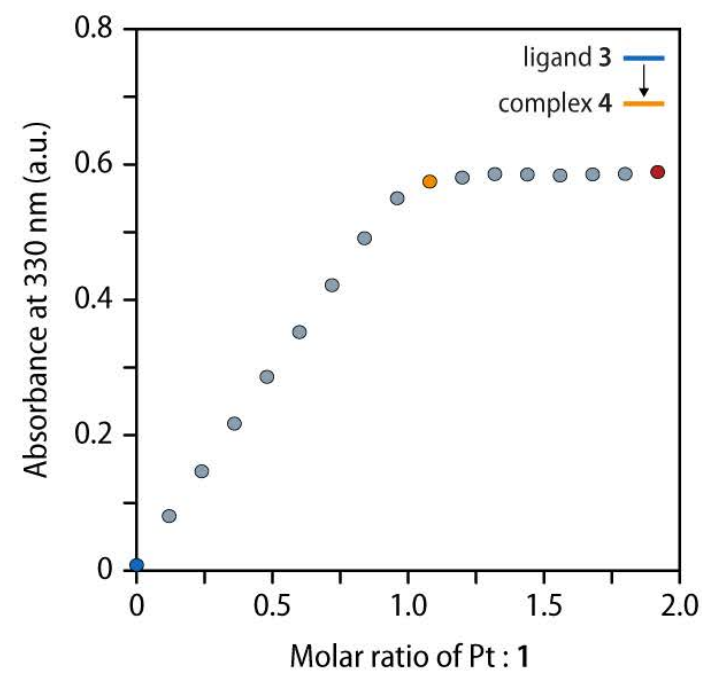

Supporting Figure S7. (A) UV-vis absorption spectra of solutions of ligand $\mathbf{3}$ ( $c=30 \mu \mathrm{mol} \mathrm{L}-1$ in $\mathrm{CHCl}_{3}$, blue line) and upon titration with aliquots of $\operatorname{Pt}(\text { styrene })_{3}\left(c=1.1 \mathrm{mmol} \mathrm{L}^{-1}\right.$ in $\left.\mathrm{CHCl}_{3}\right)$, indicating that the formation of the complex 4 is complete at a 1:2 metal-to-ligand ratio (orange line). (C) A plot of the absorption intensity of 4 at $330 \mathrm{~nm}$ against the platinum-to-ligand ratio levels off at the stoichiometric 1:2 ratio. 
A

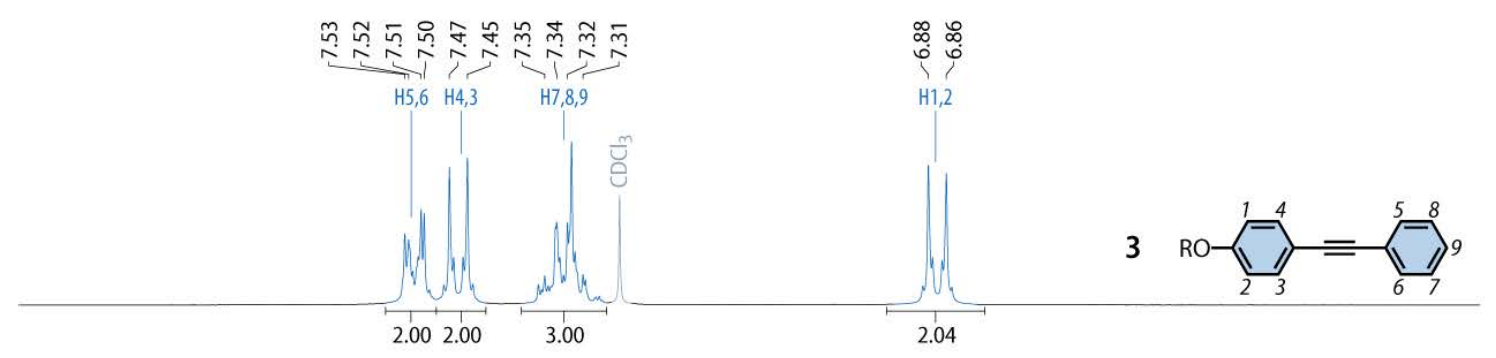

B

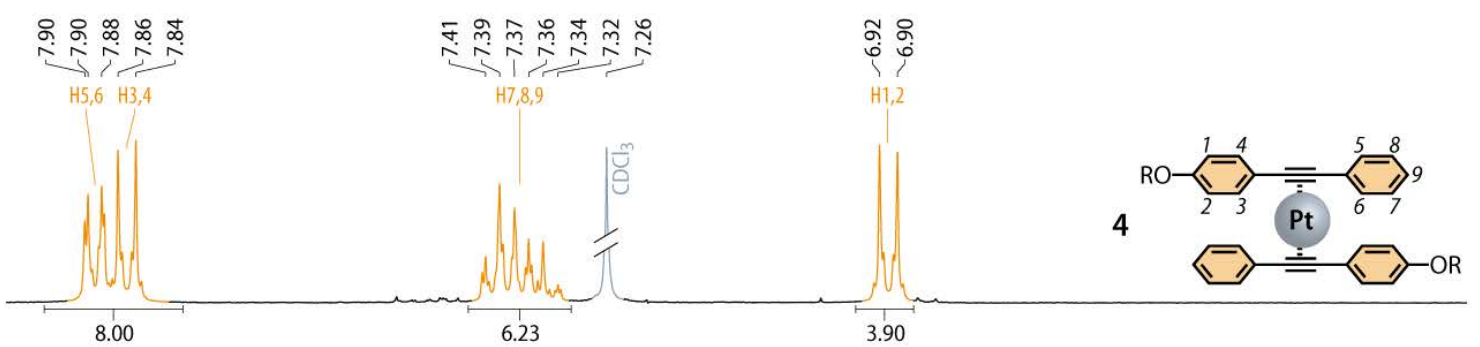

C

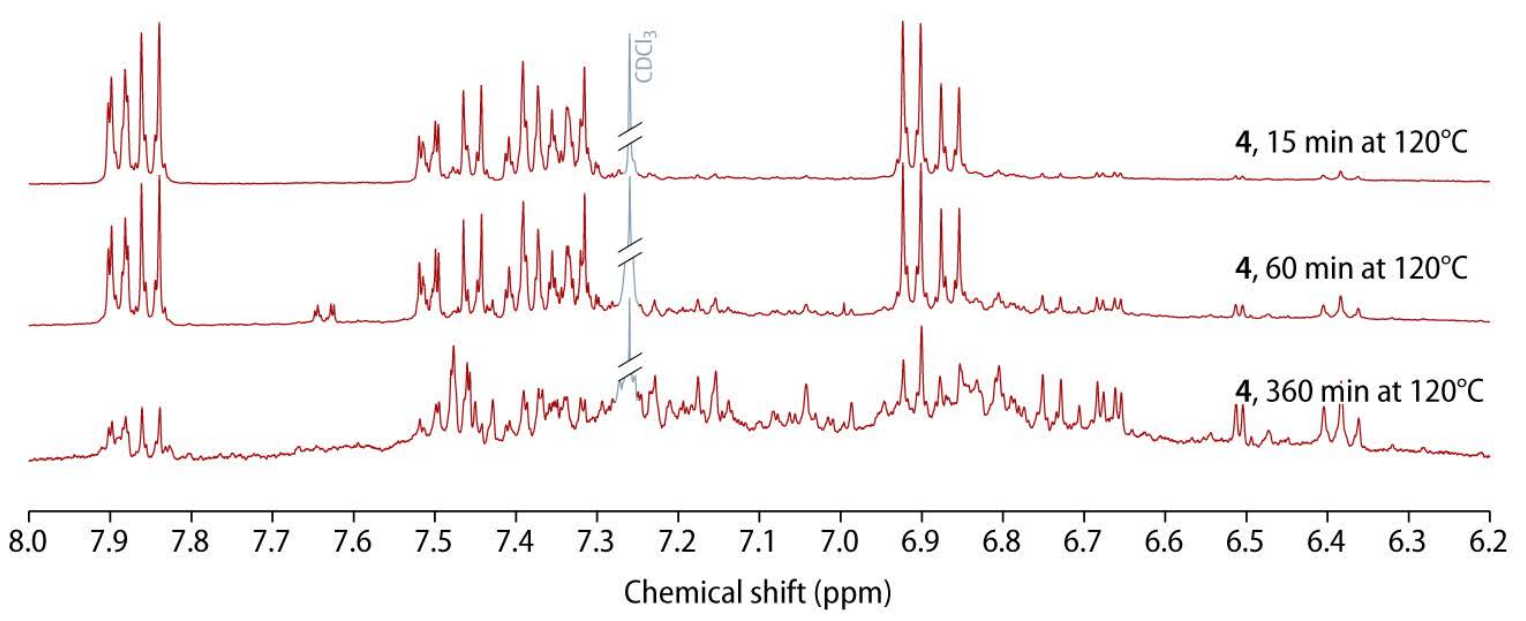

Supporting Figure S8. Comparison of the aromatic region of the ${ }^{1} \mathrm{H}$ NMR spectra $\left(400 \mathrm{MHz}, 297.2 \mathrm{~K}, \mathrm{CDCl}_{3}\right)$ of $(\mathbf{A})$ ligand 3, (B) bis( $\eta^{2}$-(1-hexyloxy-4-phenylethynyl-benzene) $) \mathrm{Pt}^{0} 4$ complex, as well as (C) the spectra of the residues of 4 obtained by heating to $120^{\circ} \mathrm{C}$ for 15,60 , and 360 min, respectively $\left(\mathrm{R}=n \mathrm{C}_{6} \mathrm{H}_{13}\right)$. 


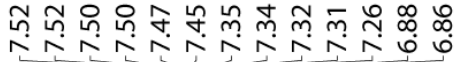

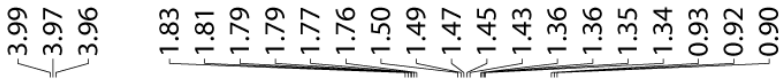

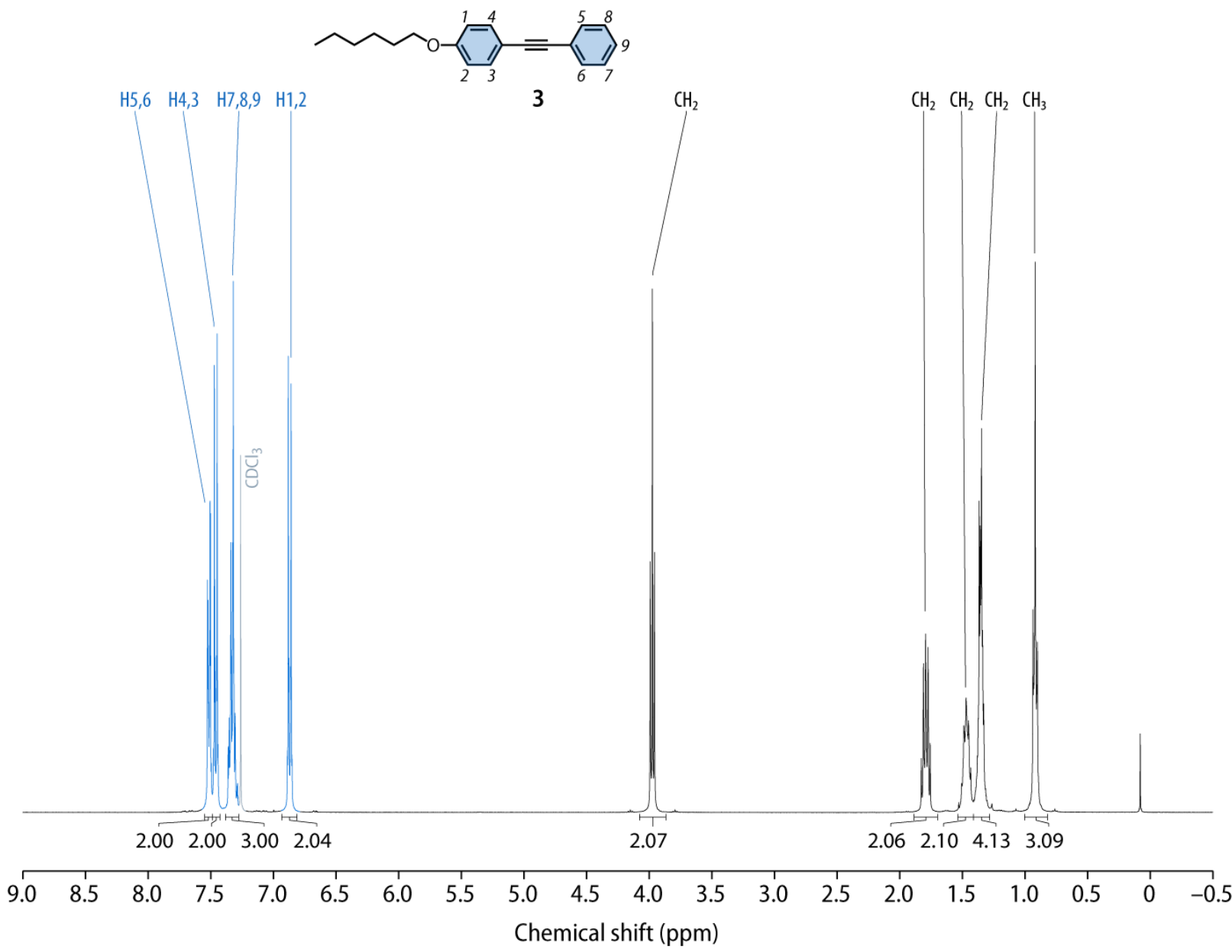

Supporting Figure S9. ${ }^{1} \mathrm{H}$ NMR spectrum $\left(400 \mathrm{MHz}, 297.2 \mathrm{~K}, \mathrm{CDCl}_{3}\right)$ of the ligand 1-hexyloxy-4-phenylethynyl-benzene $\mathbf{3}$. 


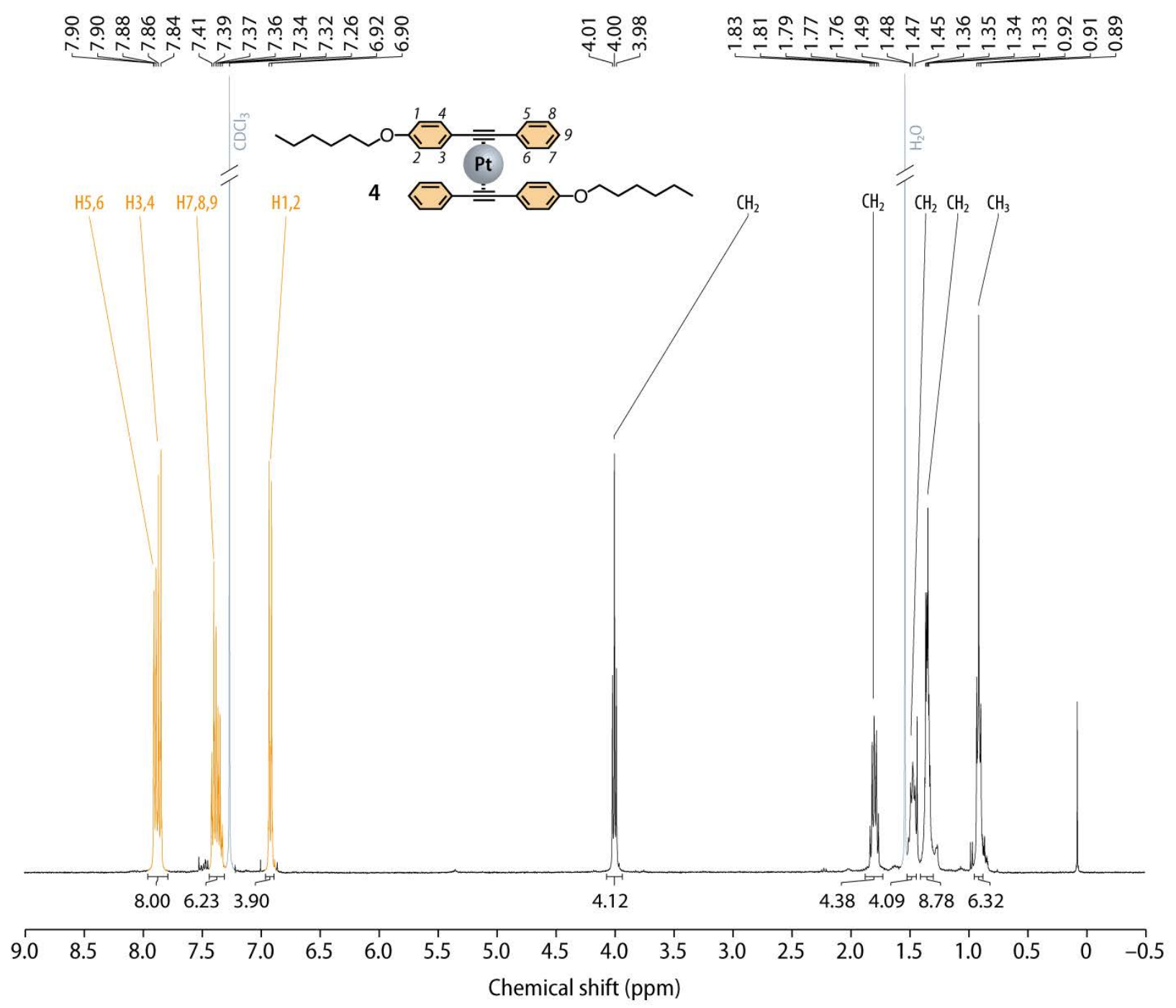

Supporting Figure S10. ${ }^{1} \mathrm{H}$ NMR spectrum $\left(400 \mathrm{MHz}, 297.2 \mathrm{~K}, \mathrm{CDCl}_{3}\right)$ of the bis $\left(\eta^{2}\right.$-(1-hexyloxy-4-phenylethynyl-benzene)) $\mathrm{Pt}^{0}$ complex 4. 
A

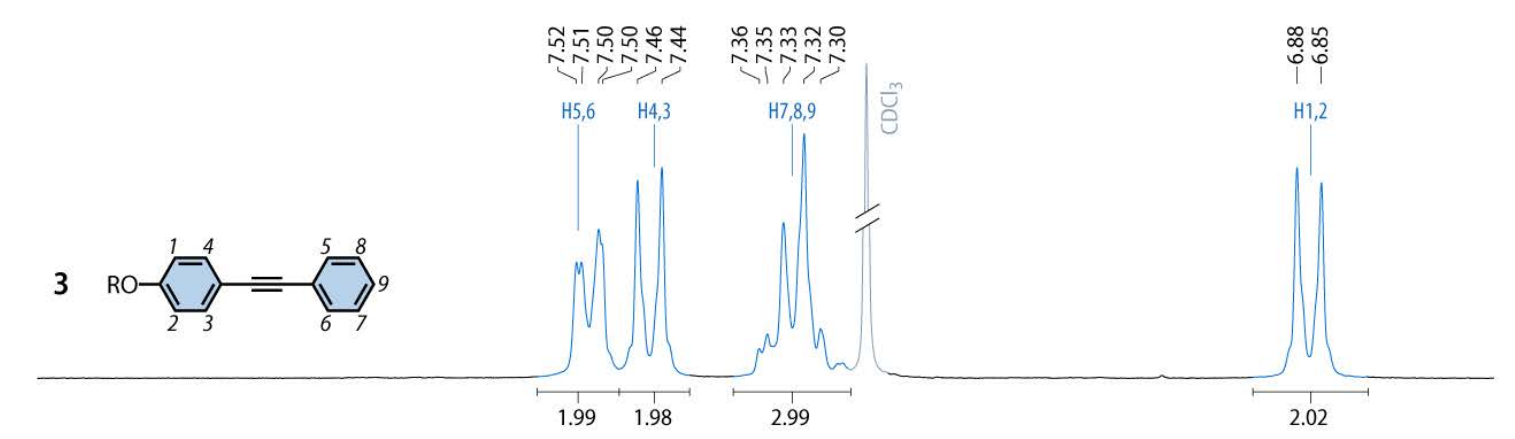

B
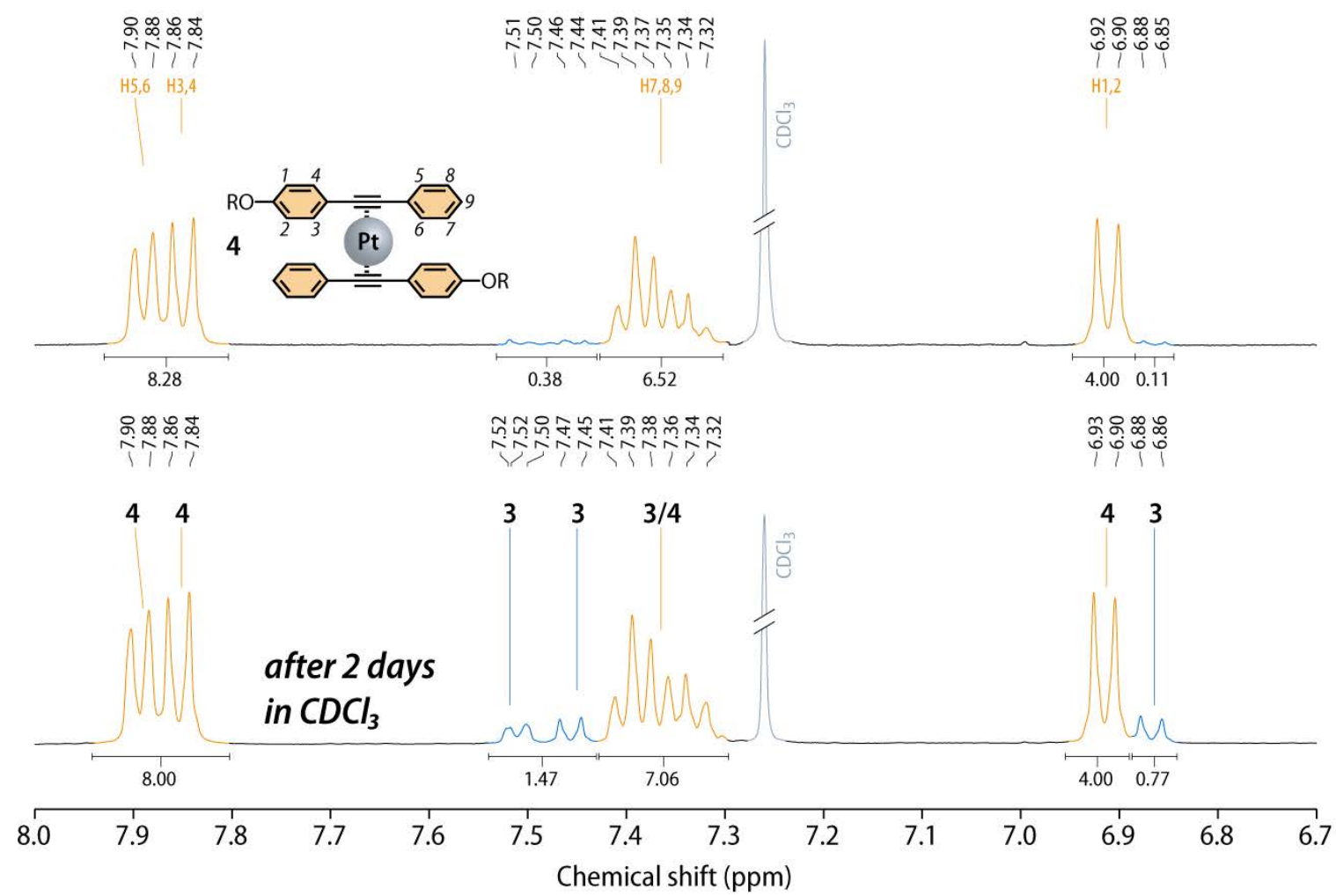

Supporting Figure S11. Comparison of the aromatic region of the ${ }^{1} \mathrm{H}$ NMR spectra $\left(400 \mathrm{MHz}, 297.2 \mathrm{~K}, \mathrm{CDCl}_{3}\right)$ of (A) ligand 3, (B) bis ( $\eta^{2}$-(1-hexyloxy-4-phenylethynyl-benzene) $) \mathrm{Pt}^{0} 4$ complex just after dissolution in $\mathrm{CDCl}_{3}$, as well as (C) the spectrum after 4 was kept in ambient conditions in $\mathrm{CDCl}_{3}$ solution for $48 \mathrm{~h}\left(\mathrm{R}=n \mathrm{C}_{6} \mathrm{H}_{13}\right)$. The fraction of free ligand 3 after dissolution is estimated to be on the order of ca. $3 \%$, while it is observed to increase to ca. $20 \%$ after $48 \mathrm{~h}$ in $\mathrm{CDCl}_{3}$ solution in ambient conditions. 


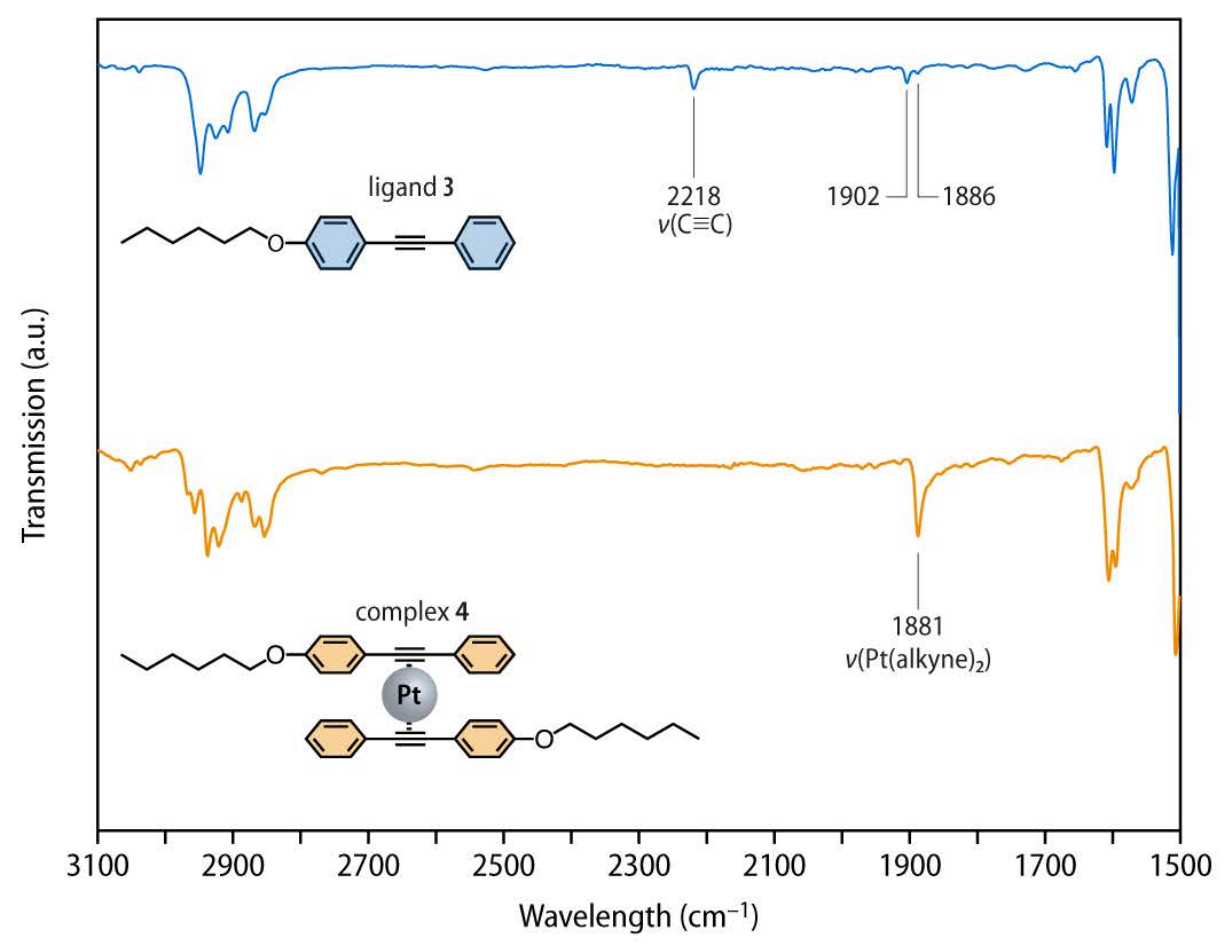

Supporting Figure S12. Comparison of the FT-IR spectra of 1-(hexyloxy)-4-(phenylethynyl)-benzene 3 and the $\operatorname{bis}\left(\eta^{2}\right.$-(1-hexyloxy-4-phenylethynyl-benzene) $) \mathrm{Pt}^{0}$ complex 4 . The acetylene stretching vibration at $2217 \mathrm{~cm}^{-1}$ of 3 is shifted to $1881 \mathrm{~cm}^{-1}$ upon coordination of $\mathrm{Pt}^{0}$ and formation of the metal-ligand complex. 


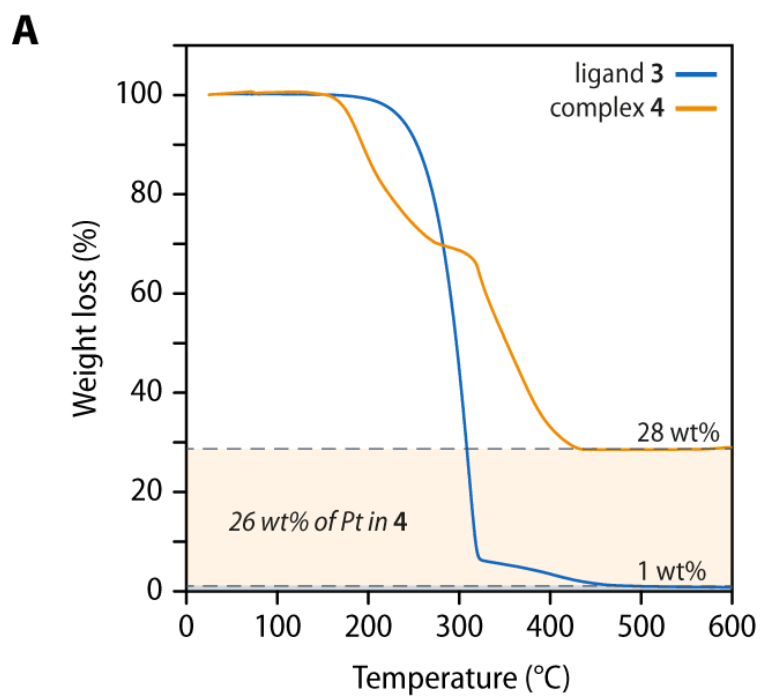

Supporting Figure S13. (A) Comparison of the thermogravimetric analysis (TGA) traces of ligand 3 and complex 4. Decomposition of 3 is indicated by the mass loss above temperatures of ca. $220^{\circ} \mathrm{C}$, respectively, and the residual mass of 3 at $600{ }^{\circ} \mathrm{C}$ is ca. $1 \mathrm{wt} \%$. Decomposition of 4 appears to occur above $170^{\circ} \mathrm{C}$ and the residual mass (ca. 28 wt $\%$ ) matches the Pt content stipulated by its molecular formula ( $26 \mathrm{wt} \%$; heating rate $\left.=1^{\circ} \mathrm{C} \mathrm{min}^{-1}\right)$. 

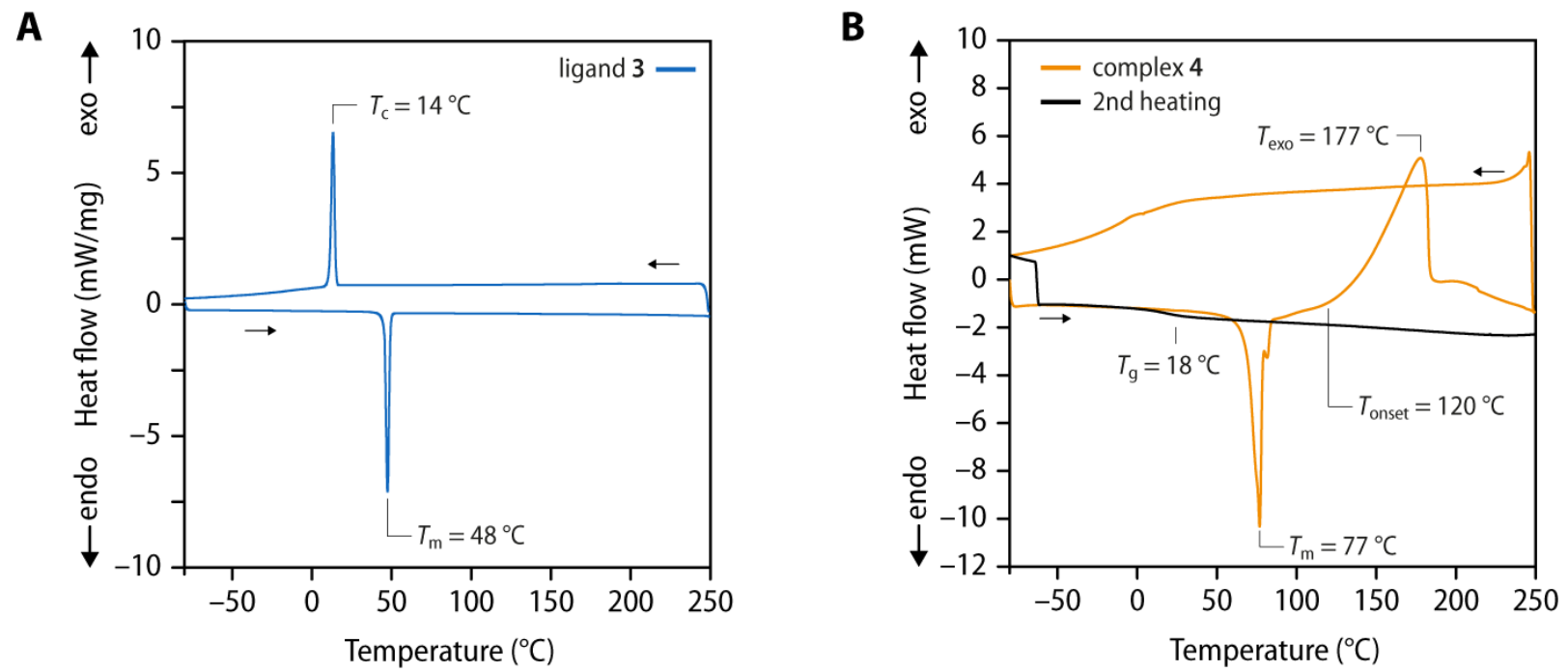

Supporting Figure S14. (A) The differential scanning calorimetry (DSC) heating and cooling traces of ligand $\mathbf{3}$ show a melting transition $\left(T_{\mathrm{m}}\right)$ at $48^{\circ} \mathrm{C}$ and a corresponding crystallization $\left(T_{\mathrm{c}}\right)$ at $14^{\circ} \mathrm{C}$. (B) The DSC traces of complex 4 display a $T_{\mathrm{m}}$ at $77^{\circ} \mathrm{C}$ that is followed by a broad exotherm with an onset at ca. $120^{\circ} \mathrm{C}$. Subsequent heating scans show only a weak signal at ca. $18{ }^{\circ} \mathrm{C}$ that appears to indicate a glass transition and suggests that the exothermal process seen in the first heating is related to an irreversible decomposition. 


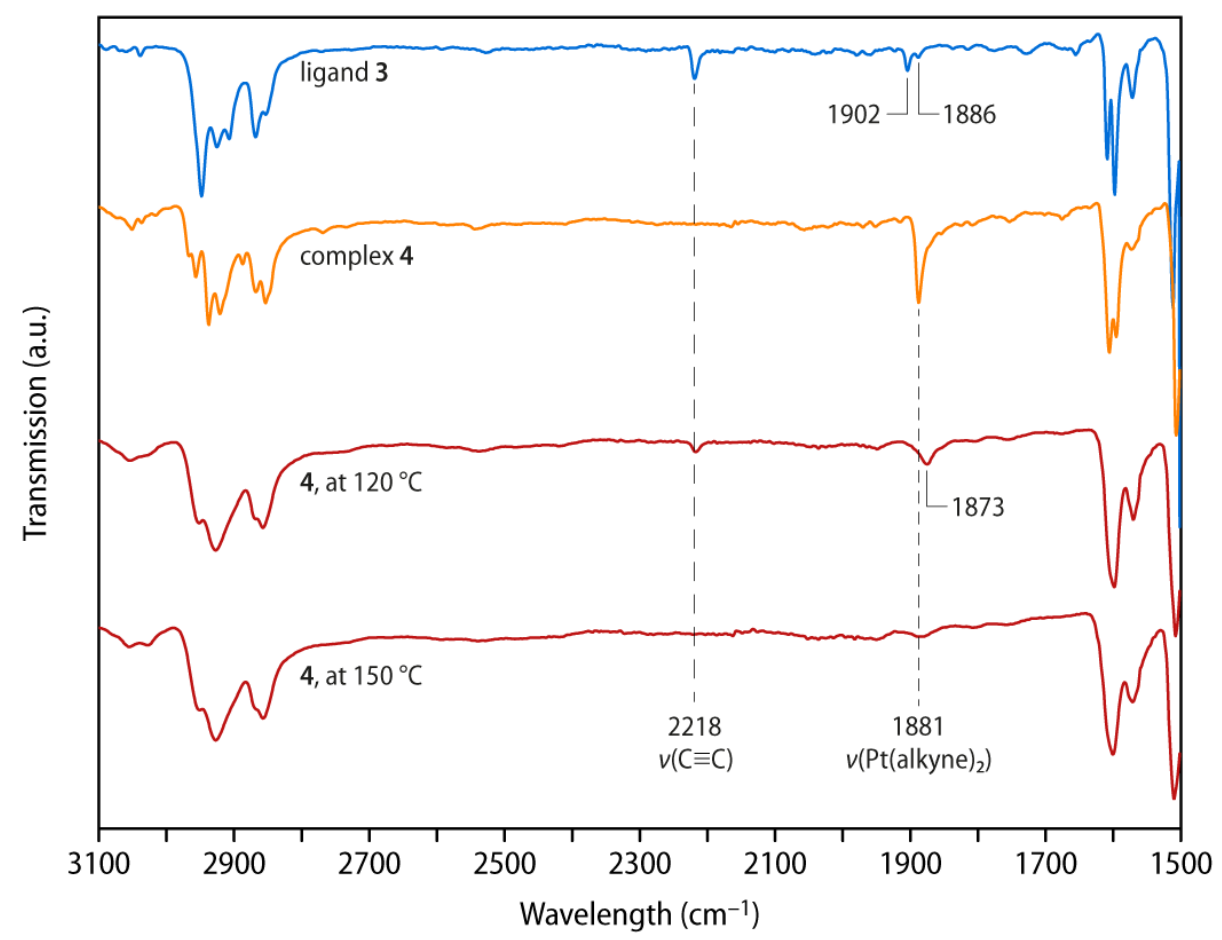

Supporting Figure S15. Comparison of the FT-IR spectra of the ligand 3, the bis( $\eta^{2}$-(1-hexyloxy-4-phenylethynyl-benzene)) $\mathrm{Pt}^{0}$ complex 4, and the spectra recorded upon heating of complex 4 . The spectrum recorded upon heating to $120^{\circ} \mathrm{C}$ (red line) shows a shift of the signal associated with the complex from 1881 to $1873 \mathrm{~cm}^{-1}$ and an increase of intensity of the acetylene stretching vibration of the ligand 3 at ca. $2218 \mathrm{~cm}^{-1}$ suggesting a dissociation of the metal-ligand complex. The spectrum recorded upon heating to a temperature of $150{ }^{\circ} \mathrm{C}$ shows that the intensity of the band associated with the complex at ca. $1881 \mathrm{~cm}^{-1}$ is further reduced while the band associated with the acetylene stretching vibration is not discernible. 

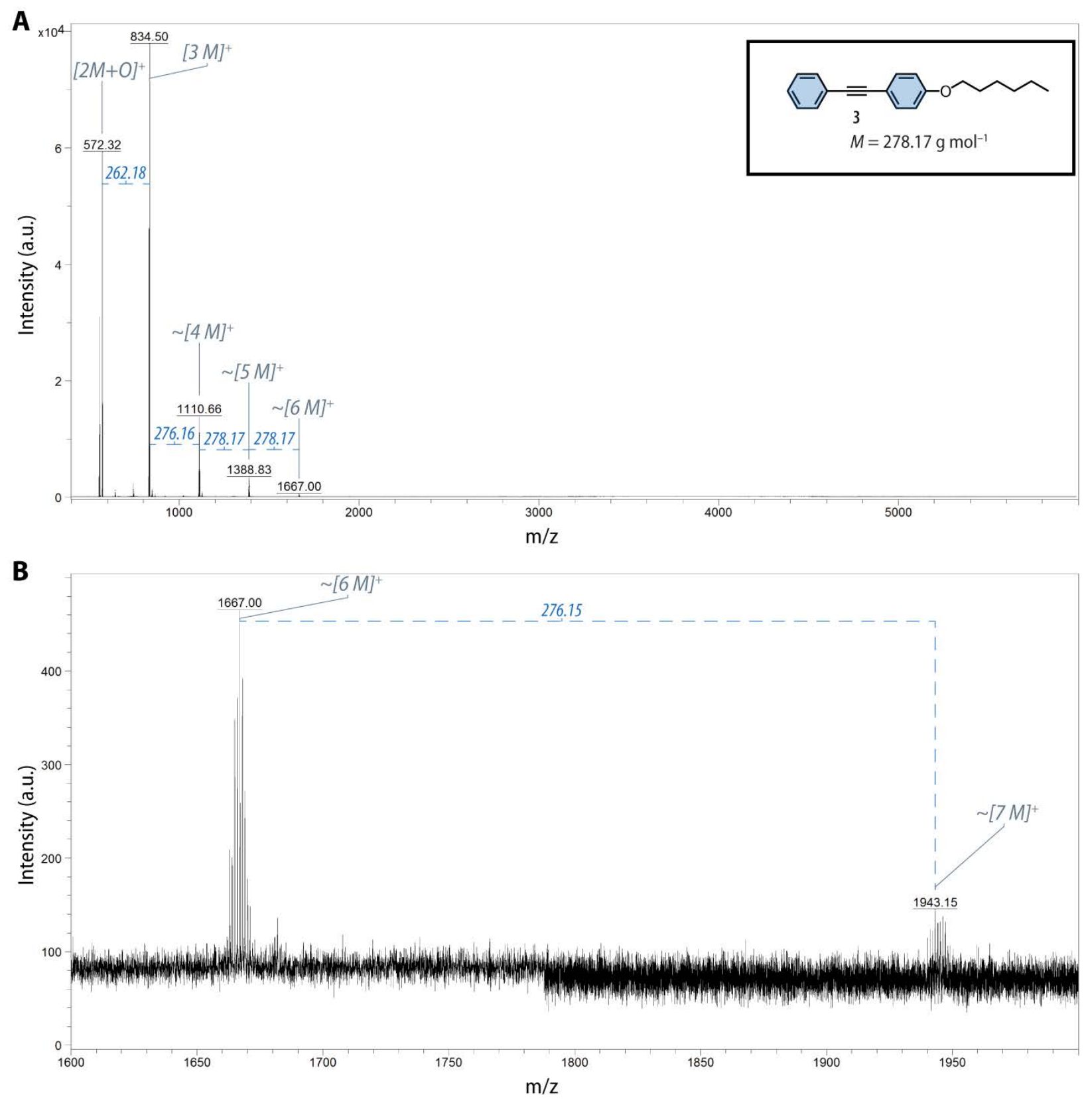

Supporting Figure S16. (A-B) Matrix-assisted laser desorption/ionization (MALDI) time of flight (TOF) spectra of the residue obtained after heating the $\operatorname{bis}\left(\eta^{2}\right.$-(1-hexyloxy-4-phenylethynyl-benzene) $) \mathrm{Pt}^{0}$ complex 4 to a temperature of $120^{\circ} \mathrm{C}$ for $6 \mathrm{~h}$ under an inert nitrogen atmosphere. The observed peaks match with multiples of the molar mass $\left(M=278.17 \mathrm{~g} \mathrm{~mol}^{-1}\right)$ of ligand 3. An analysis of the MALDI-TOF spectrum suggests that heating of 4 induces an oligomerization of up to seven diphenylacetylene ligand molecules. 
A

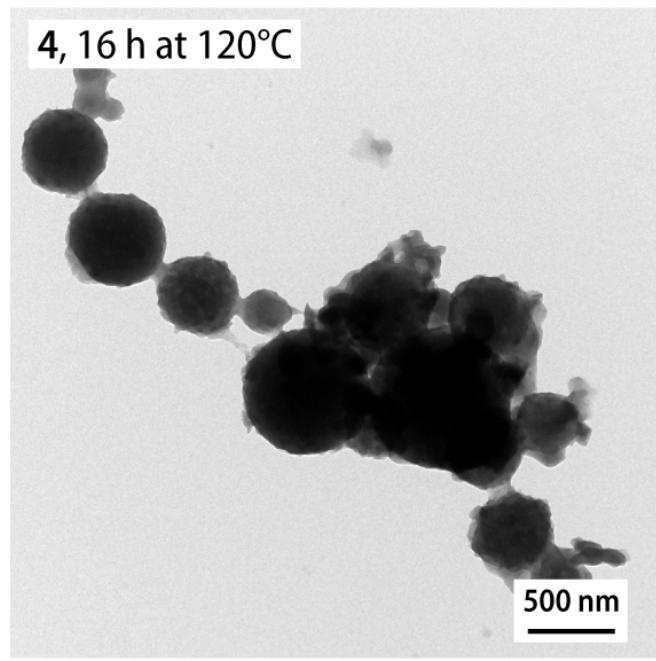

C

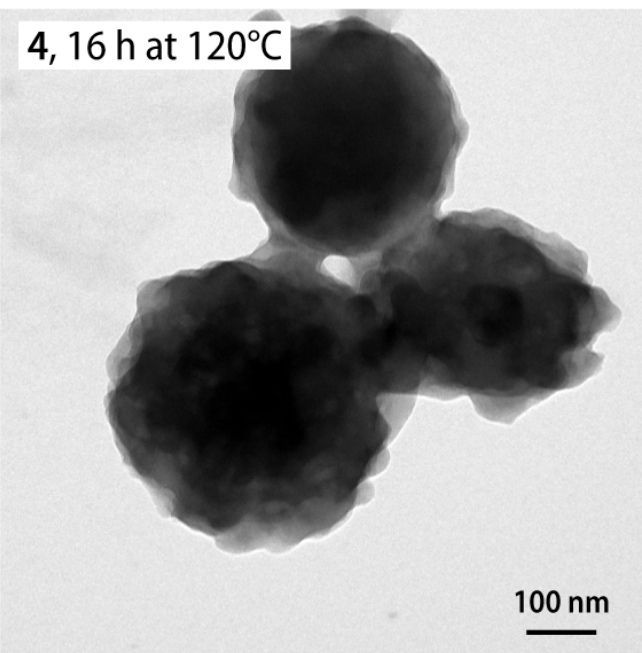

B

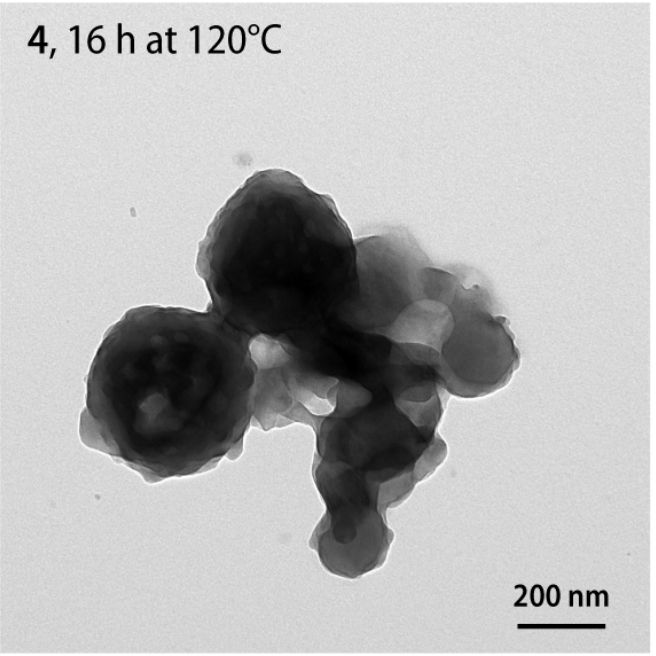

D

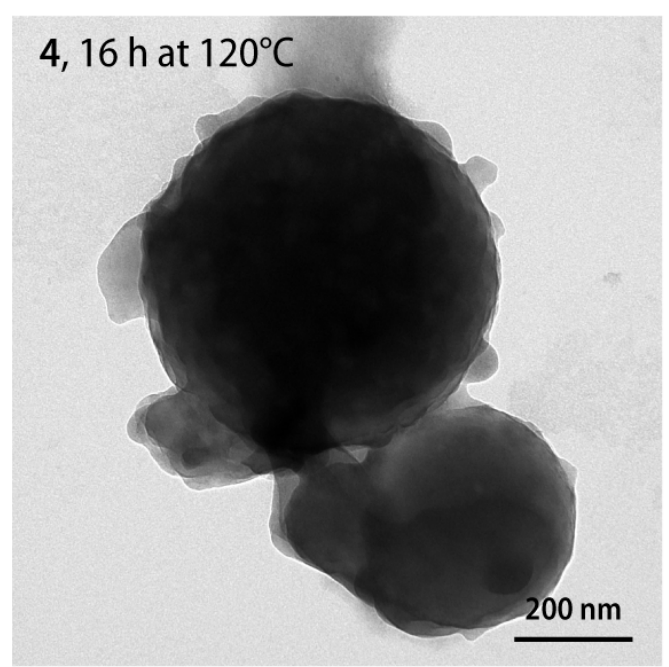

Supporting Figure S17. Bright-field transmission electron microscopy images of irregularly-shaped Pt aggregates that were observed after heating the $\operatorname{bis}\left(\eta^{2}\right.$-(1-hexyloxy-4-phenylethynyl-benzene) $) \mathrm{Pt}{ }^{0}$ complex 4 to $120^{\circ} \mathrm{C}$ for $16 \mathrm{~h}$. 
A

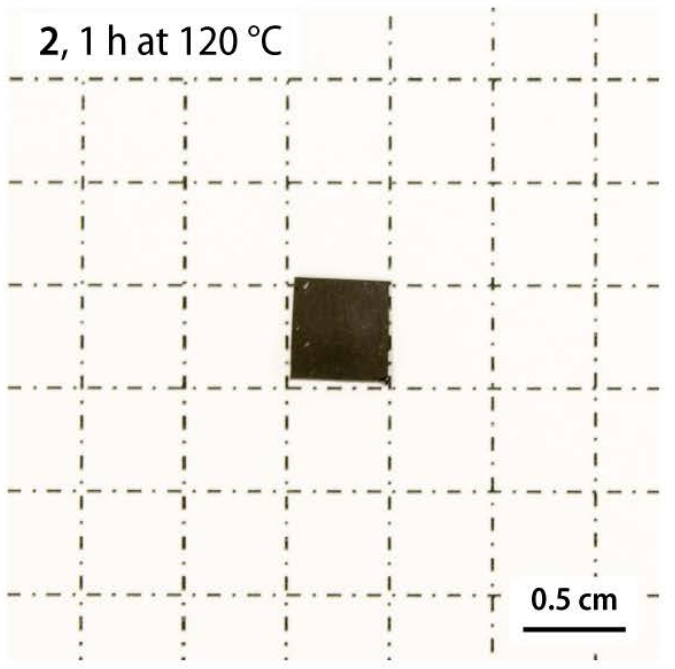

B

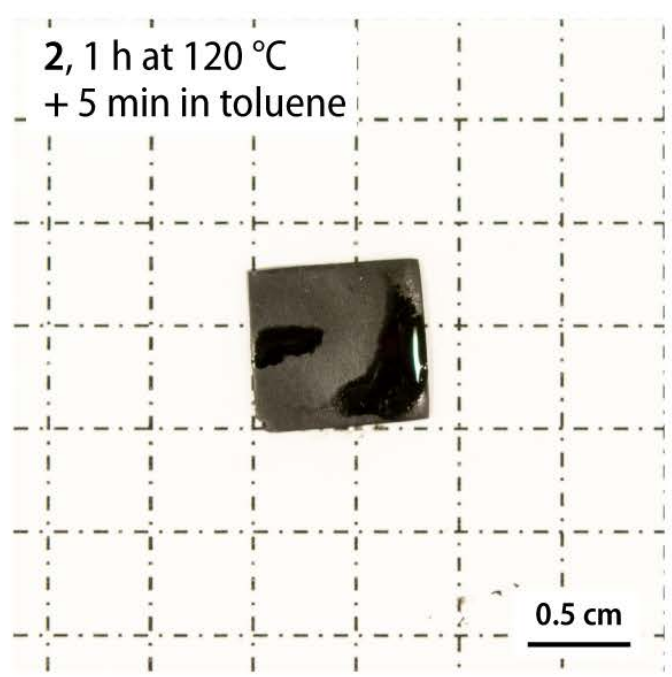

Supporting Figure S18. (A) Photograph of a square-shaped solvent-cast film of MSP 2 (ca. $200 \mu \mathrm{m}$ ) that was heated for $1 \mathrm{~h}$ at $120^{\circ} \mathrm{C}$. (B) Photograph of the same sample of MSP 2 after submersion in toluene for 5 min. While MSP 2 readily re-dissolves, the heated samples swell when placed in solvents such as toluene. 


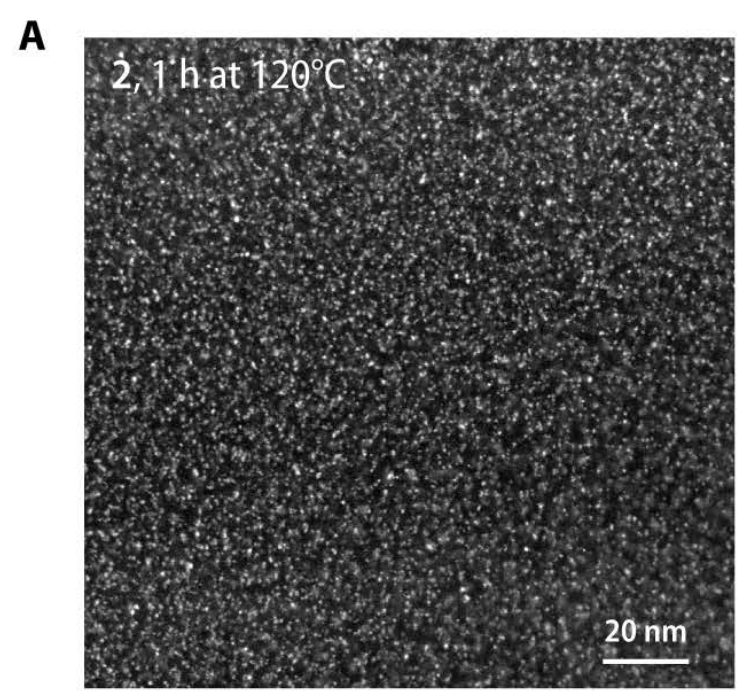

C

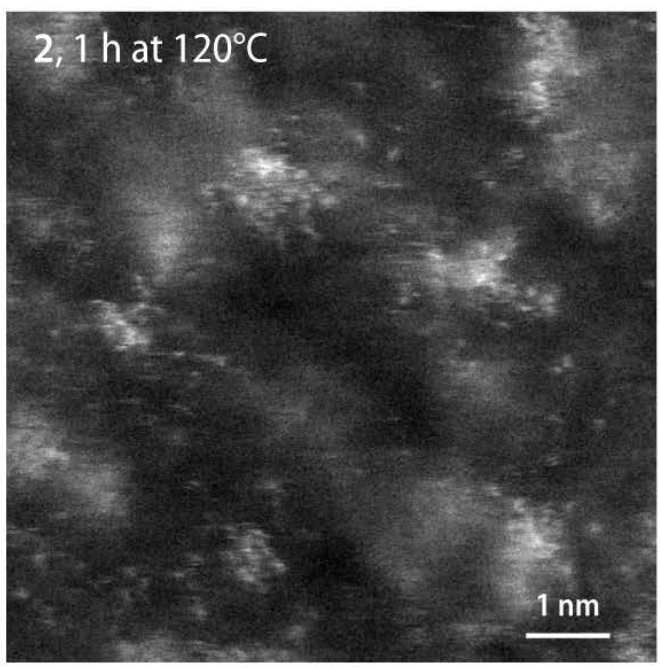

B

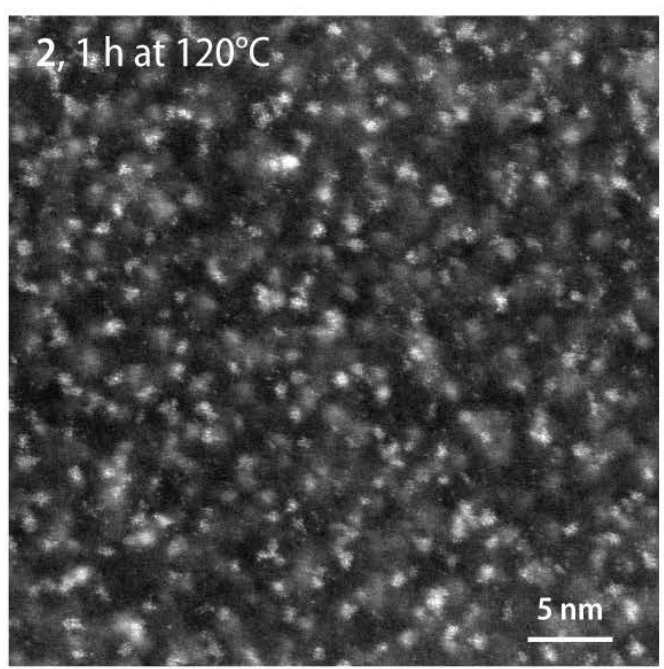

D

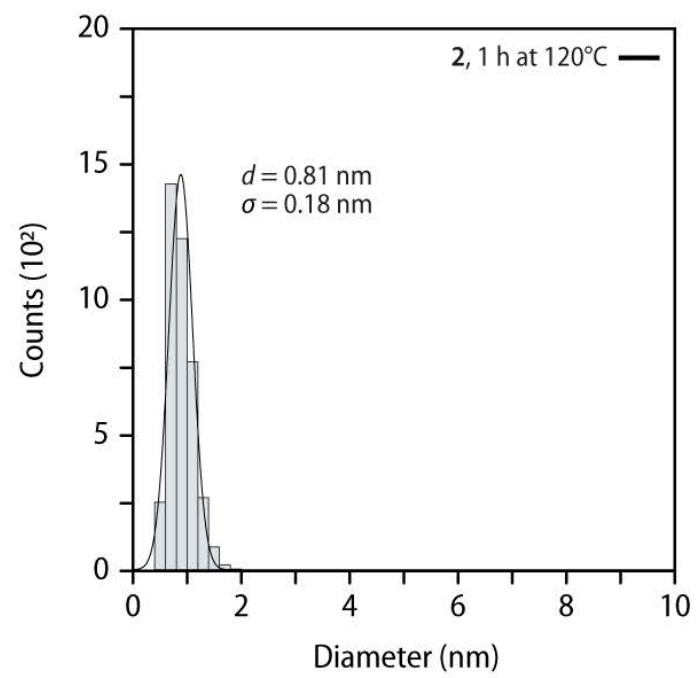

Supporting Figure S19. (A-C) High-angle annular dark-field (HAADF) scanning transmission electron microscopy (STEM) images of solvent-cast samples of MSP 2 recorded after heating at $120^{\circ} \mathrm{C}$ for $1 \mathrm{~h}$. The micrographs show homogenously distributed Pt-clusters. (D) Histogram of the size distribution of Pt-clusters as determined by an analysis of the HAADF-STEM image shown in (A). 
A

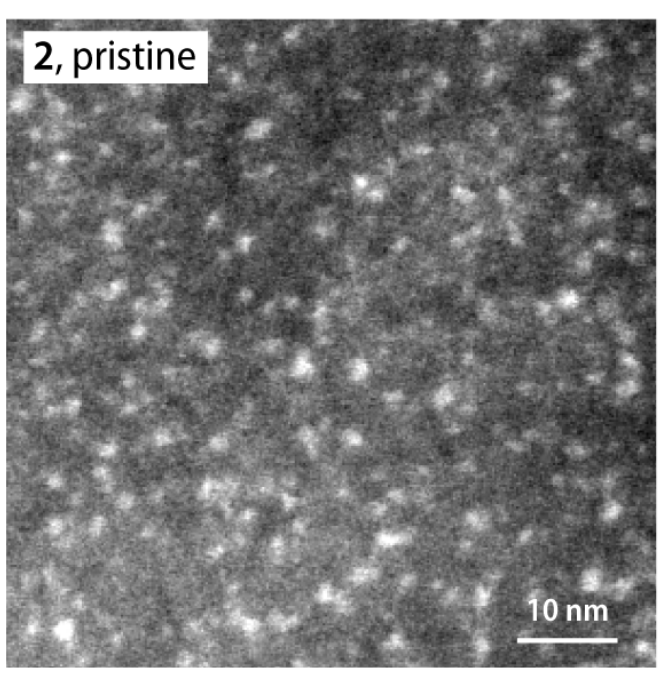

B

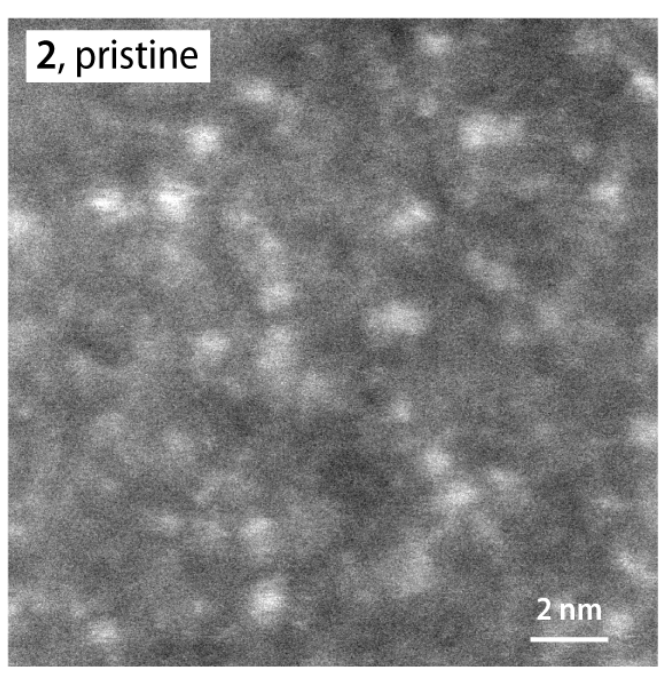

Supporting Figure S20. (A-B) High-angle annular dark-field (HAADF) scanning transmission electron microscopy (STEM) images of solvent-cast samples of MSP 2 that were ultramicrotomed show small, ill-defined Pt-clusters that are possibly created upon electron beam exposure in the TEM. 
A

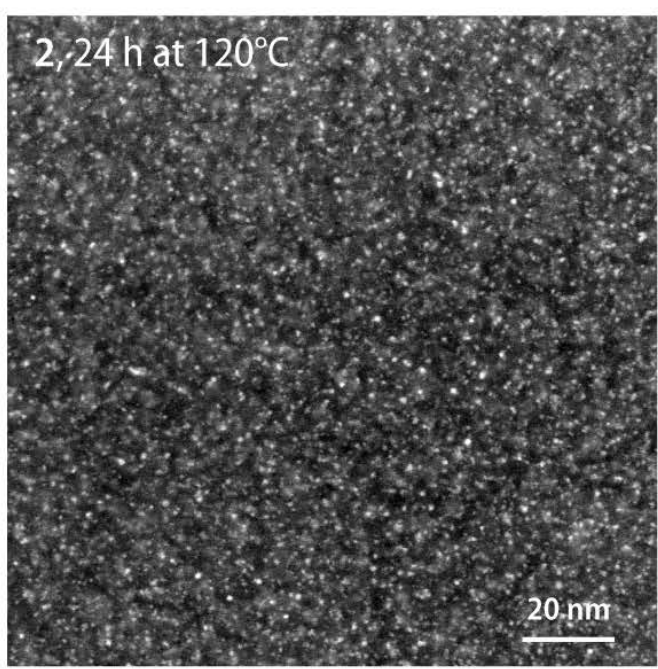

C

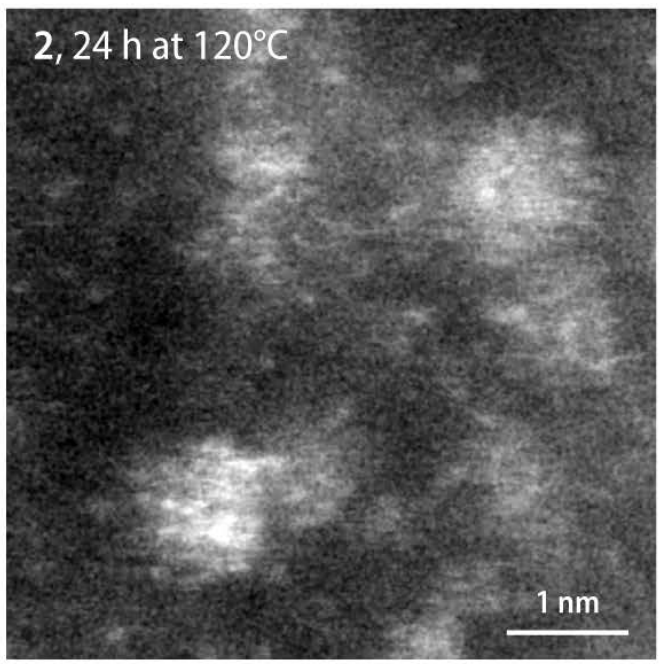

B

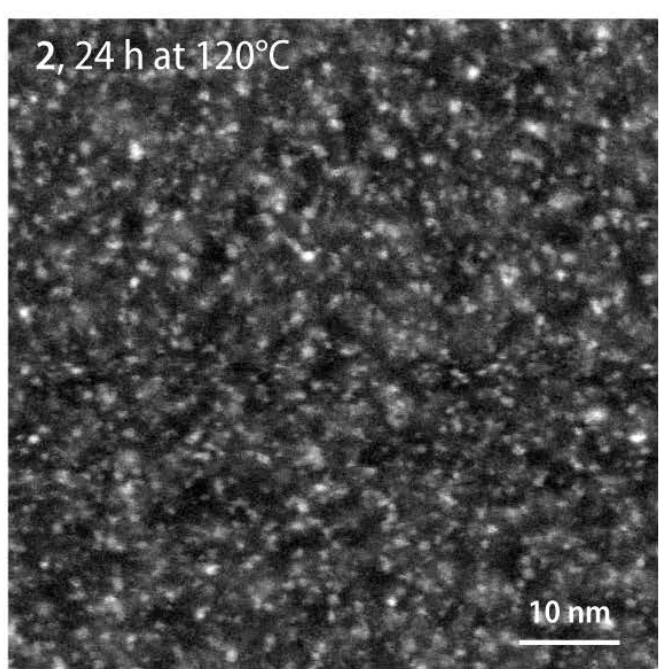

D

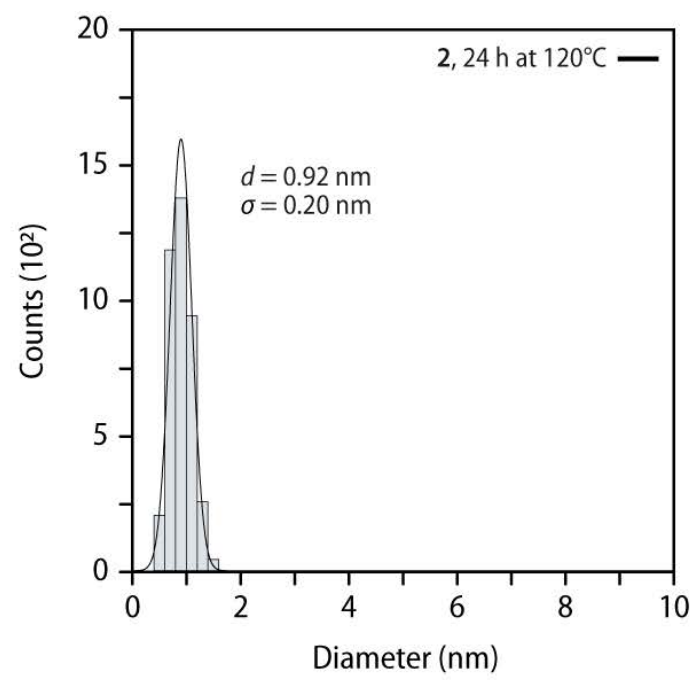

Supporting Figure S21. (A-C) High-angle annular dark-field (HAADF) scanning transmission electron microscopy (STEM) images of solvent-cast samples of MSP 2 recorded after heating at $120^{\circ} \mathrm{C}$ for $24 \mathrm{~h}$. The micrographs show homogenously distributed Pt-clusters. (D) Histogram indicating the size distribution of Pt-clusters as determined by an analysis of the HAADF-STEM image shown in (A). 


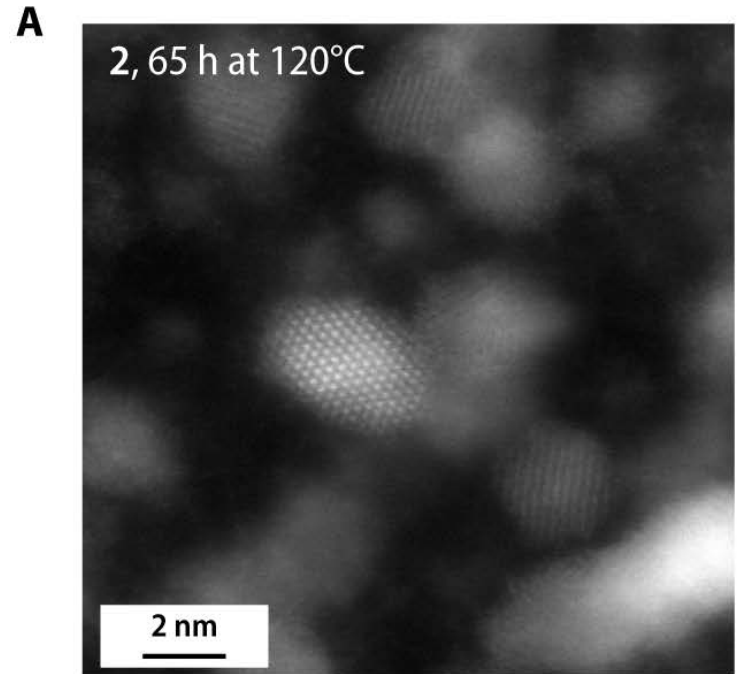

C

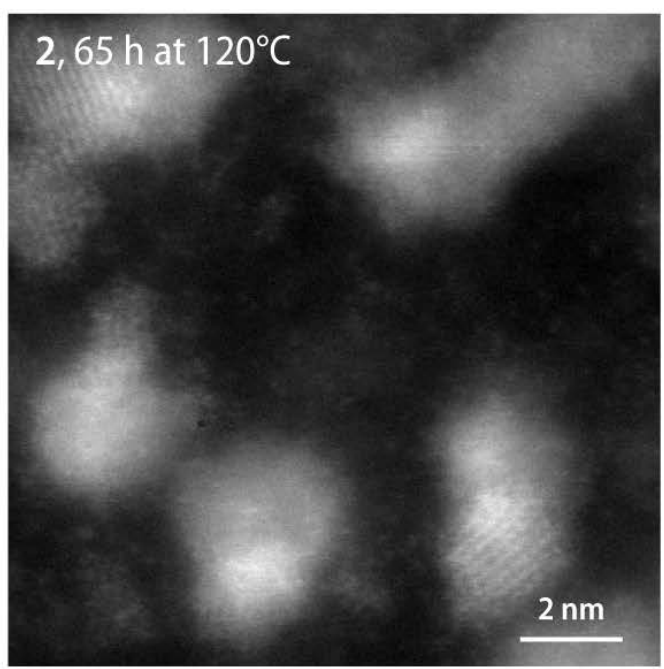

B

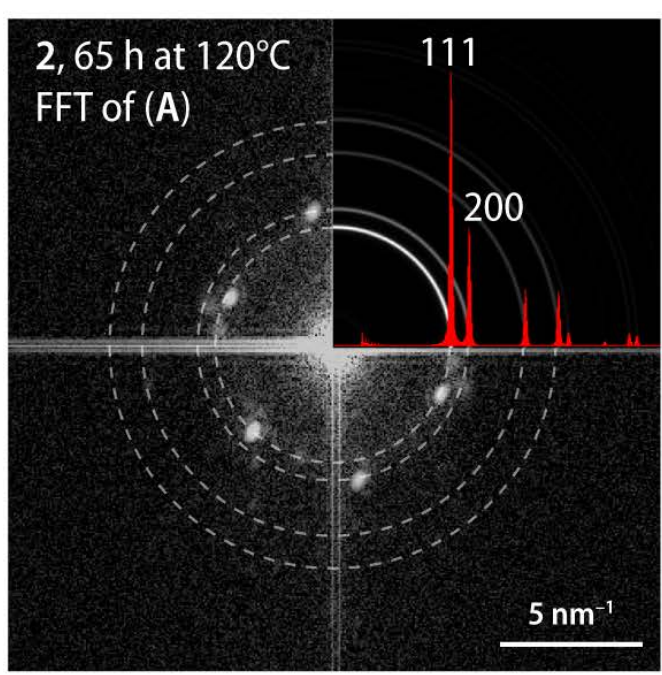

D

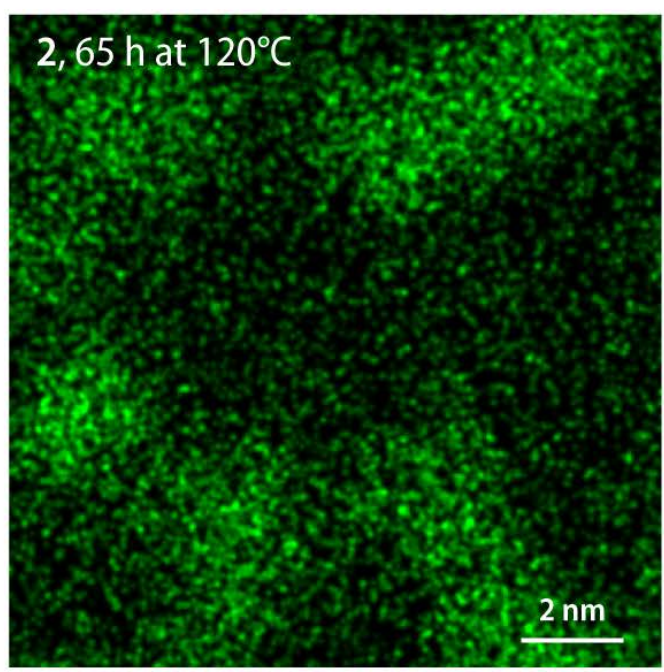

Supporting Figure S22. (A,C) High-angle annular dark-field (HAADF) scanning transmission electron microscopy (STEM) images of solvent-cast samples of MSP 2 recorded after heating at $120^{\circ} \mathrm{C}$ for $65 \mathrm{~h}$. The micrographs show instances of crystalline Pt-NPs next to Pt-clusters. (B) Fast Fourier transform (FFT) of the STEM micrograph in (A) shows reflections corresponding to the $\{111\}$ and $\{200\}$ crystallographic planes of a face-centered cubic $\mathrm{Pt}^{0} \mathrm{crystal}$ The inset shows a comparison with the simulated electron diffraction pattern (ring sampling diffraction planes and corresponding intensity profile) of a face-centered cubic $\mathrm{Pt}^{0}$ crystal. (D) Energy-dispersive X-ray spectroscopy elemental map for platinum (green) for the STEM micrograph shown in (C). 
A

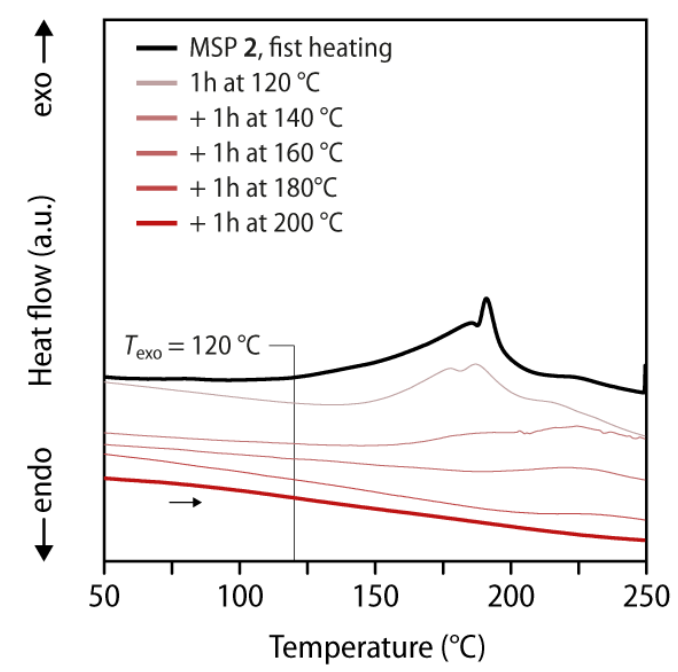

C

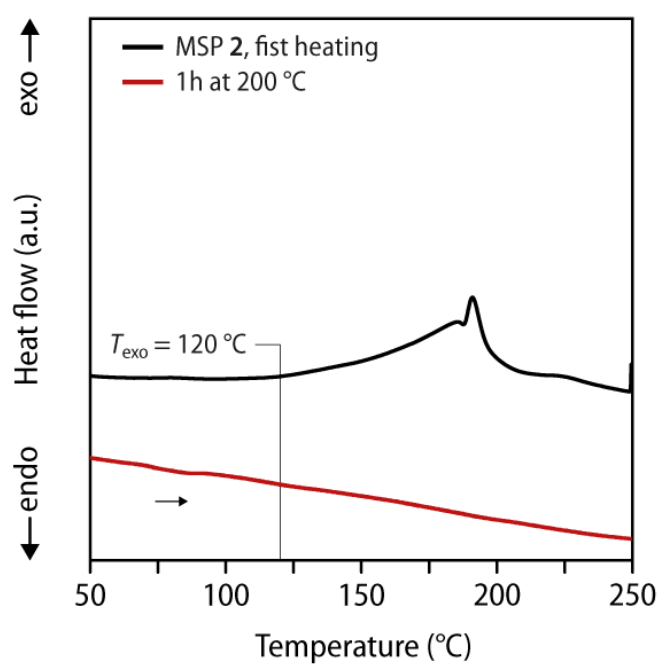

B

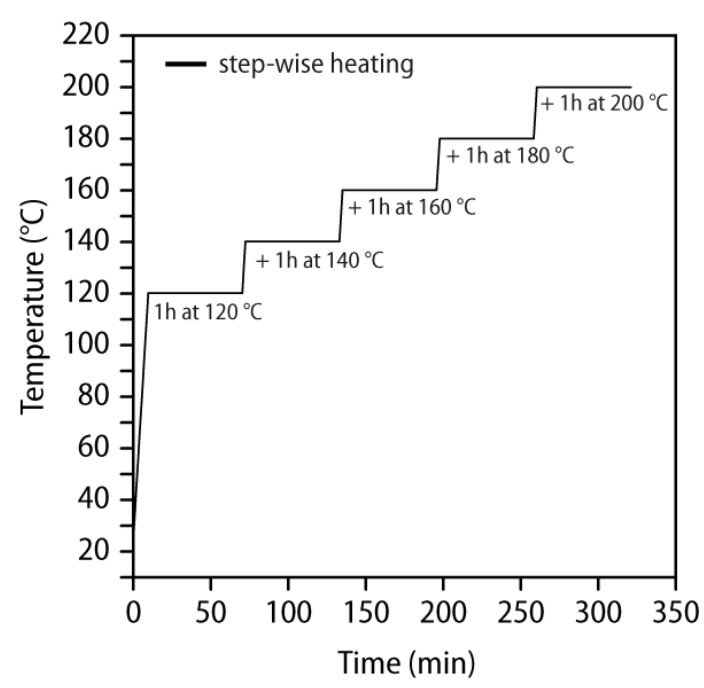

D

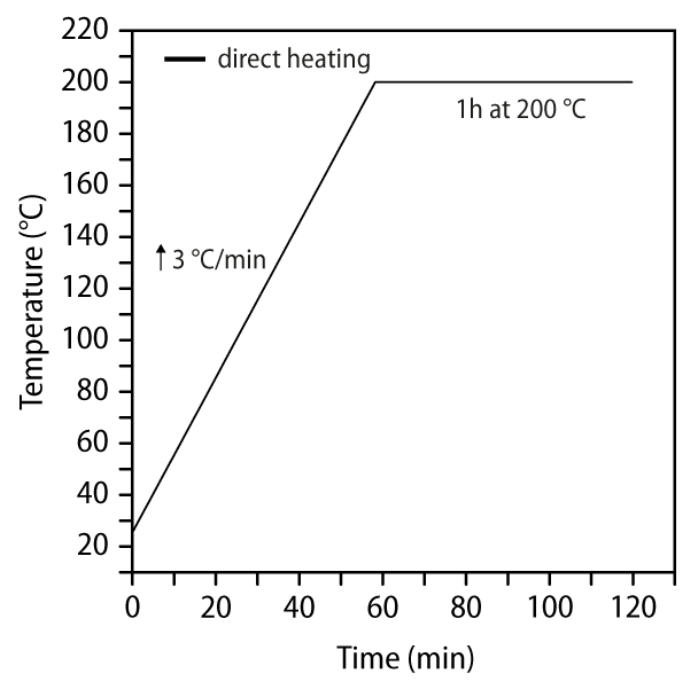

Supporting Figure S23. (A) Differential scanning calorimetry (DSC) traces of solvent-cast samples of MSP 2 after different heating steps $\left(10^{\circ} \mathrm{C} \mathrm{min}^{-1}\right)$. Shown are the first heating trace of a pristine sample (black line) and the heating traces of samples obtained by consecutively heating for $1 \mathrm{~h}$ as depicted in (B) at each temperature of 120 , 140, 160, 180, and $200^{\circ} \mathrm{C}$. (C) Comparison of the DSC traces of solvent-cast samples of MSP 2 before (black line) and after (red line) direct heating to $200{ }^{\circ} \mathrm{C}\left(10^{\circ} \mathrm{C} \mathrm{min}^{-1}\right)$ and maintaining the temperature for $1 \mathrm{~h}$ as depicted in (D). A heating rate of $3{ }^{\circ} \mathrm{C} \mathrm{min}^{-1}$ was used in all cases. The DSC heating traces in (A) and (C) have been vertically shifted for clarity. 


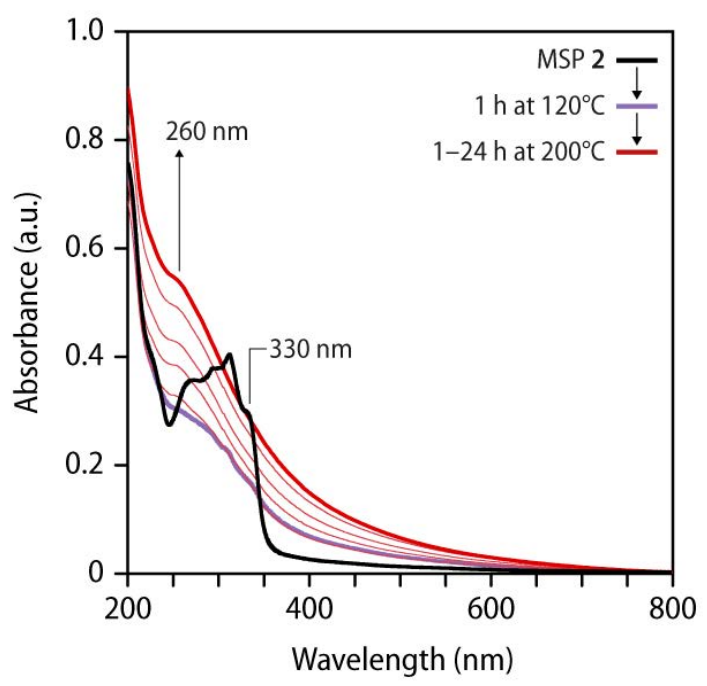

Supporting Figure S24. (A) UV-vis absorption spectrum of a thin film of pristine MSP 2 spin-coated from solution ( $c=0.02 \mathrm{~mol} \mathrm{~L}^{-1}$ ) onto a quartz glass substrate (black line), the spectrum recorded after heating to $120^{\circ} \mathrm{C}$ for $1 \mathrm{~h}$ (purple line), as well as the spectra recorded upon extended heating at $200{ }^{\circ} \mathrm{C}$ (red lines). Upon heating, the characteristic band of the bis $\left(\eta^{2}\right.$-alkyne $) \mathrm{Pt}^{0}$ complexes at $330 \mathrm{~nm}$ is replaced by a broad absorption with a local maximum at ca. $260 \mathrm{~nm}$. The heating of samples was carried out in an inert nitrogen atmosphere. 


\section{A}

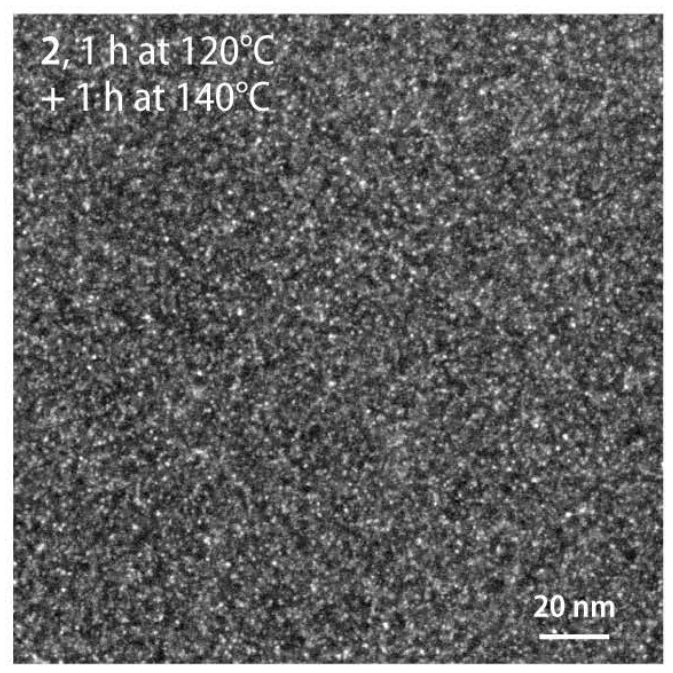

C

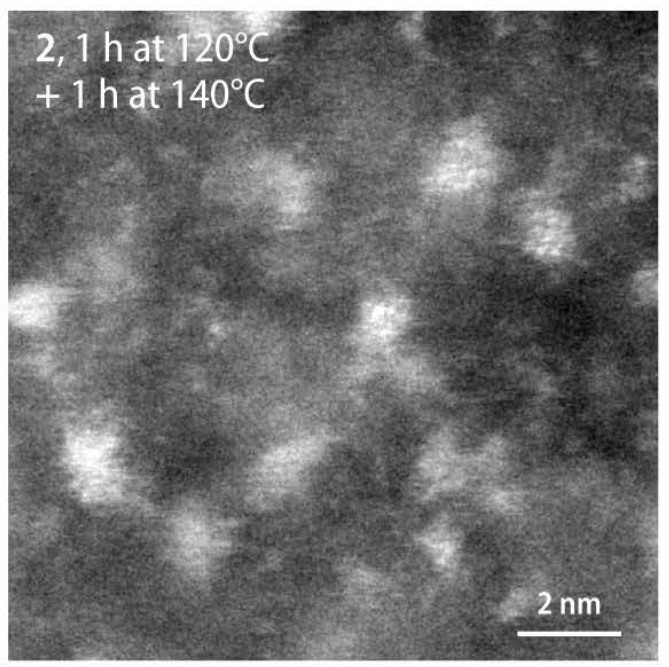

B

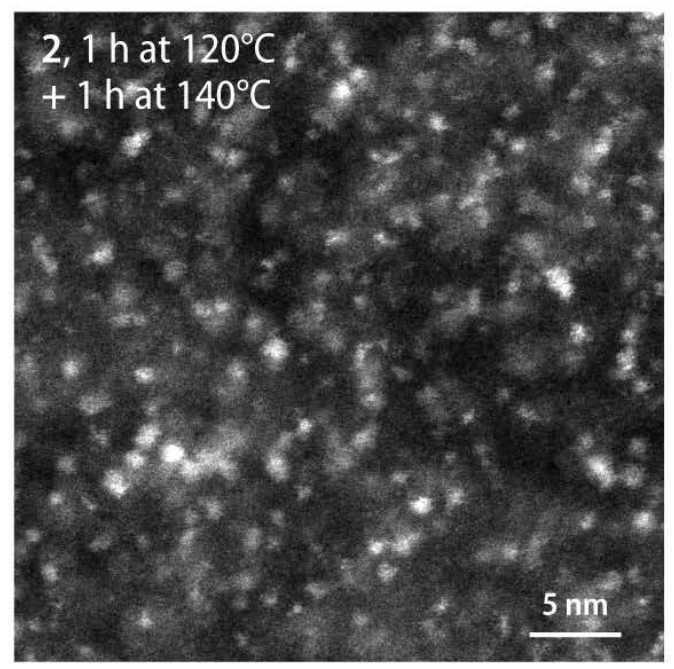

D

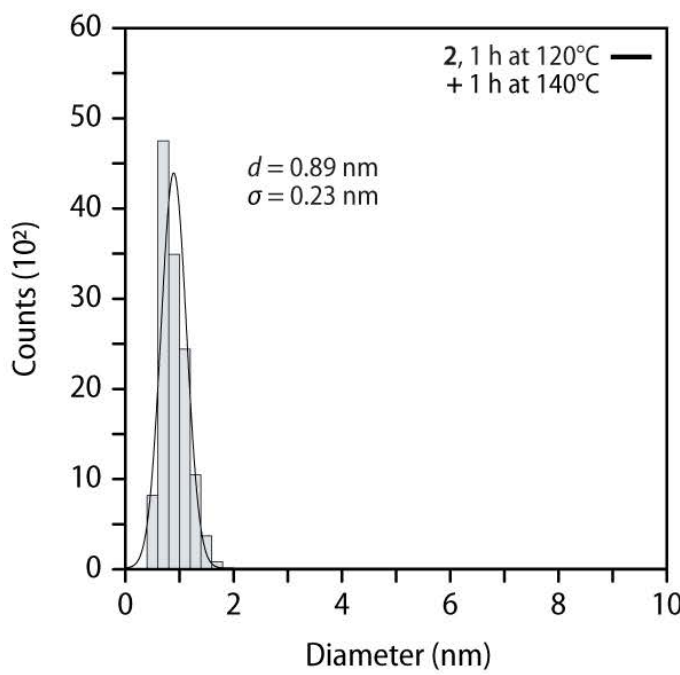

Supporting Figure S25. (A-C) High-angle annular dark-field (HAADF) scanning transmission electron microscopy (STEM) images of solvent-cast samples of MSP 2 recorded after heating at $120^{\circ} \mathrm{C}$ for $1 \mathrm{~h}$ and $140{ }^{\circ} \mathrm{C}$ for $1 \mathrm{~h}$. The micrographs show homogenously distributed Pt-clusters. (D) Histogram indicating the size distribution of Pt-clusters as determined by an analysis of the HAADF-STEM image shown in (A). 
A

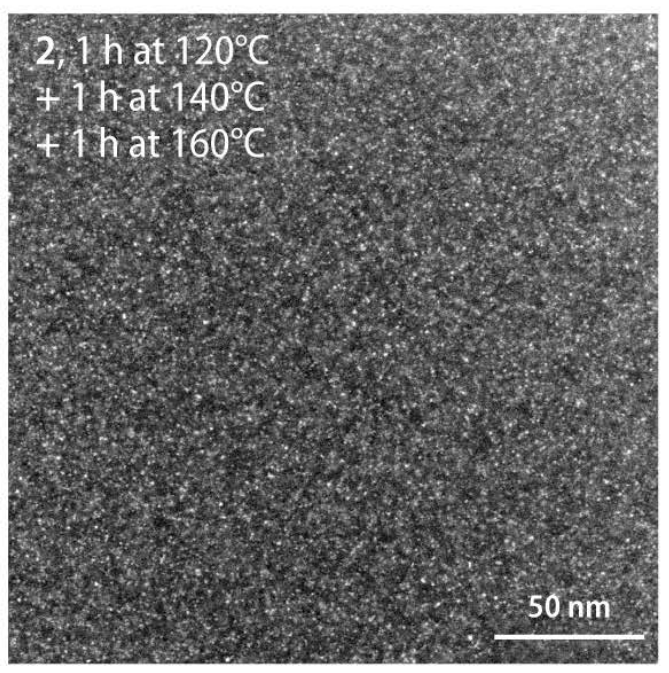

C

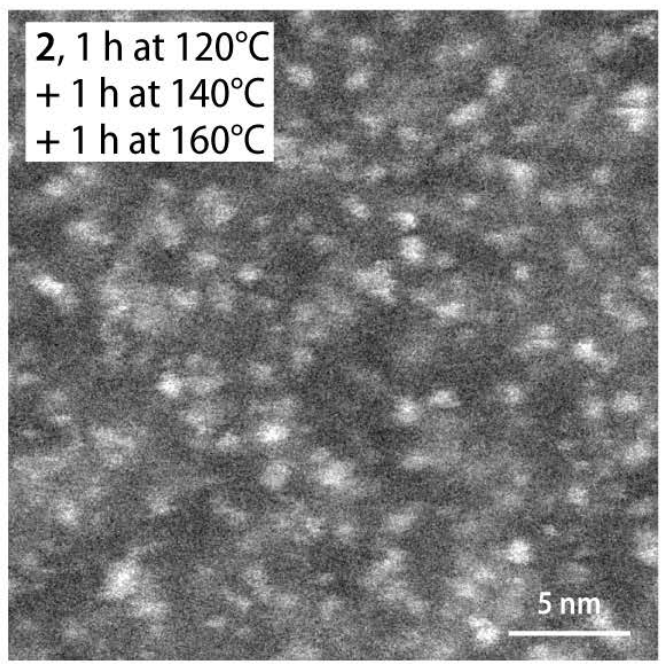

B

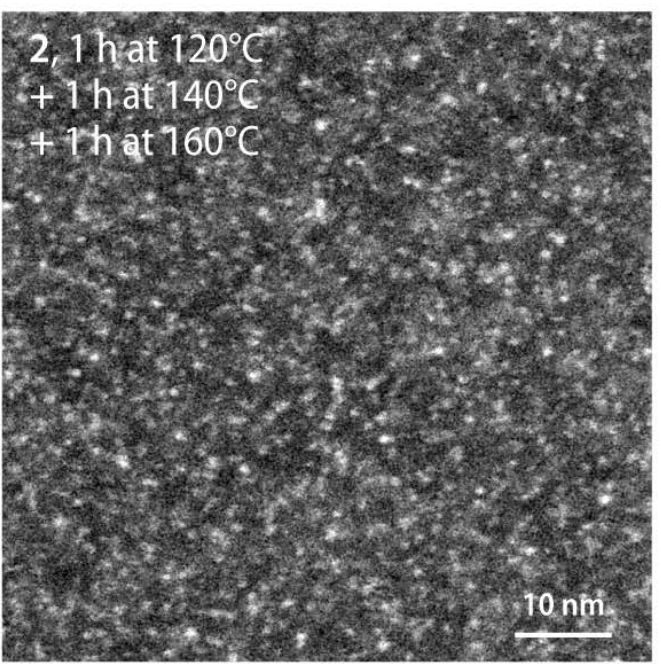

D

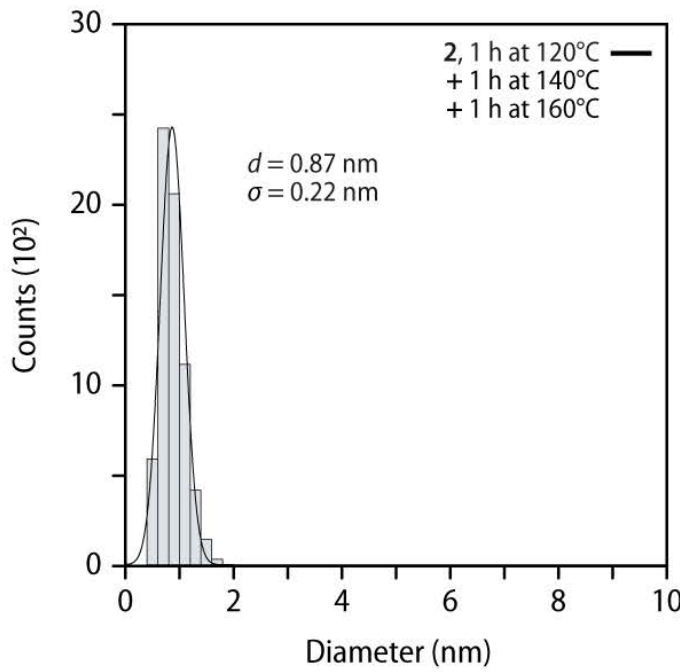

Supporting Figure S26. (A-C) High-angle annular dark-field (HAADF) scanning transmission electron microscopy (STEM) images of solvent-cast samples of MSP 2 recorded after heating at $120^{\circ} \mathrm{C}$ for $1 \mathrm{~h}, 140{ }^{\circ} \mathrm{C}$ for $1 \mathrm{~h}$, and $160{ }^{\circ} \mathrm{C}$ for $1 \mathrm{~h}$. The micrographs show homogenously distributed Pt-clusters. (D) Histogram indicating the size distribution of Pt-clusters as determined by an analysis of the HAADF-STEM image shown in (A). 
A

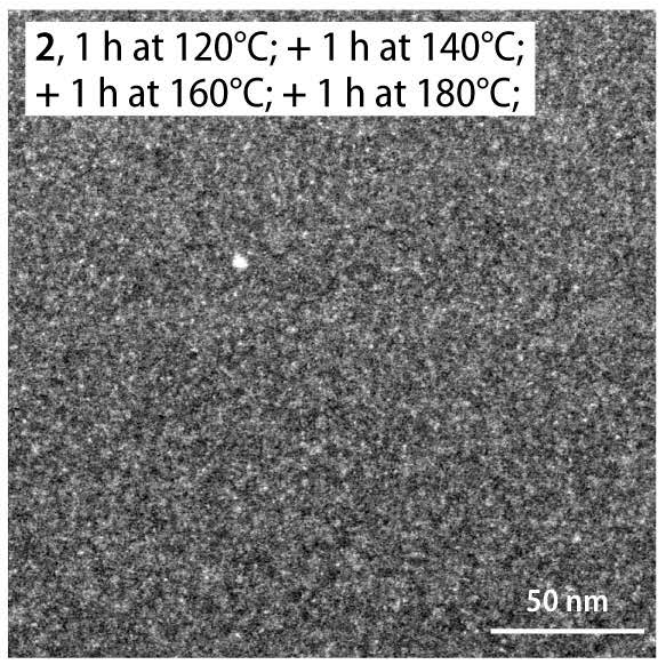

C

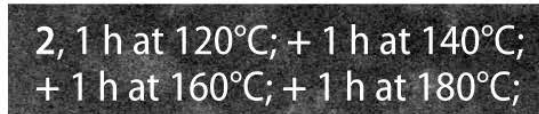

B

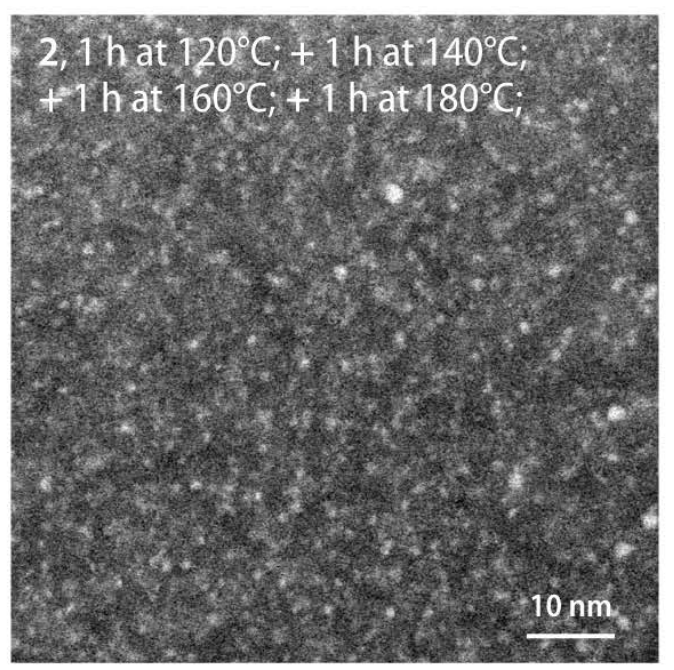

D

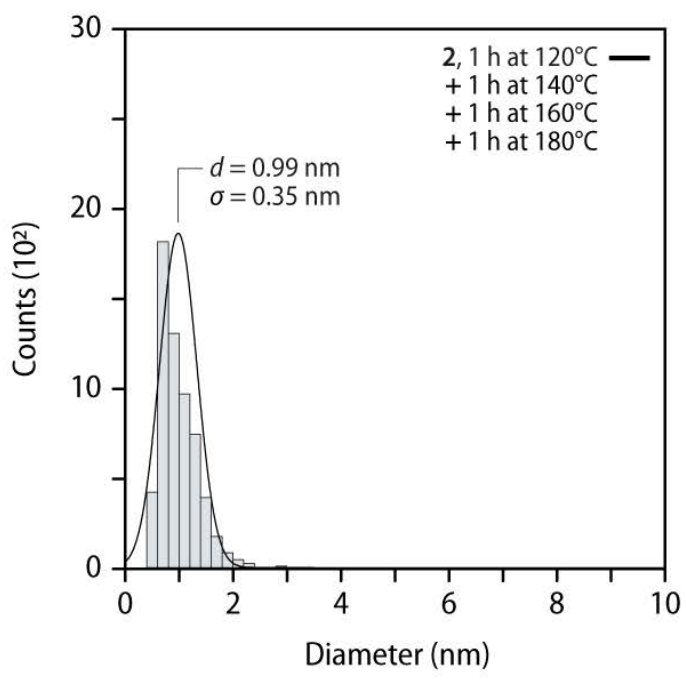

Supporting Figure S27. (A-C) High-angle annular dark-field (HAADF) scanning transmission electron microscopy (STEM) images of solvent-cast samples of MSP 2 recorded after heating at $120^{\circ} \mathrm{C}$ for $1 \mathrm{~h}, 140^{\circ} \mathrm{C}$ for $1 \mathrm{~h}, 160^{\circ} \mathrm{C}$ for $1 \mathrm{~h}$, and $180^{\circ} \mathrm{C}$ for $1 \mathrm{~h}$. The micrographs show homogenously distributed Pt-clusters as well as few instances of (larger) crystalline Pt-NPs. (D) Histogram indicating the size distribution of Pt-clusters and NPs as determined by an analysis of the HAADF-STEM image in (B). 
A

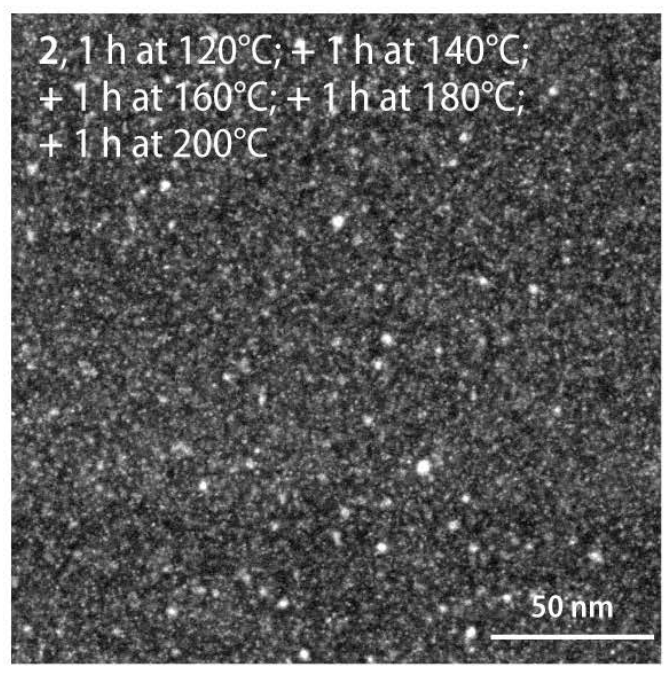

C

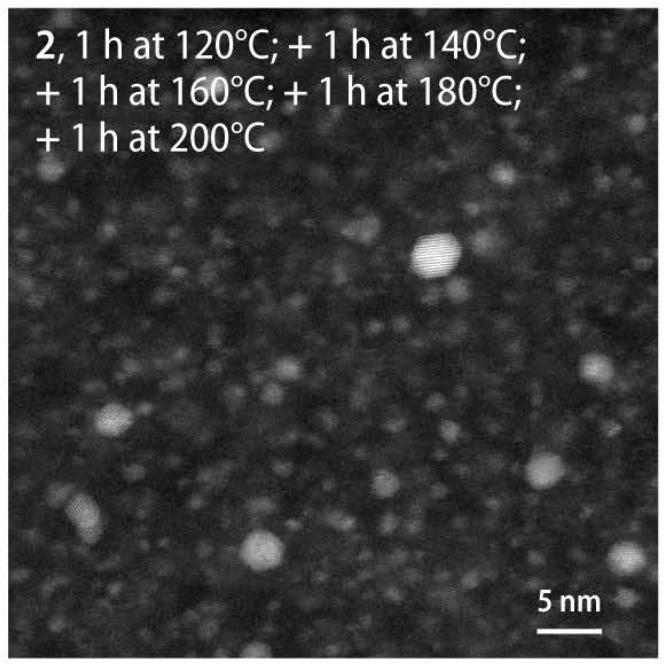

B

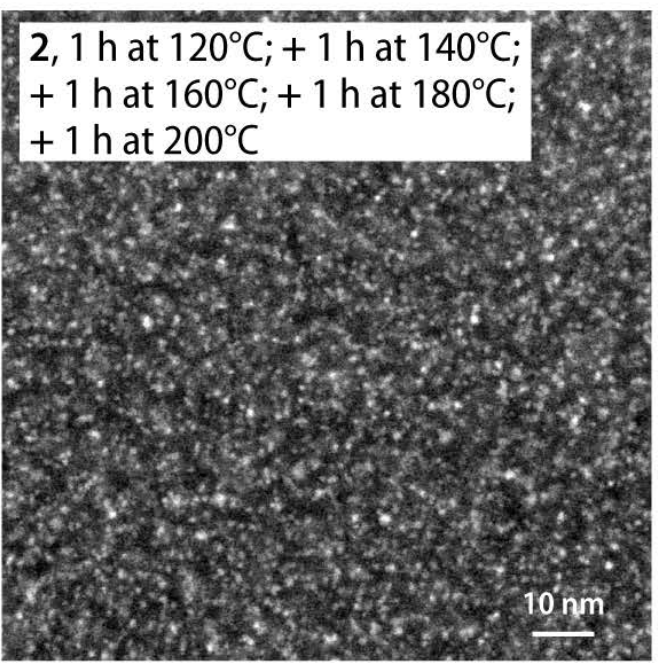

D

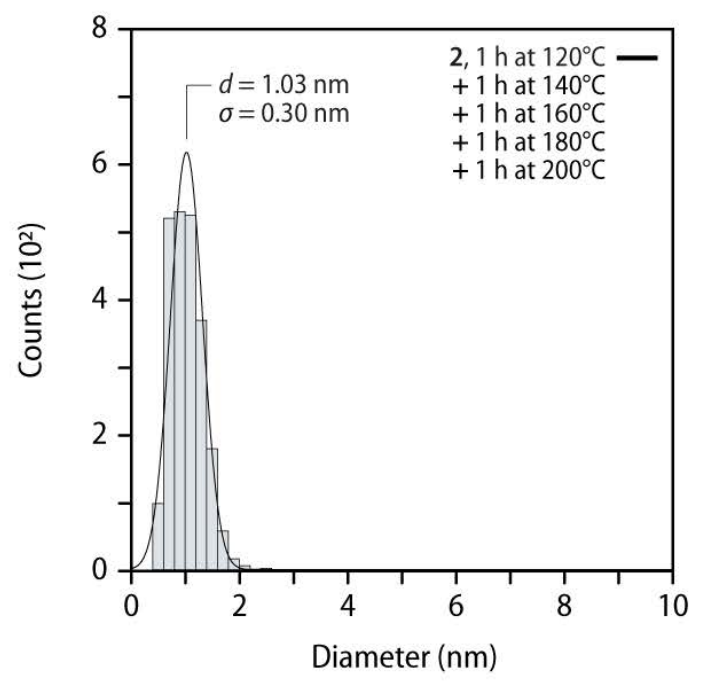

Supporting Figure S28. (A-C) High-angle annular dark-field (HAADF) scanning transmission electron microscopy (STEM) images of solvent-cast samples of MSP 2 recorded after heating at $120^{\circ} \mathrm{C}$ for $1 \mathrm{~h}, 140{ }^{\circ} \mathrm{C}$ for $1 \mathrm{~h}, 160^{\circ} \mathrm{C}$ for $1 \mathrm{~h}, 180^{\circ} \mathrm{C}$ for $1 \mathrm{~h}$, and $200^{\circ} \mathrm{C}$ for $1 \mathrm{~h}$. The micrographs show homogenously distributed crystalline Pt-NPs next to Pt-clusters. (D) Histogram indicating the size distribution of Pt-clusters and NPs as determined by an analysis of the HAADF-STEM image shown in (A). 
A

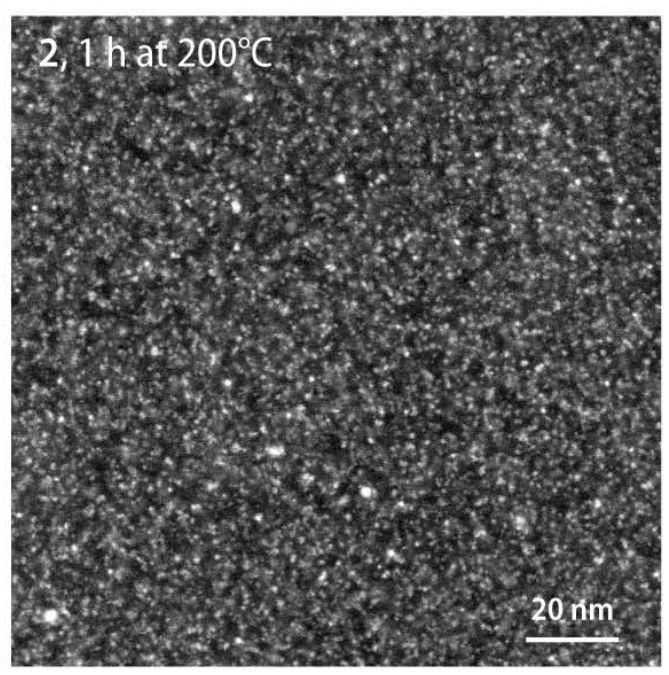

C

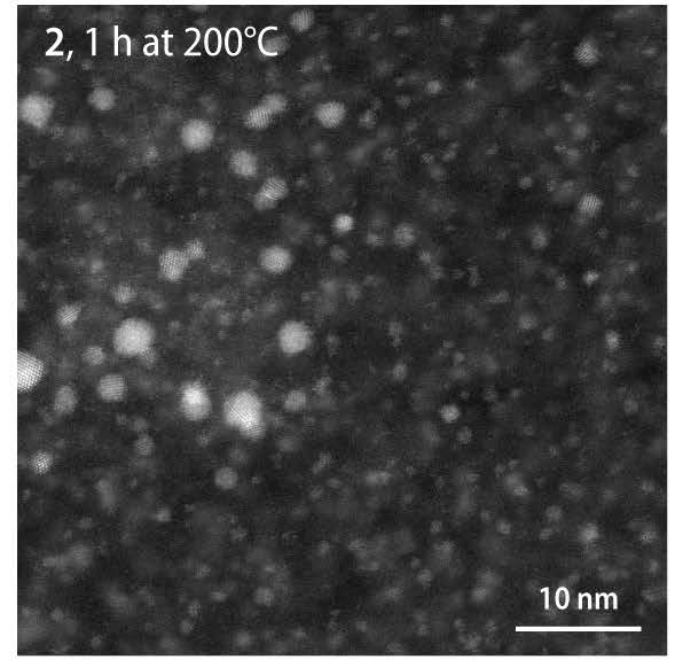

B

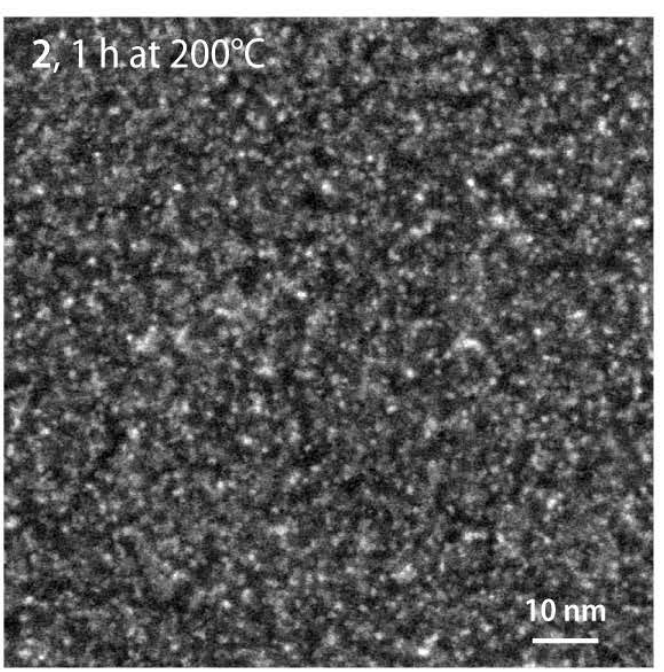

D

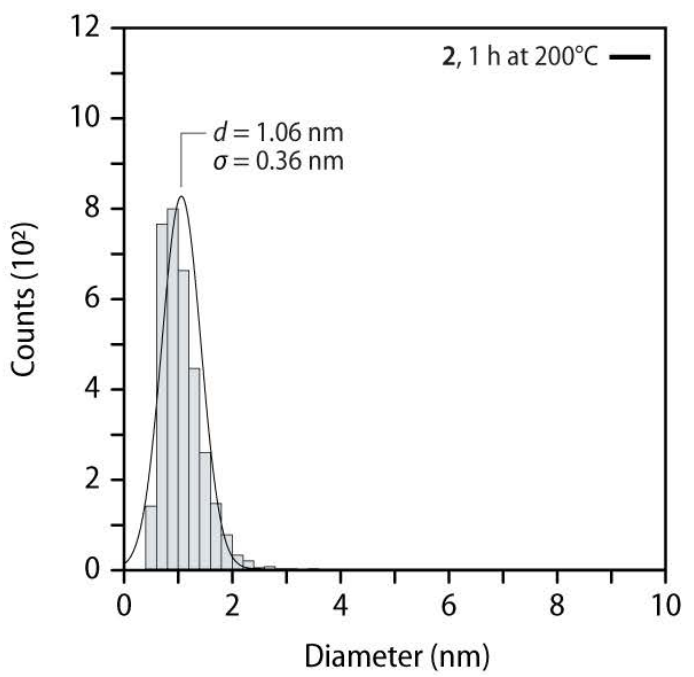

Supporting Figure S29. (A-C) High-angle annular dark-field (HAADF) scanning transmission electron microscopy (STEM) images of solvent-cast samples of MSP 2 recorded after heating from $25^{\circ} \mathrm{C}$ to $200{ }^{\circ} \mathrm{C}$ with a heating rate of $3^{\circ} \mathrm{C} \mathrm{min}^{-1}$ and heating at $200{ }^{\circ} \mathrm{C}$ for $1 \mathrm{~h}$. The micrographs show homogenously distributed crystalline Pt-NPs next to some Pt-clusters. (D) Histogram indicating the size distribution of Pt-clusters and NPs as determined by an analysis of the HAADF-STEM image shown in (A). 
A

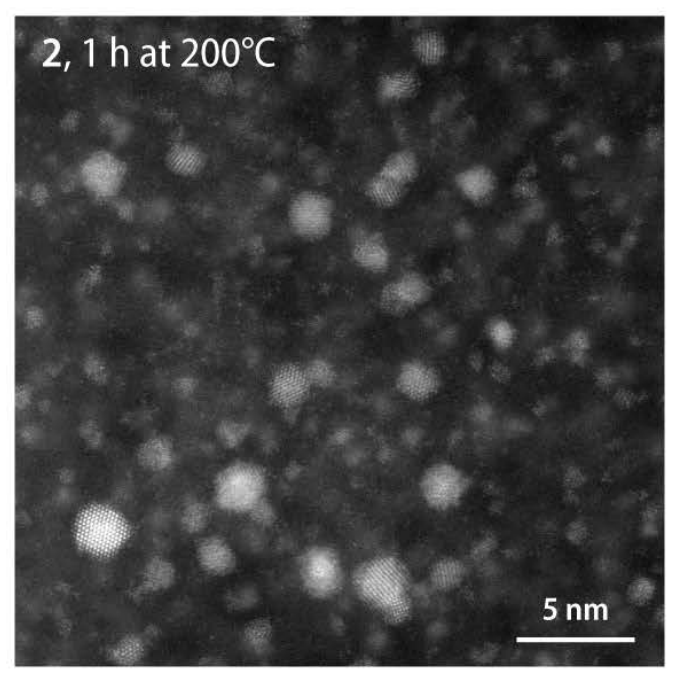

C

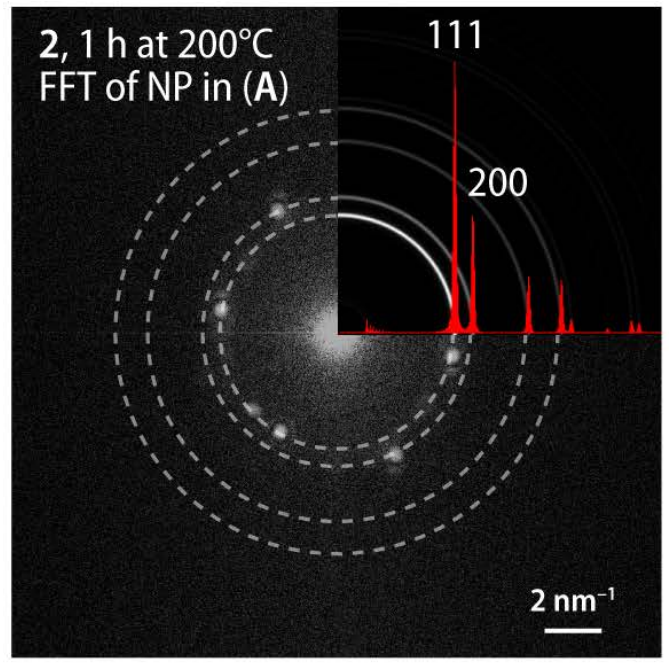

B

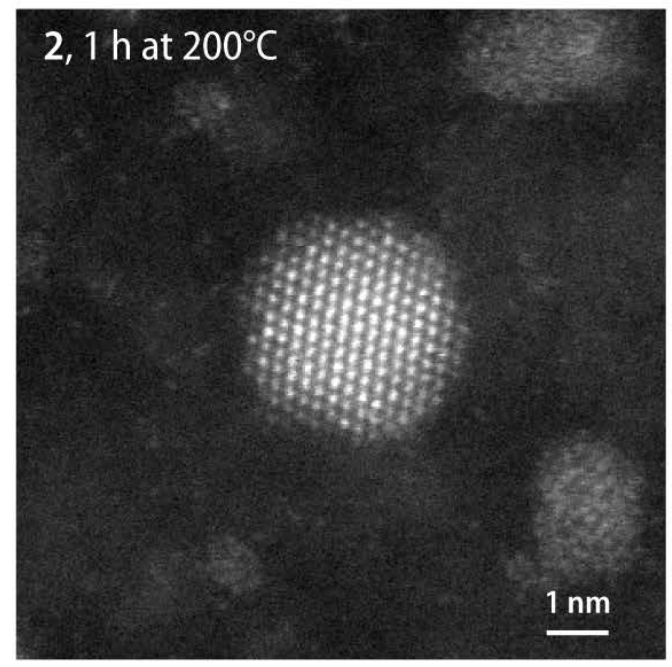

D

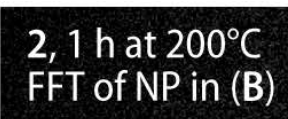

\section{0}

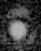

1118
The

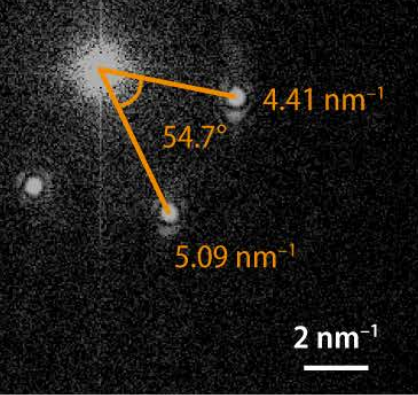

Supporting Figure S30. (A-B) High-angle annular dark-field (HAADF) scanning transmission electron microscopy (STEM) images of solvent-cast samples of MSP 2 recorded after heating from $25^{\circ} \mathrm{C}$ to $200{ }^{\circ} \mathrm{C}$ with a heating rate of $3^{\circ} \mathrm{C} \mathrm{min}^{-1}$ and heating at $200^{\circ} \mathrm{C}$ for $1 \mathrm{~h}$. The micrographs show crystalline Pt-NPs next to some Pt-clusters. (C) Fast Fourier transform (FFT) of the STEM micrograph displayed in (A). The inset shows the simulated electron diffraction pattern (ring sampling diffraction planes and corresponding intensity profile) of a face-centered cubic $\mathrm{Pt}^{0} \mathrm{crystal}$ (D) Fast Fourier transform of the STEM micrograph displayed in (B) showing reflections corresponding to the $\{111\}$ and $\{200\}$ crystallographic planes of a face-centered cubic $\mathrm{Pt}^{0}$ crystal oriented such that the electron beam is parallel to the $<110>$ zone axis. 


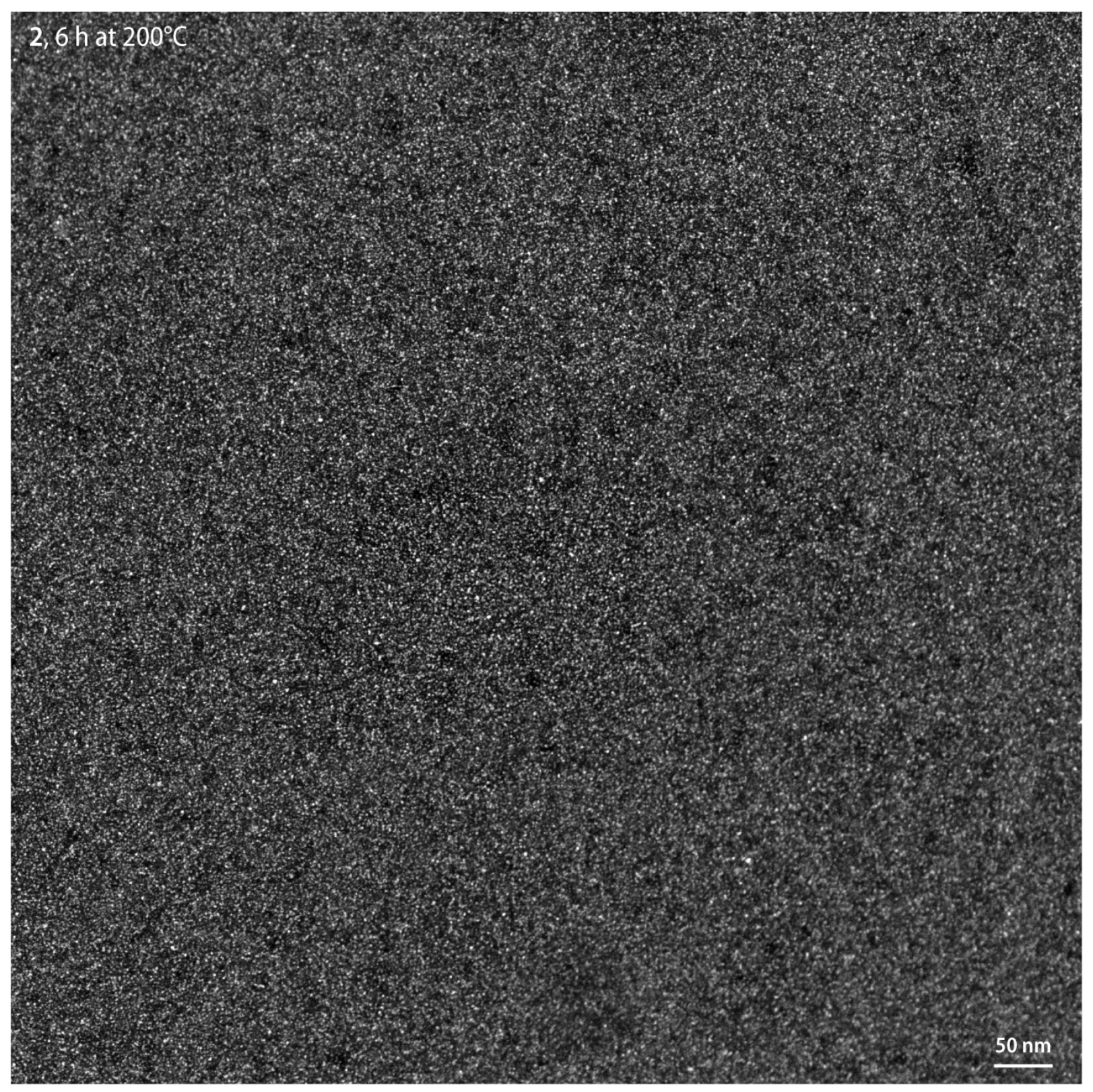

Supporting Figure S31. High-angle annular dark-field (HAADF) scanning transmission electron microscopy (STEM) images of a solvent-cast sample of MSP 2 recorded after heating at $200{ }^{\circ} \mathrm{C}$ for $6 \mathrm{~h}$. The micrographs show homogenously distributed crystalline Pt-NPs. 


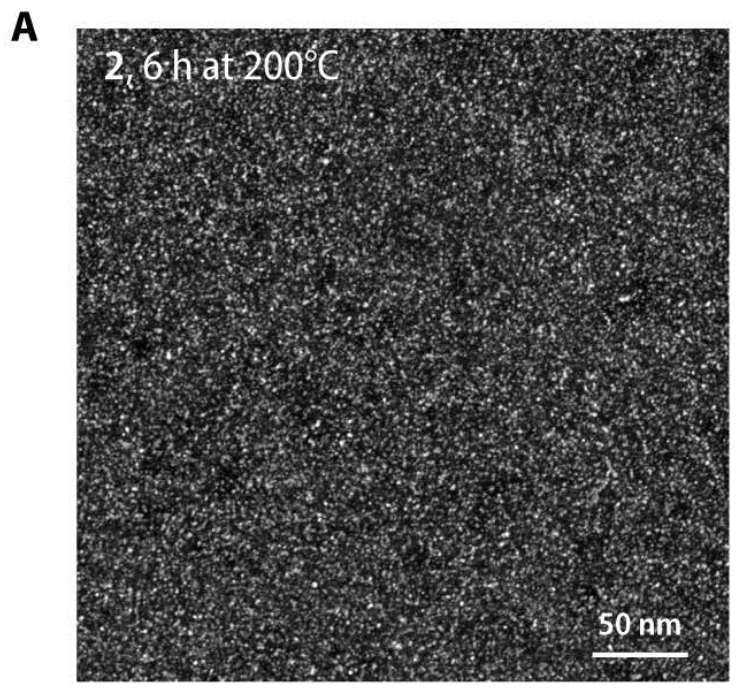

C

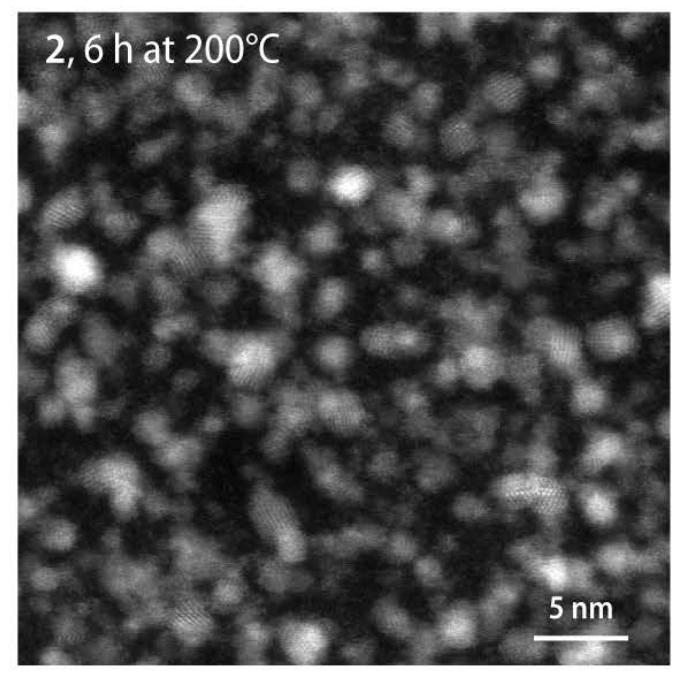

\section{B}

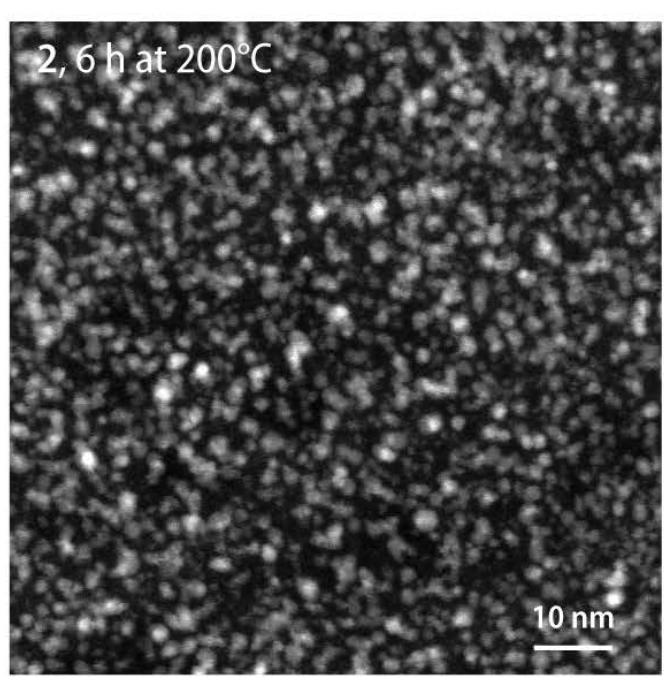

D

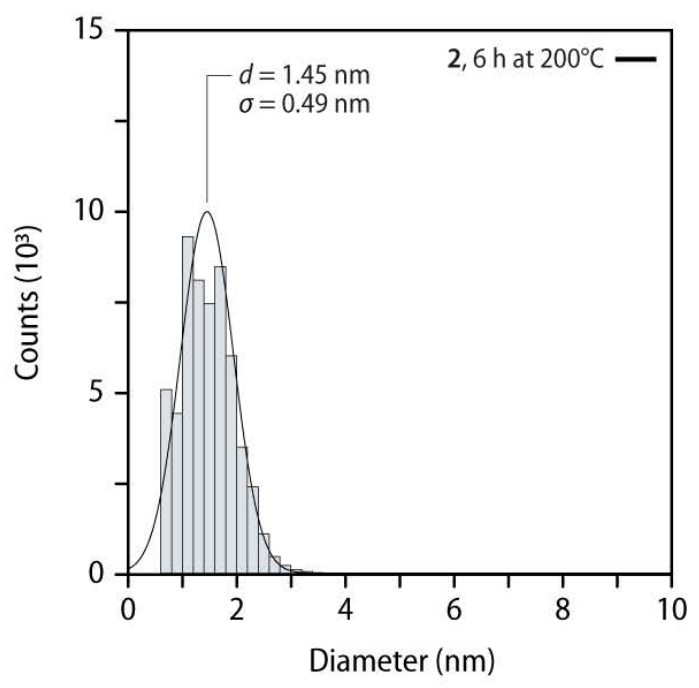

Supporting Figure S32. (A-C) High-angle annular dark-field (HAADF) scanning transmission electron microscopy (STEM) images of solvent-cast samples of MSP 2 recorded after heating at $200^{\circ} \mathrm{C}$ for $6 \mathrm{~h}$. The micrographs show homogenously distributed crystalline Pt-NPs. (D) Histogram indicating the size distribution of Pt-NPs as determined by an analysis of the HAADF-STEM image shown in Figure S31. 
A

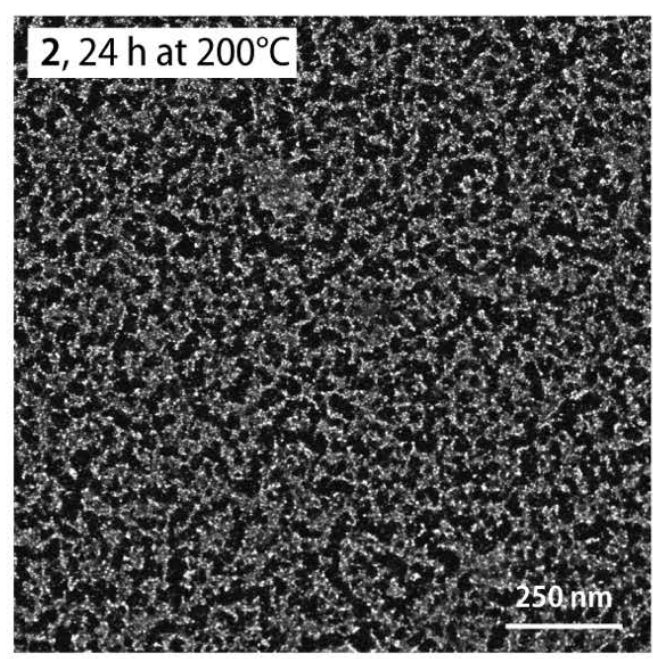

C

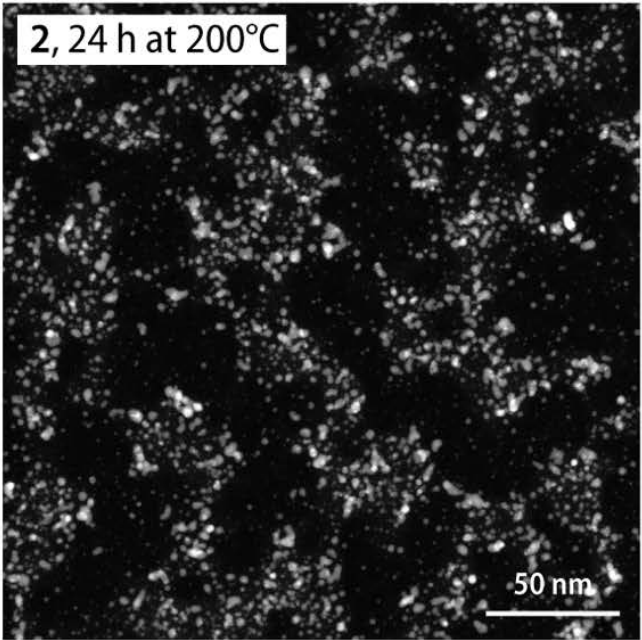

$\mathbf{E}$

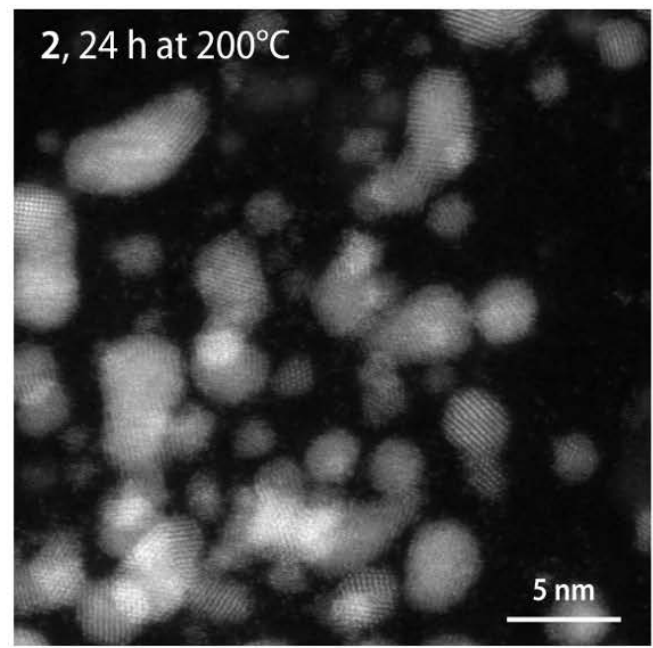

B

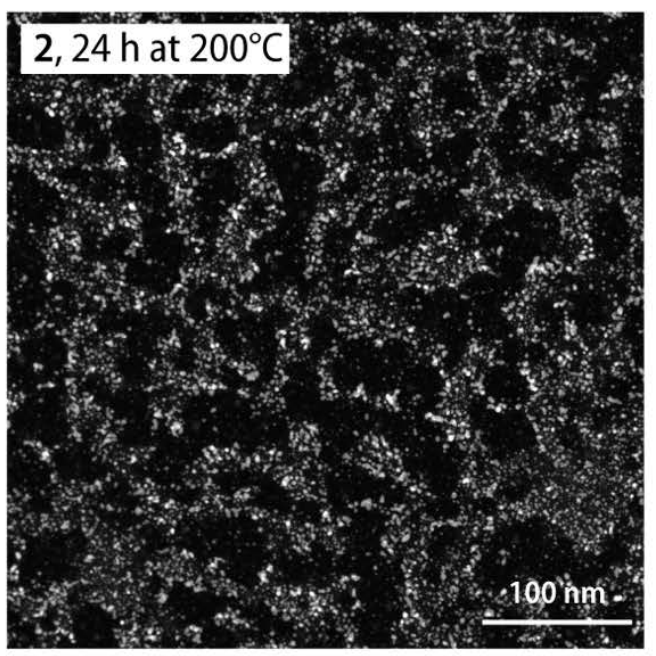

D

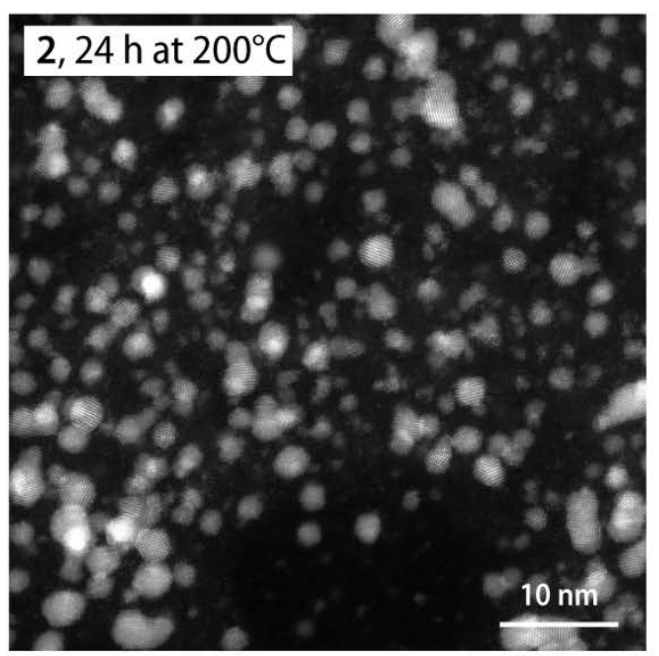

$\mathbf{F}$

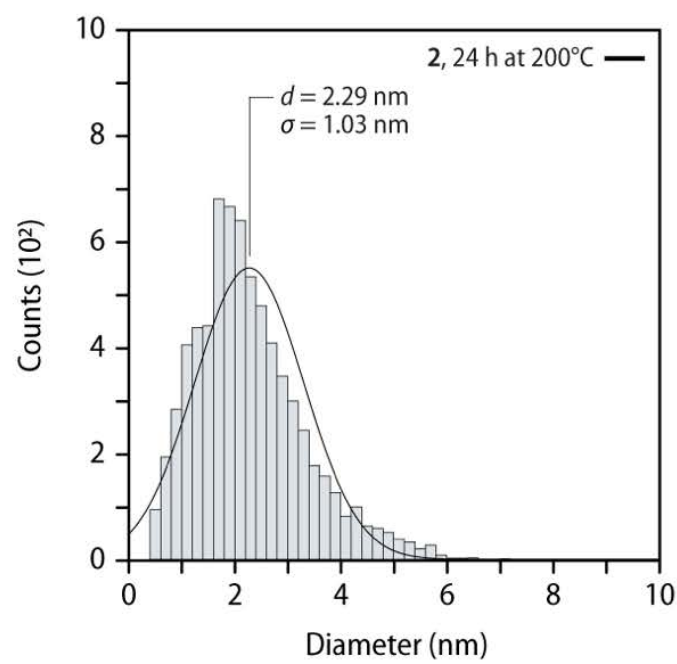

Supporting Figure S33. (A-E) High-angle annular dark-field (HAADF) scanning transmission electron microscopy (STEM) images of solvent-cast samples of MSP 2 recorded after heating at $200^{\circ} \mathrm{C}$ for $24 \mathrm{~h}$. The micrographs show crystalline Pt-NPs that have segregated from the polymer matrix. (F) Histogram indicating the size distribution of Pt-NPs as determined by an analysis of the HAADF-STEM image shown in (B). 
A

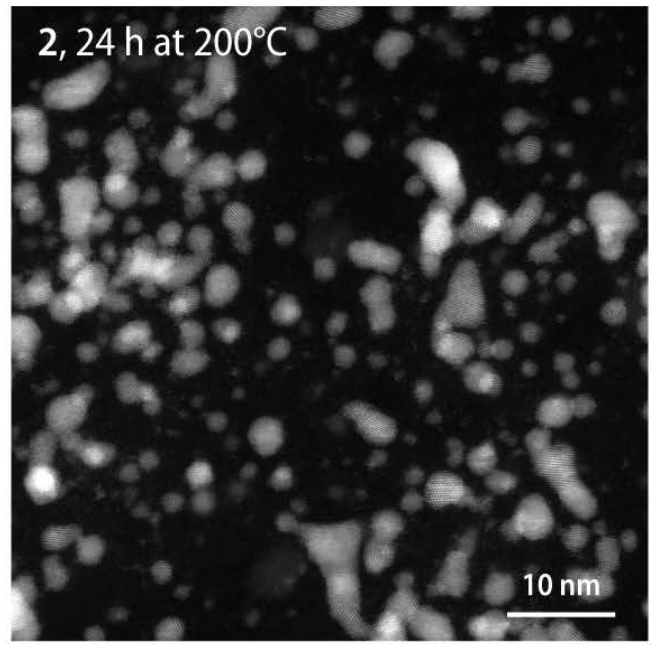

B

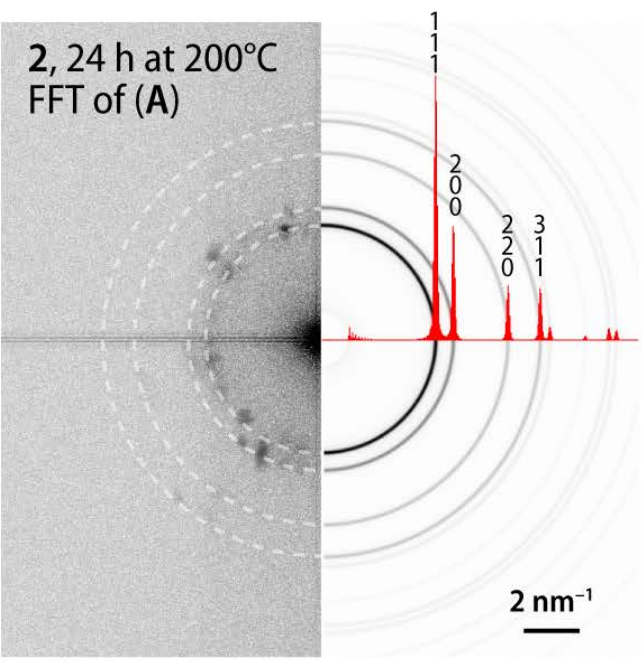

Supporting Figure S34. (A) High-angle annular dark-field (HAADF) scanning transmission electron microscopy (STEM) image of solvent-cast sample of MSP 2 recorded after heating at $200^{\circ} \mathrm{C}$ for $24 \mathrm{~h}$. The micrograph show crystalline Pt-NPs. (B) Fast Fourier transform (FFT) of the STEM micrograph displayed in (A). The FFT shows reflections corresponding to the $\{111\},\{200\},\{220\}$, as well as $\{311\}$ crystallographic planes of a face-centered cubic $\mathrm{Pt}^{0}$ crystal, as indicated by the comparison with the inset of the simulated electron diffraction pattern (ring sampling diffraction planes and corresponding intensity profile). 
A

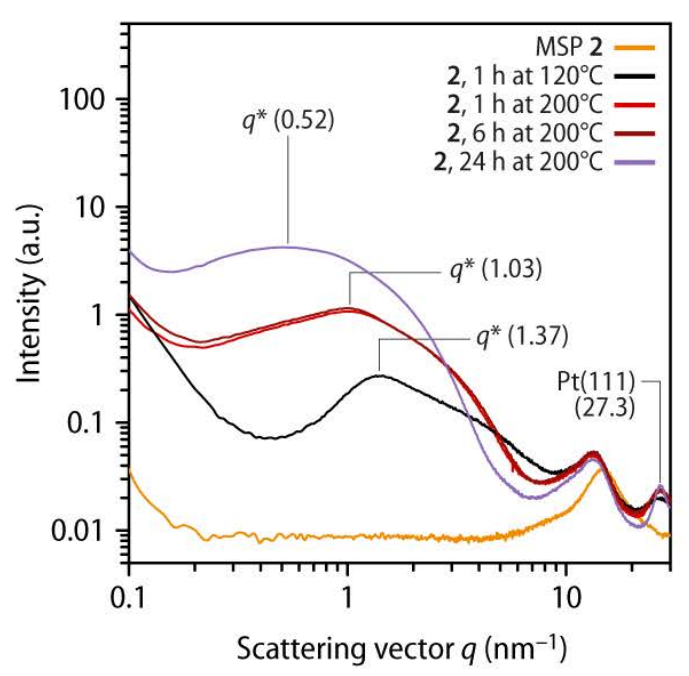

B

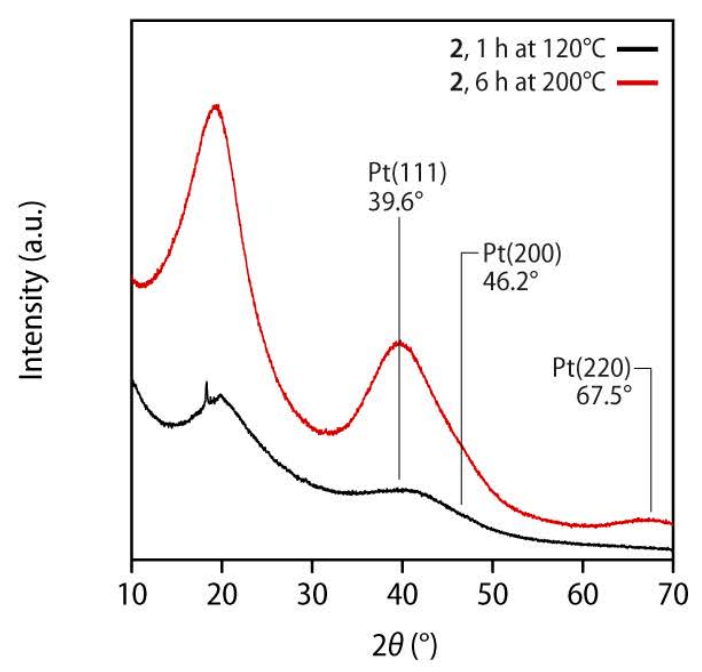

Supporting Figure S35. (A) Comparison of the small angle X-ray scattering (SAXS) spectrum of MSP 2 (orange line) with those of samples of MSP 2 that were heated at either $120^{\circ} \mathrm{C}$ for $1 \mathrm{~h}$ (black line), at $200^{\circ} \mathrm{C}$ for $1 \mathrm{~h}$ (red line), at $200{ }^{\circ} \mathrm{C}$ for $6 \mathrm{~h}$ (dark red line), or at $200{ }^{\circ} \mathrm{C}$ for $24 \mathrm{~h}$ (purple line). The main scattering maxima $q^{*}$ observed in the SAXS traces shift towards lower scattering vectors with increasing heating time, which indicates that the characteristic distance between the domains of Pt-NPs increases. Moreover, the slope beyond the main maximum also shifts towards lower scattering vectors with increasing heating time, suggesting that the volume of the Pt-NP domains increases. The maximum at ca. $12-16 \mathrm{~nm}^{-1}$ corresponds to the so-called amorphous halo and the background of the polyimide (Kapton) substrate. (B) Comparison of the powder X-ray diffraction spectra of samples of MSP 2 after heating at $120^{\circ} \mathrm{C}$ for $1 \mathrm{~h}$ (black line) and after heating at $200^{\circ} \mathrm{C}$ for $6 \mathrm{~h}$ (blue line). The indicated diffraction peaks correspond to the expected reflections from the (111) plane at $39.6^{\circ}$, the (200) plane at $46.2^{\circ}$, and the (220) plane at $67.5^{\circ}$ of a face-centered cubic $\mathrm{Pt}^{0} \mathrm{crystal}^{1}$. 


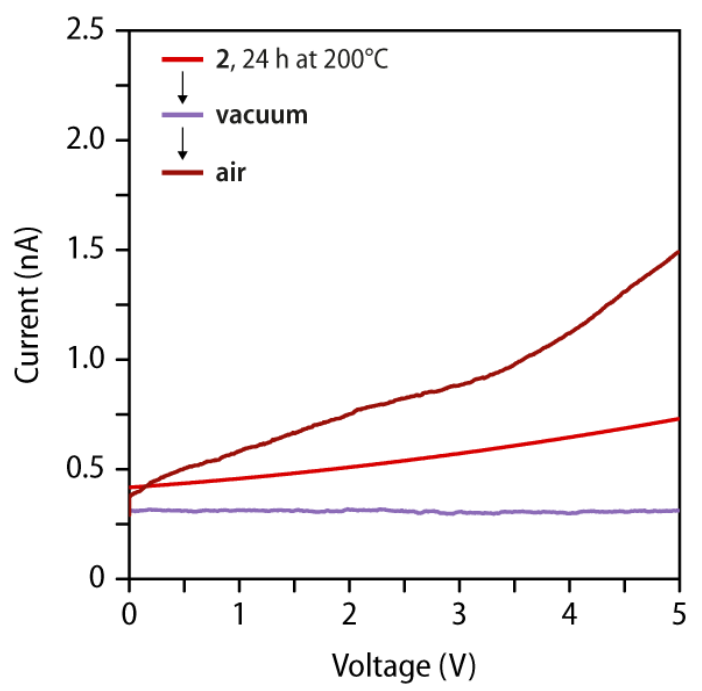

Supporting Figure S36. Comparison of the $I-V$ curves recorded in two-point measurements with samples of MSP 2 after heating for $24 \mathrm{~h}$ at a temperature of $200{ }^{\circ} \mathrm{C}$ (red line), after placing the heated sample in a vacuum (purple line), and after re-exposure of the sample to the atmospheric environment (brown line). 


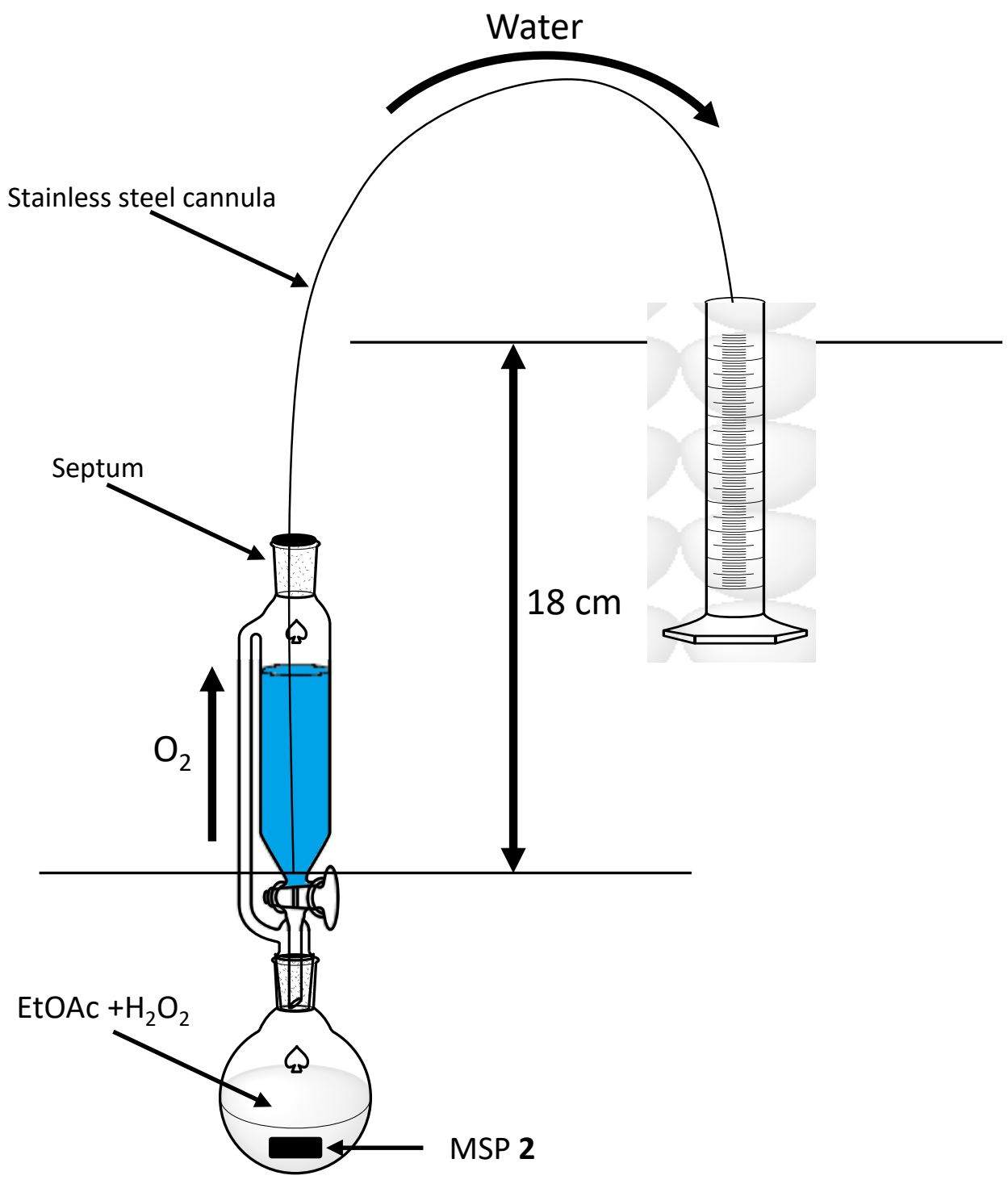

Supporting Figure S37. Schematic depiction of the volumetric setup employed to determine the catalytic activity of MSP 2 as well as the Pt-NP-containing composite materials in nanoparticle-catalyzed decomposition reaction of $\mathrm{H}_{2} \mathrm{O}_{2}$ into $\mathrm{O}_{2}$ and $\mathrm{H}_{2} \mathrm{O}$. The material was immersed in a flask containing a $1 \mathrm{M} \mathrm{H}_{2} \mathrm{O}_{2}$ solution in aqueous ethyl acetate. As a result of the evolving gas an overpressure built that displaced water from the dropping funnel into a volumetric flask. The amount of displaced water was measured to determine the rate of gas evolution. 


\section{A}

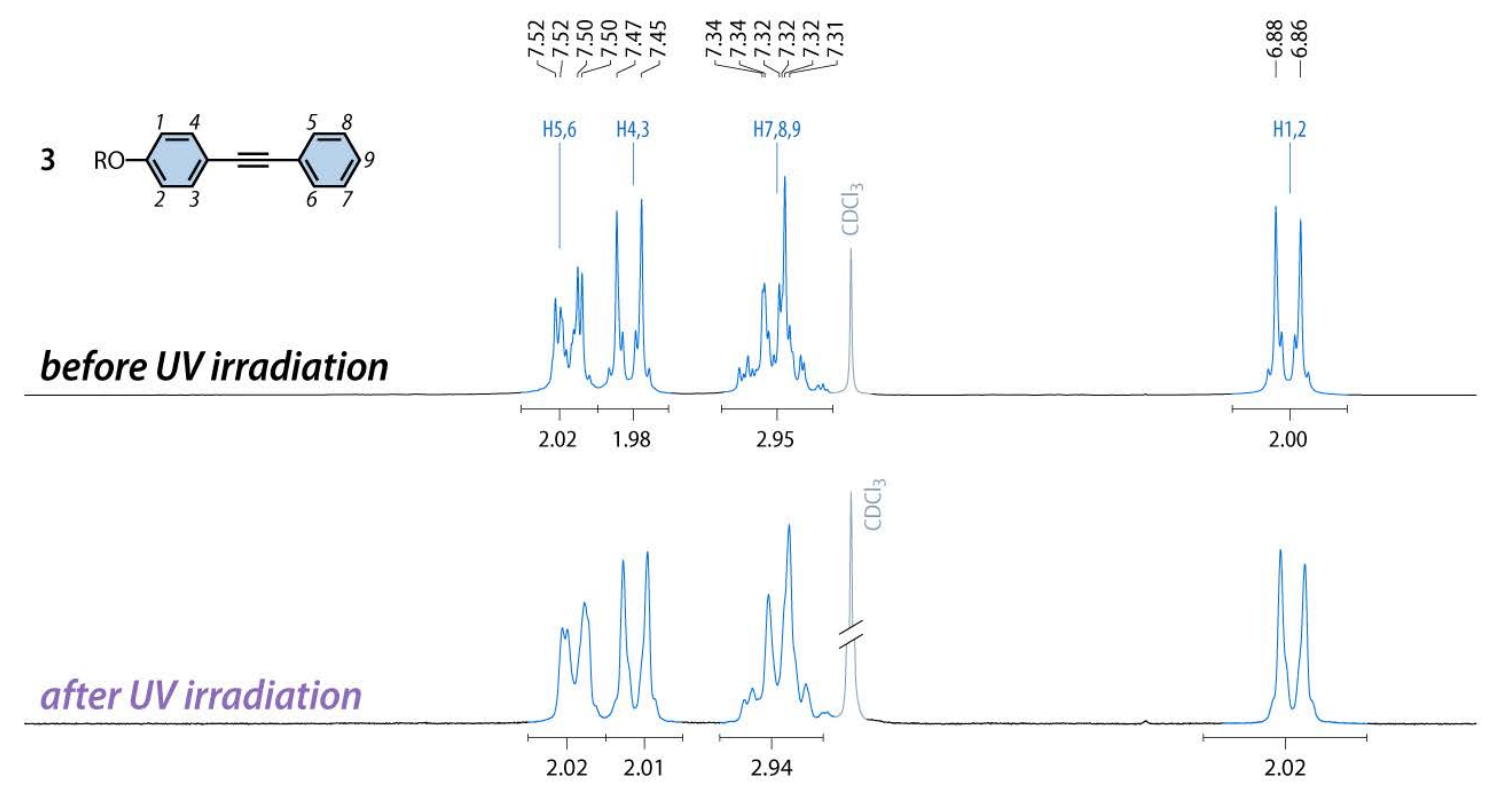

B

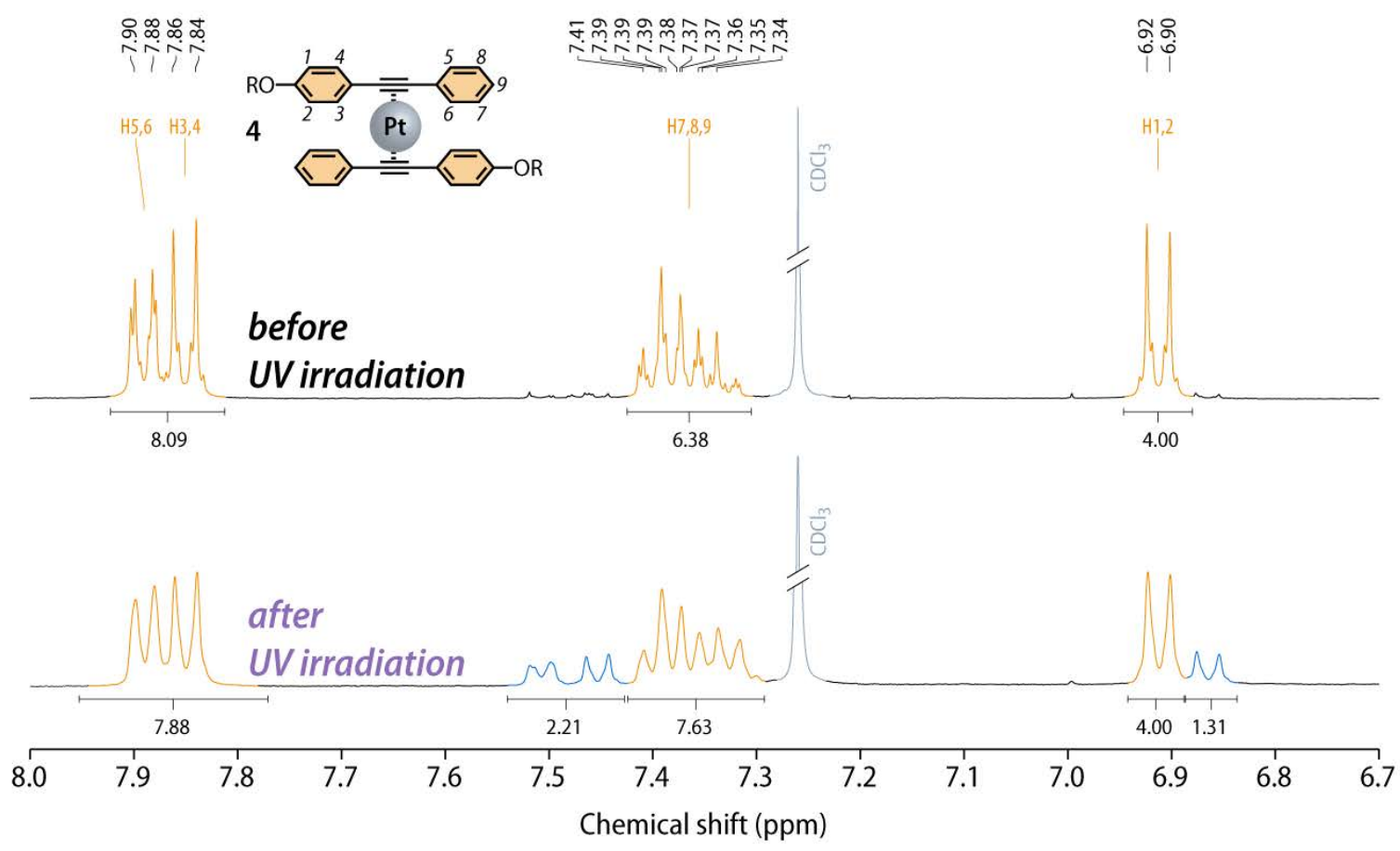

Supporting Figure S38. Comparison of the aromatic region of the ${ }^{1} \mathrm{H}-\mathrm{NMR}$ spectra $\left(400 \mathrm{MHz}, 297.2 \mathrm{~K}, \mathrm{CDCl}_{3}\right)$ of (A) the 1-hexyloxy-4-phenylethynyl-benzene ligand $\mathbf{3}$ and (B) the bis $\left(\eta^{2}\right.$-(1-hexyloxy-4-phenylethynyl-benzene) $) \mathrm{Pt}^{0}$ complex 4 before and after $30 \mathrm{~s}$ of UV irradiation $\left(700 \mathrm{~mW} / \mathrm{cm}^{2}, 320-390 \mathrm{~nm} ; \mathrm{R}=n \mathrm{C}_{6} \mathrm{H}_{13}\right)$. Whereas no significant changes are observed in the spectrum of the ligand 3, the spectrum recorded after irradiation of the complex 4 indicates the presence of free ligand and, hence, a dissociation of the metal-ligand complex upon UV irradiation. The fraction of free ligand after $30 \mathrm{~s}$ of UV irradiation is estimated to be on the order of ca. $33 \%$. 
A

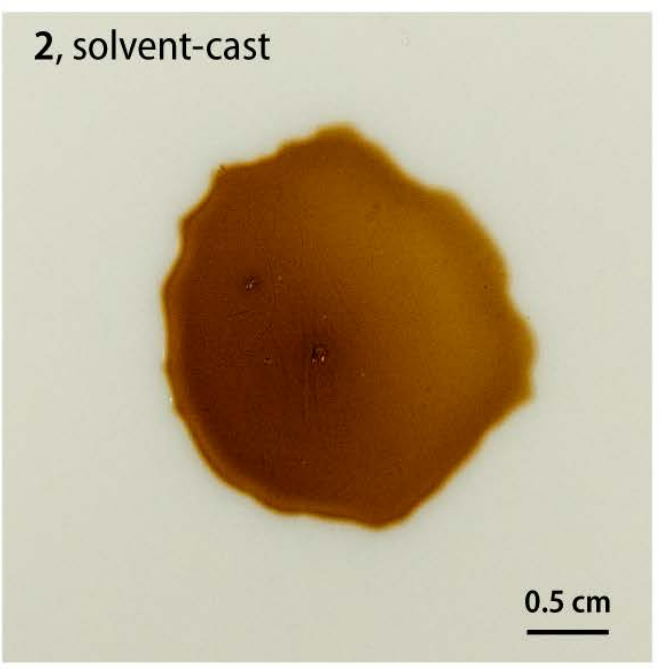

C

\section{2, after washing}

\section{$0.5 \mathrm{~cm}$}

B
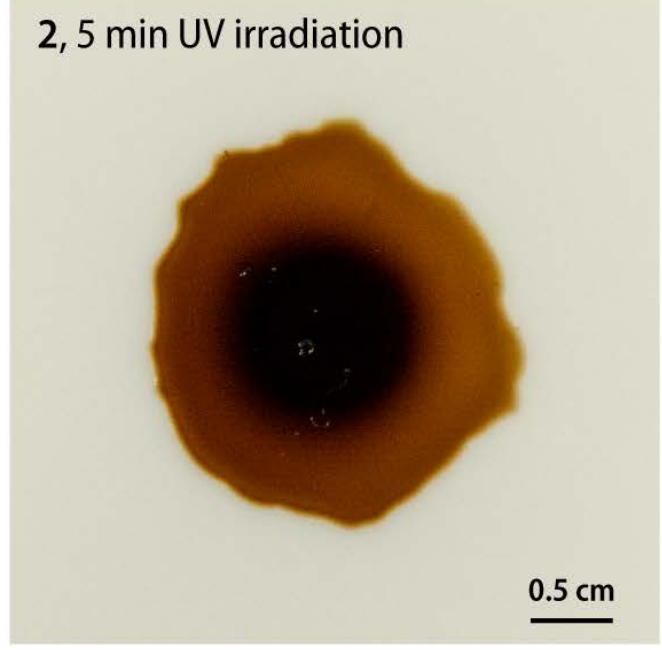

Supporting Figure S39. (A) Photograph of a solvent-cast film of MSP $2(<200 \mu \mathrm{m})$ on a PTFE substrate. (B) Photograph of the solvent-cast film of 2 after exposure to UV irradiation (320-390 nm; $900 \mathrm{~mW} \mathrm{~cm}^{-2}$ ) in the center for $5 \mathrm{~min}$. (C) Photograph of the sample after removal of the non-irradiated part by rinsing with hexanes. 
A

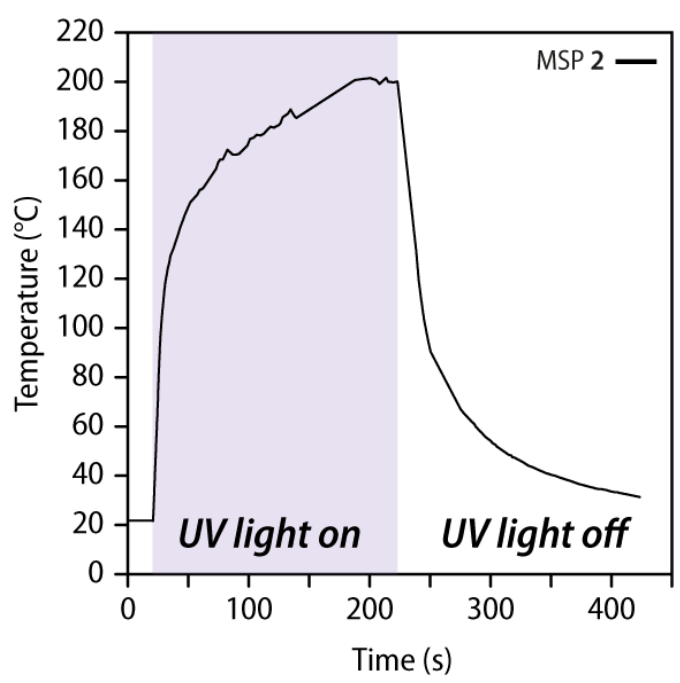

B

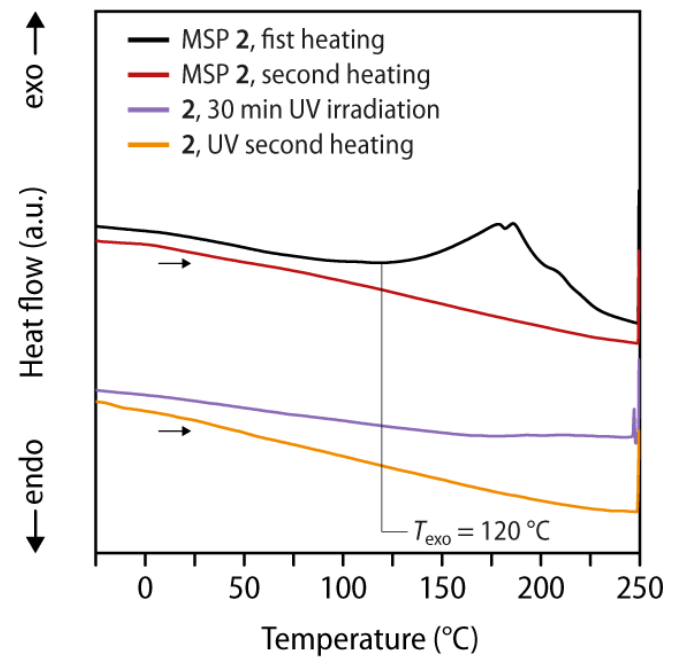

Supporting Figure S40. (A) Plot of the surface temperature of a solvent-cast film of MSP 2 measured using an infrared camera before, during (200 s), and after UV irradiation (320-390 nm; $700 \mathrm{~mW} \mathrm{~cm}^{-2}$ ). (B) Differential scanning calorimetry traces of solvent-cast samples of MSP 2 and comparison with the trace recorded after UV irradiation (30 min, $\left.320-390 \mathrm{~nm} ; 700 \mathrm{~mW} \mathrm{~cm}^{-2}\right)$. Shown are first heating and second heating scans $\left(10^{\circ} \mathrm{C} \mathrm{min}^{-1}\right)$. 
A

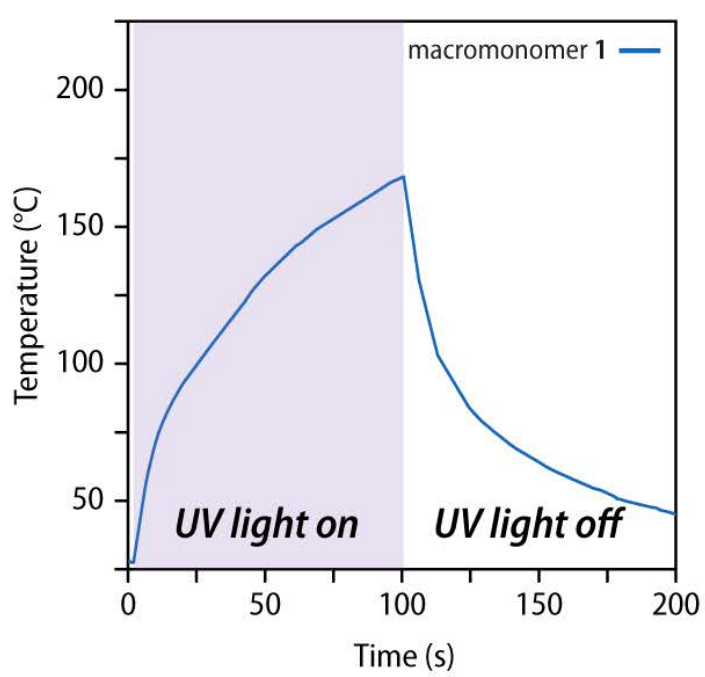

B
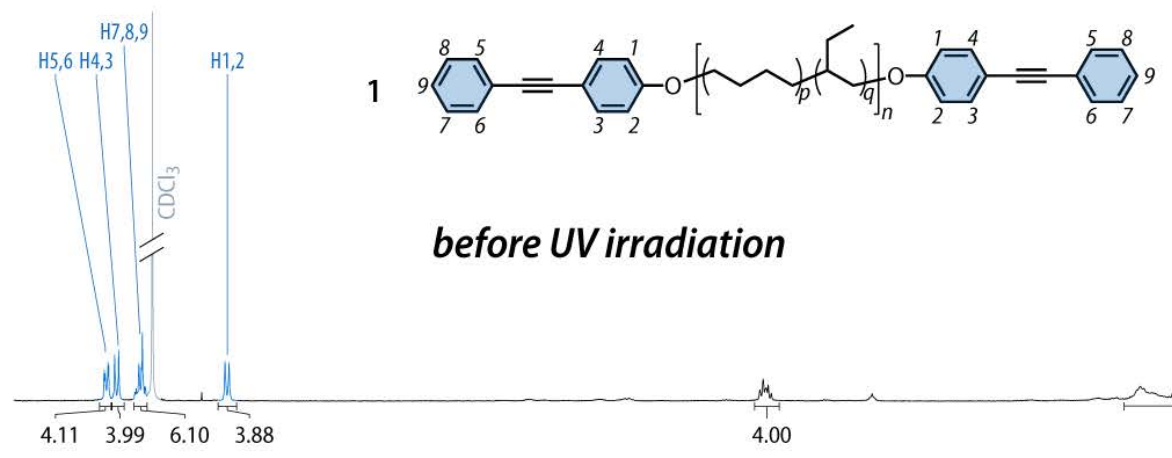

before UV irradiation

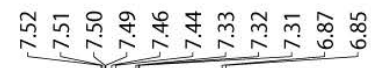

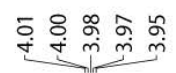
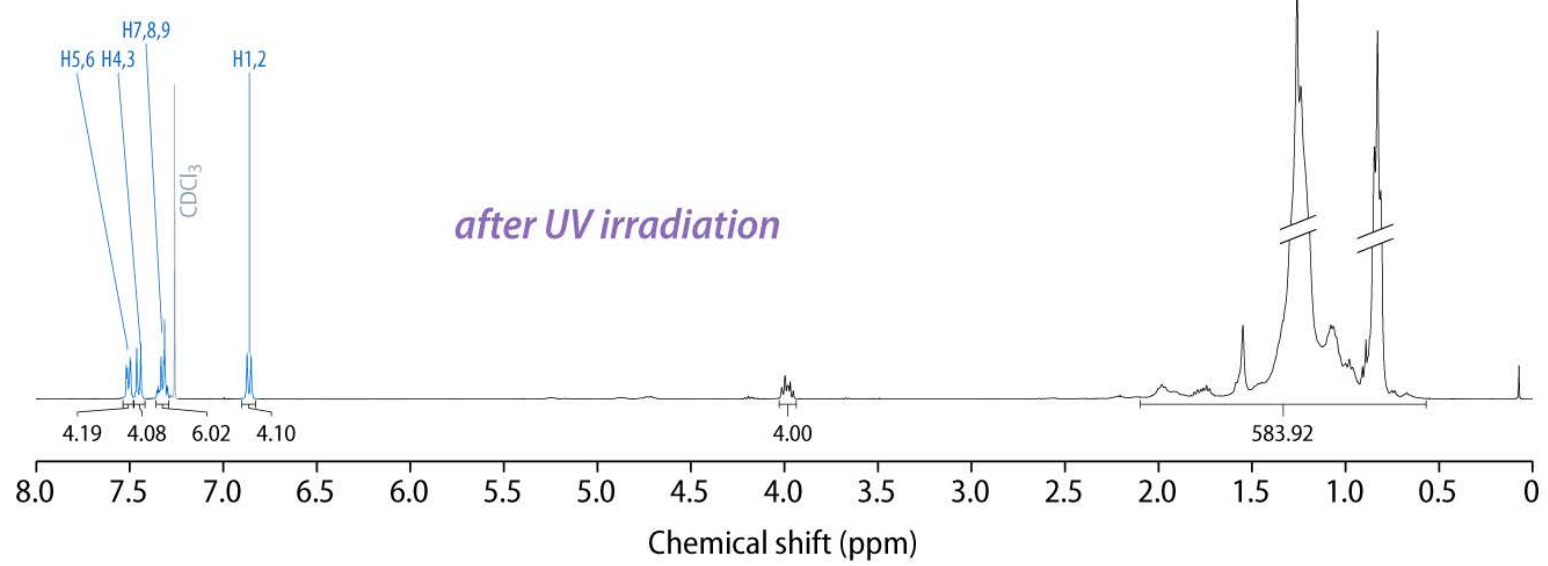

Supporting Figure S41. (A) Plot of the surface temperature of a solvent-cast film of macromonomer 1 during and after UV irradiation (ca. $100 \mathrm{~s} ; 320-390 \mathrm{~nm} ; 700 \mathrm{~mW} \mathrm{~cm}{ }^{-2}$ ) measured using an infrared camera. (B) Comparison of the ${ }^{1} \mathrm{H}$ NMR spectra $\left(400 \mathrm{MHz}, 297.2 \mathrm{~K}, \mathrm{CDCl}_{3}\right.$ ) of samples of macromonomer $\mathbf{1}$ before (top) as well as after (bottom) $2 \mathrm{~min}$ of UV irradiation (320-390 nm; $700 \mathrm{~mW} \mathrm{~cm}^{-2}$ ). The spectra suggest that macromonomer 1 does not undergo structural changes upon irradiation. 


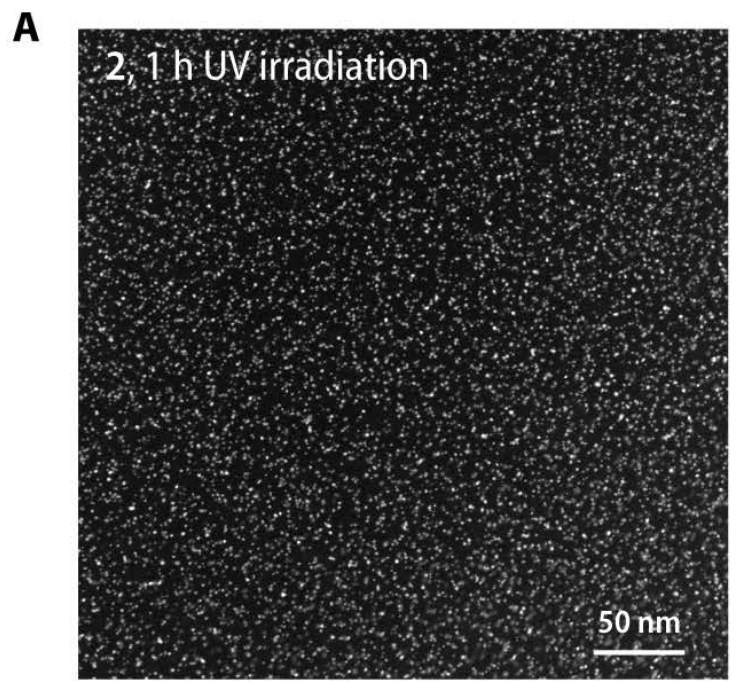

C

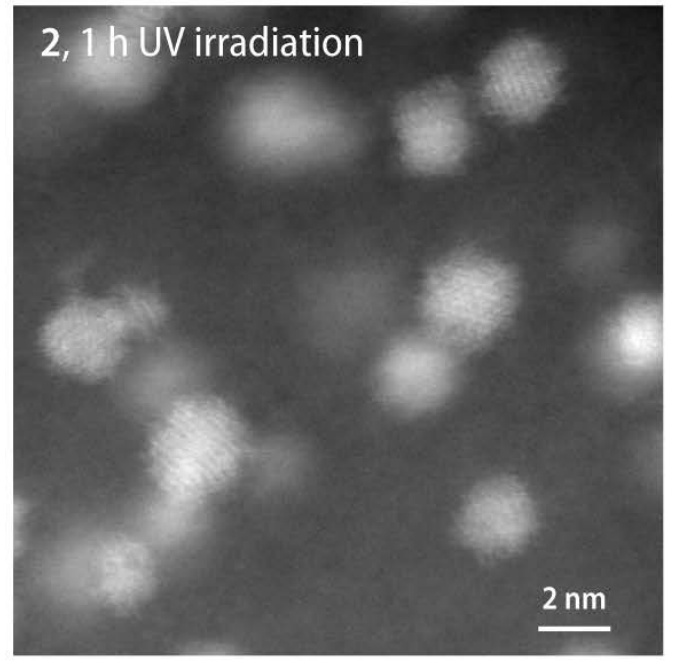

B

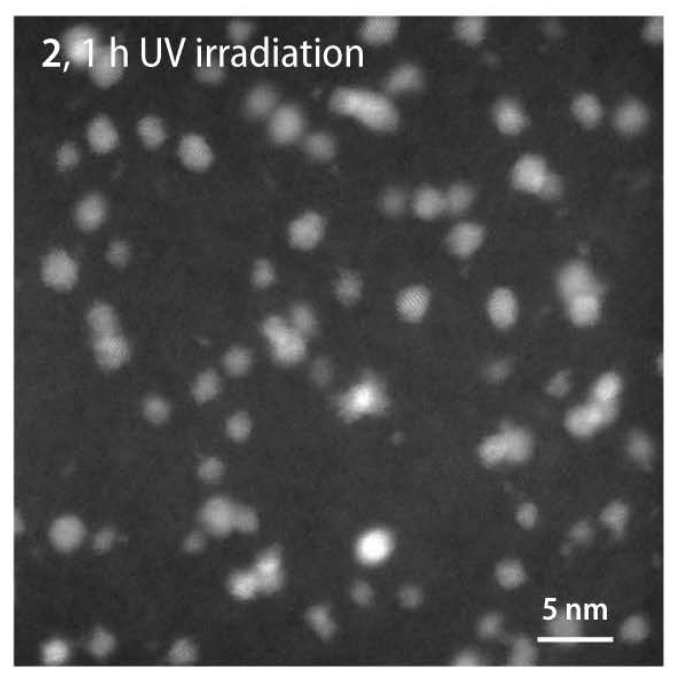

D

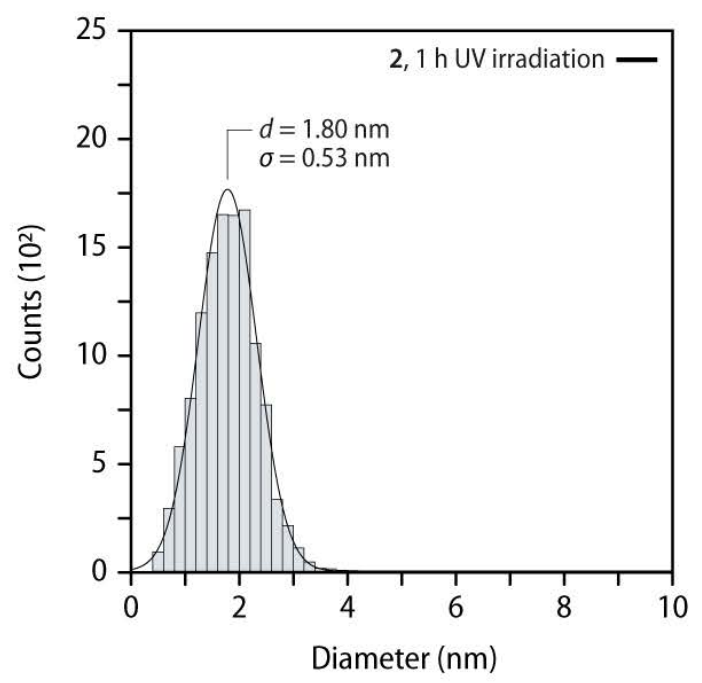

Supporting Figure S42. (A-C) High-angle annular dark-field (HAADF) scanning transmission electron microscopy (STEM) images of solvent-cast samples of MSP 2 that were exposed to UV irradiation (320-390 nm; $1000 \mathrm{~mW} \mathrm{~cm}^{-2}$ ) for $1 \mathrm{~h}$ and subsequently ultramicrotomed for STEM measurements. The micrographs show homogenously distributed crystalline Pt-NPs and some Pt-clusters. (D) Histogram indicating the size distribution of Pt-NPs and clusters as determined by an analysis of the HAADF-STEM image shown in $(\mathbf{A}, \mathbf{B})$. 


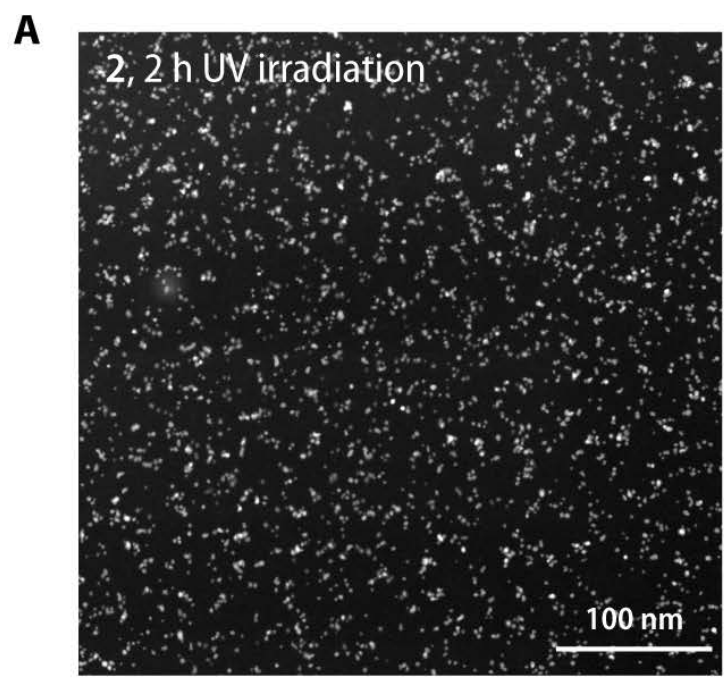

C

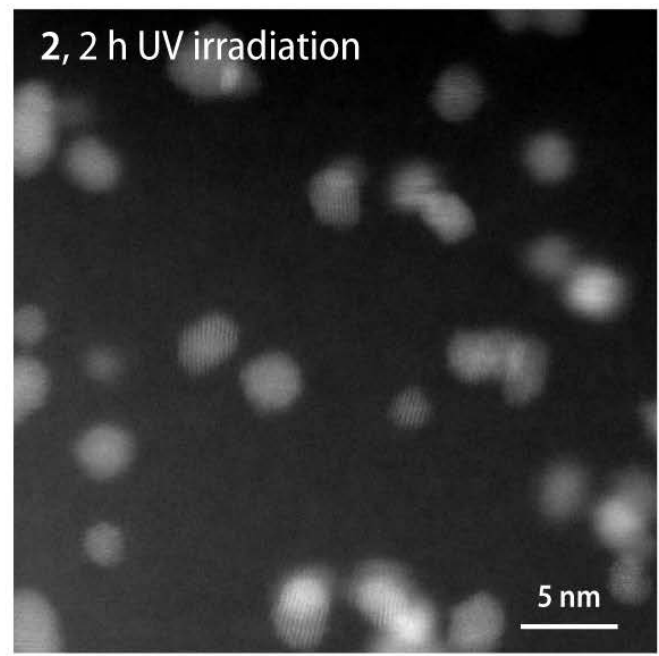

B

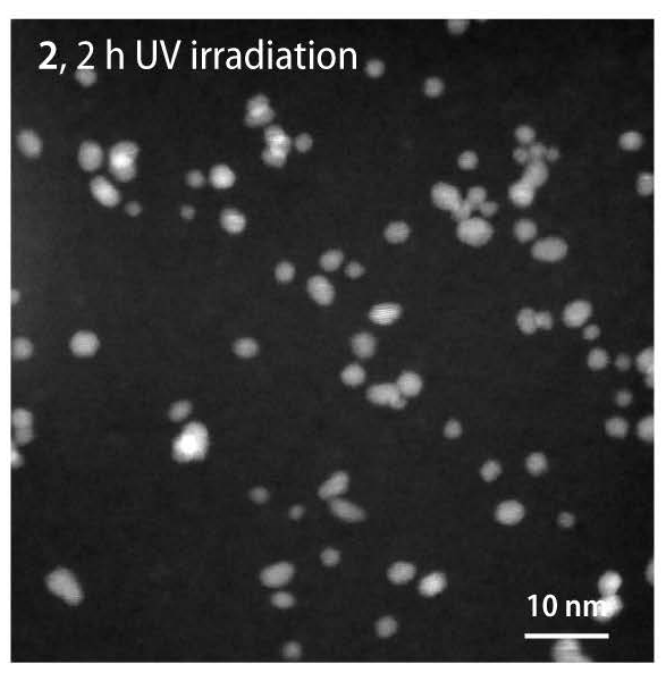

D

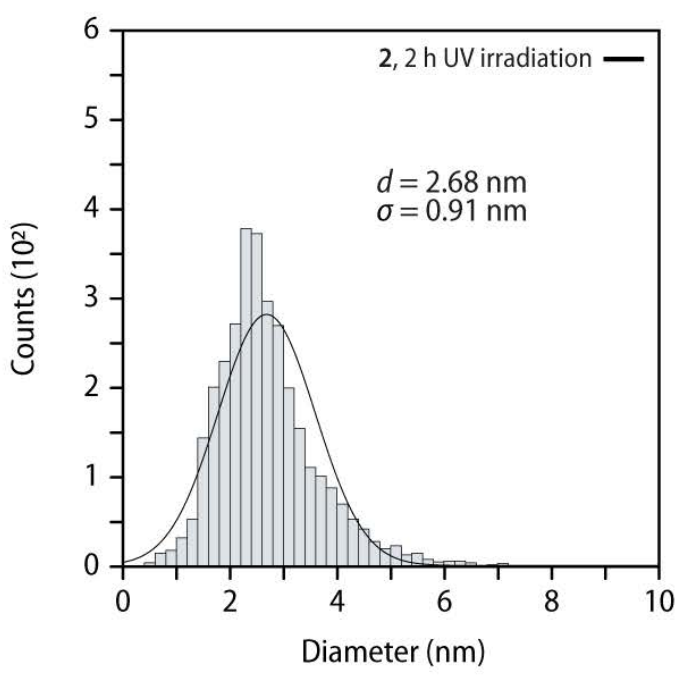

Supporting Figure S43. (A-C) High-angle annular dark-field (HAADF) scanning transmission electron microscopy (STEM) images of solvent-cast samples of MSP 2 that were exposed to UV irradiation (320-390 nm; $1000 \mathrm{~mW} \mathrm{~cm}^{-2}$ ) for $2 \mathrm{~h}$ and subsequently ultramicrotomed for STEM measurements. The micrographs show homogenously distributed crystalline Pt-NPs. (D) Histogram indicating the size distribution of Pt-NPs as determined by an analysis of the HAADF-STEM image shown in (A). 
A

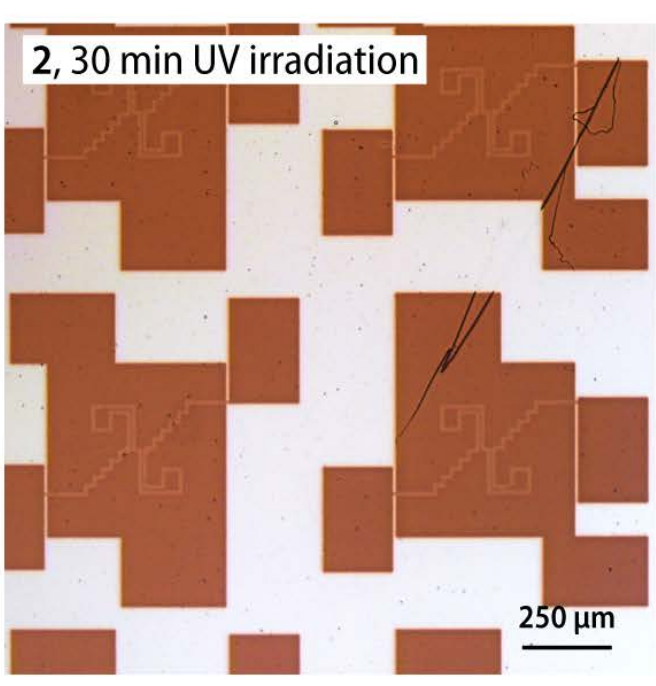

C

2, 30 min UV irradiation

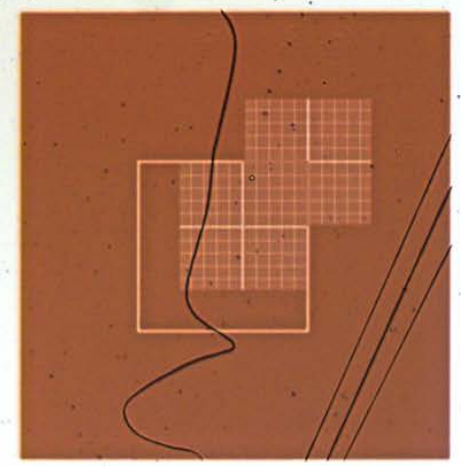

$200 \mu \mathrm{m}$
B

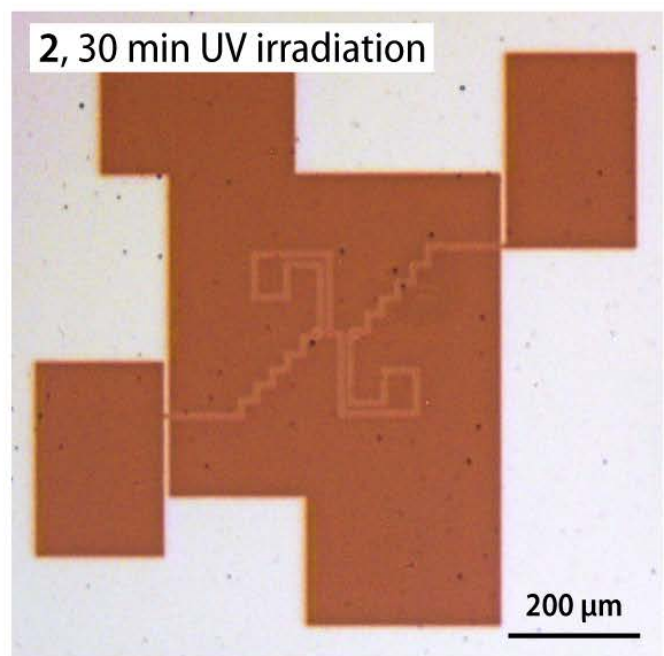

D

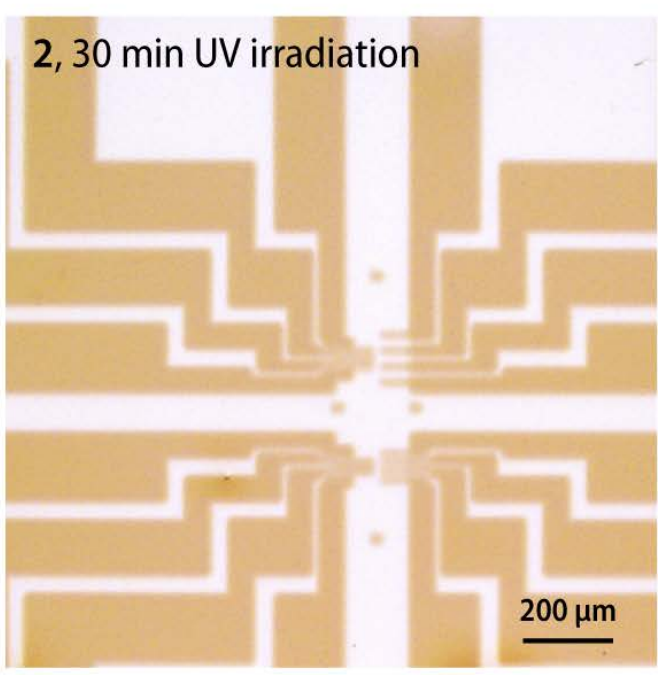

Supporting Figure S44. (A-D) Optical microscopy images showing thin solvent-cast films of MSP $2(<200 \mu \mathrm{m})$ on glass substrates after exposure to UV irradiation (30 $\mathrm{min} ; 320-390 \mathrm{~nm} ; 300 \mathrm{~mW} \mathrm{~cm}{ }^{-2}$ ) through a photomask. Only the exposed parts of the films of MSP 2 were observed to change their color. 
A

\section{2, 30 min UV irradiation}

$200 \mu \mathrm{m}$

\section{C}

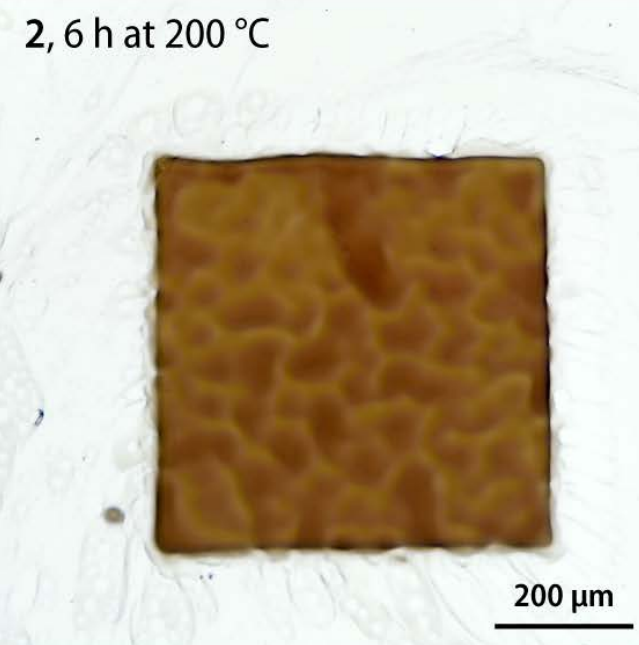

B

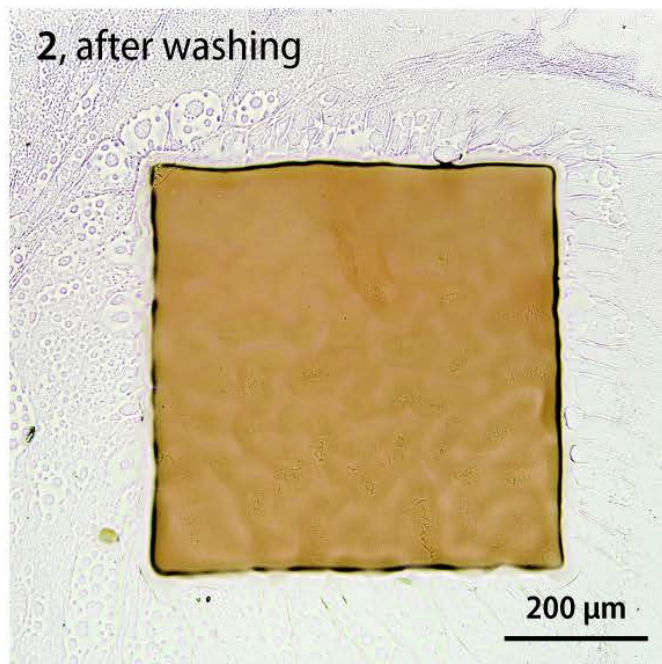

Supporting Figure S45. (A) Optical microscopy image showing a thin solvent-cast film of MSP $2(<200 \mu \mathrm{m})$ on a glass substrate after exposure to UV light (30 min; $320-390 \mathrm{~nm} ; 300 \mathrm{~mW} \mathrm{~cm}{ }^{-2}$ ) through a photomask. Only the exposed part of the film changes color acting in the sense of a negative photoresist. (B) Optical microscopy image showing the film after rinsing with pentane to remove the non-irradiated MSP $\mathbf{2}$ and (C) after an additional heating of the sample at a temperature of $200^{\circ} \mathrm{C}$ for $6 \mathrm{~h}$. 

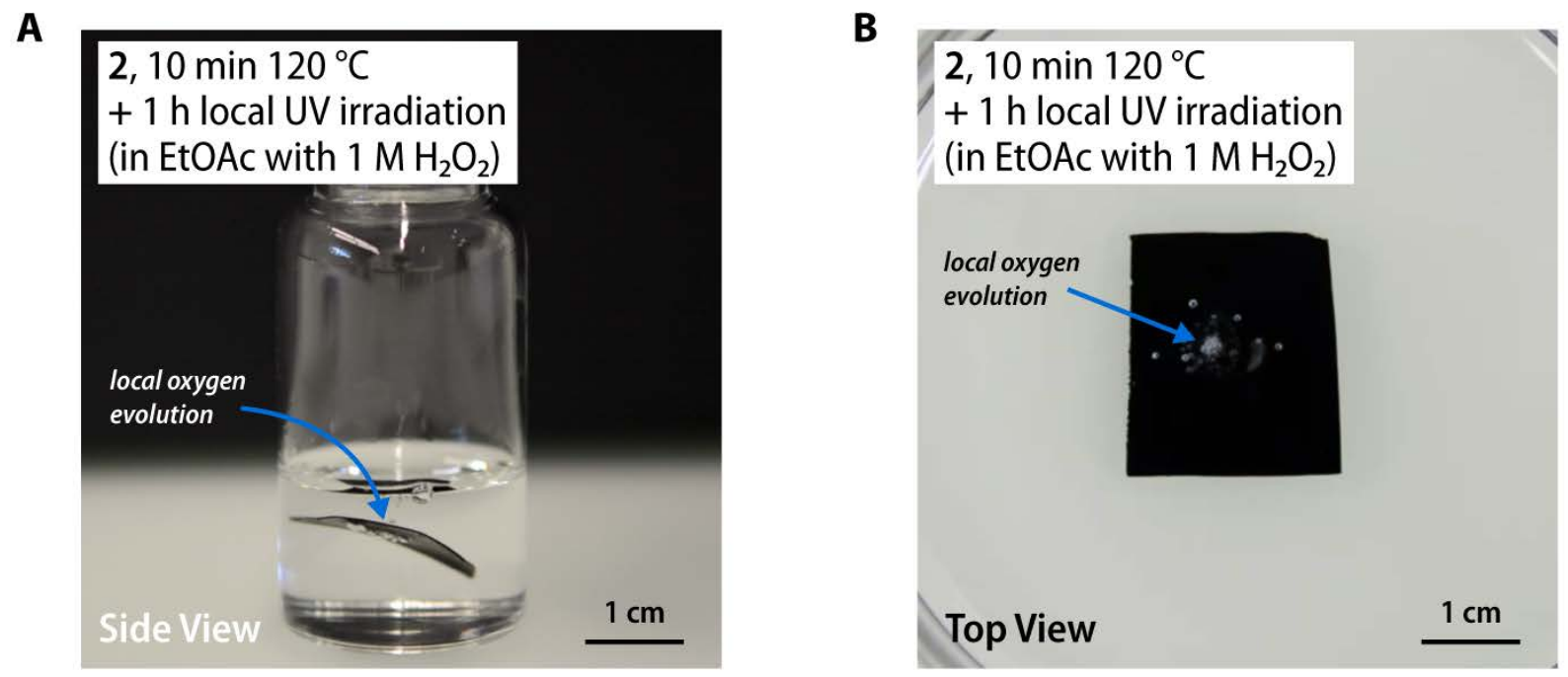

Supporting Figure S46. (A-B) Photographs of a nanocomposite film immersed in ethyl acetate with $1 \mathrm{M}_{2} \mathrm{O}_{2}$ that displays local oxygen evolution. The film was prepared by heating MSP 2 to $120^{\circ} \mathrm{C}(10 \mathrm{~min})$ followed by exposure to local UV irradiation ( $\left.1 \mathrm{~h} ; 320-390 \mathrm{~nm} ; 1000 \mathrm{~mW} \mathrm{~cm}^{-2}\right)$ through a photomask with a pin-hole. The gas evolution is limited to the sample region that was irradiated. 


\section{Supporting Tables S1-S4}

Supporting Table S1. Mechanical properties of solvent-cast films of the MSP $\mathbf{2}$ measured after compression-molding between PTFE sheets with a pressure of 3 tons for $1 \mathrm{~h}$ at the onset of the exotherm $\left(120^{\circ} \mathrm{C}\right)$ and with additional heating at $200{ }^{\circ} \mathrm{C}$ under $\mathrm{N}_{2}$ atmosphere. Data represent averages of $n=3$ individual measurements \pm standard deviation.

\begin{tabular}{ccccc}
\hline $\begin{array}{c}\text { Sample } \\
\text { Young's Modulus } \\
(\mathrm{MPa})^{a}\end{array}$ & $\begin{array}{c}\text { Tensile strength } \\
(\mathrm{MPa})^{a}\end{array}$ & $\begin{array}{c}\text { Strain at break } \\
(\%)^{a}\end{array}$ & $\begin{array}{c}\text { Toughness } \\
\left(\mathrm{kJ} \cdot \mathrm{m}^{-3}\right)^{a}\end{array}$ \\
\hline \hline $\mathbf{1 ~ h / 1 2 0}{ }^{\circ} \mathbf{C}$ & $0.45 \pm 0.08$ & $0.23 \pm 0.04$ & $69 \pm 5$ & $10.1 \pm 2.1$ \\
$\mathbf{6 ~ h ~} / \mathbf{2 0 0}{ }^{\circ} \mathbf{C}$ & $0.77 \pm 0.08$ & $0.66 \pm 0.001$ & $102 \pm 22$ & $35.58 \pm 0.8$ \\
\hline
\end{tabular}

${ }^{a}$ Measured by DMA in uniaxial stress-strain experiments at $25^{\circ} \mathrm{C}$ with a strain rate of $1 \% \mathrm{~min}^{-1}$.

Supporting Table S2. Overview of the parameters determined by conductivity measurements at $5 \mathrm{~V}$ for samples of MSP 2 after heating to different temperatures for different times.

\begin{tabular}{|c|c|c|c|c|c|c|c|}
\hline Sample & $\begin{array}{c}\text { Resistance } \\
(\Omega)\end{array}$ & $\begin{array}{l}\text { Resistivity } \\
\qquad\left(\Omega \cdot \mathrm{cm}^{-1}\right)\end{array}$ & $\begin{array}{c}\text { Conductivity } \\
\text { (S) }\end{array}$ & $\begin{array}{l}\text { Conductance } \\
\qquad\left(\mathrm{S} \cdot \mathrm{cm}^{-1}\right)\end{array}$ & $\begin{array}{c}\mathbf{X} \\
\mathrm{cm}\end{array}$ & $\begin{array}{c}\mathbf{Y} \\
\mathrm{cm}\end{array}$ & $\begin{array}{c}\text { Thickness } \\
\text { mm }\end{array}$ \\
\hline $30 \mathrm{~min} / 120^{\circ} \mathrm{C}$ & $2.99 \mathrm{E}+8$ & $1.01 \mathrm{E}+7$ & $3.35 \mathrm{E}-9$ & $9.86 \mathrm{E}-8$ & 1.03 & 1.03 & 0.36 \\
\hline $6 \mathrm{~h} / 200^{\circ} \mathrm{C}$ & $1.78 \mathrm{E}+10$ & $8.36 \mathrm{E}+8$ & $5.62 \mathrm{E}-11$ & $1.20 \mathrm{E}-9$ & 0.82 & 0.70 & 0.27 \\
\hline $24 \mathrm{~h} / 200^{\circ} \mathrm{C}^{a}$ & $6.89 \mathrm{E}+9$ & $2.56 \mathrm{E}+8$ & $1.45 \mathrm{E}-10$ & $3.90 \mathrm{E}-9$ & 0.80 & 0.80 & 0.24 \\
\hline$\underset{\text { dried }}{24 \mathrm{~h} / 200}{ }^{\circ} \mathrm{C}^{a}$ & $1.62 \mathrm{E}+10$ & $6.01 \mathrm{E}+8$ & $6.19 \mathrm{E}-11$ & $1.66 \mathrm{E}-9$ & 0.80 & 0.80 & 0.24 \\
\hline $\begin{array}{c}24 \mathbf{h} / 200{ }^{\circ} \mathrm{C}^{a} \\
\text { re-exposed }\end{array}$ & $3.36 \mathrm{E}+9$ & $1.25 \mathrm{E}+8$ & $2.98 \mathrm{E}-10$ & $8.00 \mathrm{E}-9$ & 0.80 & 0.80 & 0.24 \\
\hline
\end{tabular}

aFilms of the nanocomposite of uniform thickness were prepared by compression molding samples of MSP 2 in between PTFE sheets in a square shaped mold in a Carver CE Press at $120^{\circ} \mathrm{C}$ for $30 \mathrm{~min}$ with a pressure of 3 tons. All other samples were initially compression molded in the same way at $120^{\circ} \mathrm{C}$ for $1 \mathrm{~h}$ with a pressure of 3 tons and subsequently heated at $200{ }^{\circ} \mathrm{C}$ in an oven under an inert nitrogen atmosphere. 
Supporting Table S3. Overview of the parameters determined by conductivity measurements at $10 \mathrm{~V}$ for samples of with MSP 2 after heating to different temperatures for different times.

\begin{tabular}{|c|c|c|c|c|c|c|c|}
\hline Sample & $\begin{array}{c}\text { Resistance } \\
(\Omega)\end{array}$ & $\begin{array}{c}\text { Resistivity } \\
\qquad\left(\Omega \cdot \mathrm{cm}^{-1}\right)\end{array}$ & $\begin{array}{c}\text { Conductivity } \\
\text { (S) }\end{array}$ & $\begin{array}{l}\text { Conductance } \\
\qquad\left(\mathrm{S} \cdot \mathrm{cm}^{-1}\right)\end{array}$ & $\begin{array}{l}\mathbf{X} \\
\mathrm{cm}\end{array}$ & $\begin{array}{l}\mathbf{Y} \\
\mathrm{cm}\end{array}$ & $\begin{array}{c}\text { Thickness } \\
\mathrm{mm}\end{array}$ \\
\hline $30 \min / 120^{\circ} \mathrm{C}$ & $4.10 \mathrm{E}+8$ & $1.39 \mathrm{E}+7$ & $2.44 \mathrm{E}-9$ & $7.19 \mathrm{E}-8$ & 1.03 & 1.03 & 0.36 \\
\hline $6 \mathrm{~h} / 200^{\circ} \mathrm{C}$ & $3.30 \mathrm{E}+10$ & $1.55 E+9$ & $3.03 \mathrm{E}-11$ & $6.44 \mathrm{E}-10$ & 0.82 & 0.70 & 0.27 \\
\hline $24 \mathbf{h} / 200^{\circ} \mathbf{C}^{a}$ & $7.60 \mathrm{E}+9$ & $2.83 E+8$ & $1.32 \mathrm{E}-10$ & $3.54 \mathrm{E}-9$ & 0.80 & 0.80 & 0.24 \\
\hline$\underset{\text { dried }}{24 \mathrm{~h} / 200}{ }^{\circ} \mathrm{C}^{a}$ & $3.30 \mathrm{E}+10$ & $1.23 \mathrm{E}+9$ & $3.03 \mathrm{E}-11$ & $8.15 \mathrm{E}-10$ & 0.80 & 0.80 & 0.24 \\
\hline $\begin{array}{c}24 \mathbf{h} / 200{ }^{\circ} \mathrm{C}^{a} \\
\text { re-exposed }\end{array}$ & $2.45 E+9$ & $9.11 \mathrm{E}+7$ & $4.08 \mathrm{E}-10$ & $1.10 \mathrm{E}-8$ & 0.80 & 0.80 & 0.24 \\
\hline
\end{tabular}

$a$ Films of the nanocomposite of uniform thickness were prepared by compression molding samples of MSP 2 in between PTFE sheets in a square shaped mold in a Carver CE Press at $120^{\circ} \mathrm{C}$ for $30 \mathrm{~min}$ with a pressure of 3 tons. All other samples were initially compression molded in the same way at $120^{\circ} \mathrm{C}$ for $1 \mathrm{~h}$ with a pressure of 3 tons and subsequently heated at $200{ }^{\circ} \mathrm{C}$ in an oven under an inert nitrogen atmosphere.

Supporting Table S4. Rate of gas evolution as determined by volumetric measurements (vide supra) as produced with the Pt-NP-composite materials as dip catalysts for the decomposition reaction of $\mathrm{H}_{2} \mathrm{O}_{2}$. The samples of MSP 2 after heating for different times were immersed in $1 \mathrm{M} \mathrm{H}_{2} \mathrm{O}_{2}$ aqueous ethyl acetate solutions.

\begin{tabular}{|c|c|}
\hline Sample & $\begin{array}{l}\text { Catalytic activity } \\
\left(\mu \mathrm{mol} \cdot \mathrm{min}^{-1} \cdot \mathrm{mg}^{-1}\right)\end{array}$ \\
\hline MSP 2 & 0 \\
\hline $1 \mathrm{~h} / 200^{\circ} \mathrm{C}$ & 1.99 \\
\hline $6 \mathrm{~h} / 200^{\circ} \mathrm{C}$ & 3.69 \\
\hline $24 \mathrm{~h} / 200^{\circ} \mathrm{C}$ & 5.86 \\
\hline
\end{tabular}




\section{Captions for Supporting Movies S1-S8}

Supporting Movie S1. Flexible Nanocomposite. Heating of samples transforms the tacky, transparent solid metallosupramolecular polymer (MSP) 2 into a self-standing flexible black film. Shown is a sample that was compression-molded in a Carver press for $1 \mathrm{~h}$ at $120^{\circ} \mathrm{C}$ with a pressure of 3 tons and subsequently heated for $6 \mathrm{~h}$ at $200{ }^{\circ} \mathrm{C}$.

Supporting Movie S2. Diffusion of Pt-atoms and -clusters. The diffusion of Pt-cluster and individual $\mathrm{Pt}^{0}$ atoms can be observed during high-angle annular dark-field (HAADF) scanning transmission electron microscopy (STEM) imaging of samples of metallosupramolecular polymer (MSP) 2 that were heated for $1 \mathrm{~h}$ at $120^{\circ} \mathrm{C}$. The movie is a series of rapidly acquired HAADF-STEM images ( 0.52 second per frame). To better visualize the diffusion dynamics the movie displays $5 \mathrm{fps}$. The width of the frame corresponds to $13.3 \mathrm{~nm}$.

Supporting Movie S3. Gas Formation. Samples of MSP 2 and the Pt-NP composites display an increasing production of $\mathrm{O}_{2}$ gas with increasing heating upon submersion in a $1 \mathrm{M} \mathrm{H}_{2} \mathrm{O}_{2}$ solution in aqueous ethyl acetate. The significant difference in gas evolution indicates the increased catalytic hydrogen peroxide decomposition reaction for composites with an increasing fraction of the crystalline Pt-NPs.

Supporting Movie S4. Light-to-Heat Conversion. On account of light-to-heat conversion solvent-cast samples of MSP 2 readily reach temperatures of up to $200^{\circ} \mathrm{C}$ upon UV irradiation $\left(320-390 \mathrm{~nm} ; 1000 \mathrm{~mW} \mathrm{~cm}^{-2}\right.$ ). The movie shows the surface temperature of a sample of 2 as recorded by an IR camera during UV irradiation.

Supporting Movie S5. Local Gas Formation. A sample of MSP 2 that was compression-molded for $1 \mathrm{~h}$ at $120^{\circ} \mathrm{C}$ with a pressure of 3 tons and subsequently exposed to UV light $\left(1 \mathrm{~h} ; 320-390 \mathrm{~nm} ; 1000 \mathrm{~mW} \mathrm{~cm}^{-2}\right)$ through a photomask with a pin-hole displays local gas formation in the irradiated region upon submersion in a $1 \mathrm{M}_{2} \mathrm{O}_{2}$ solution in aqueous ethyl acetate. The gas formation arises due to the hydrogen peroxide decomposition reaction that is catalyzed by the Pt-NPs present in the irradiated region.

Supporting Movie S6-S7. Local Gas Formation. A sample of MSP 2 that was compression-molded for $1 \mathrm{~h}$ at $120^{\circ} \mathrm{C}$ with a pressure of 3 tons and subsequently exposed to UV light $\left(1 \mathrm{~h} ; 320-390 \mathrm{~nm} ; 1000 \mathrm{~mW} \mathrm{~cm}^{-2}\right)$ through a photomask with a pin-hole displays local gas formation in the irradiated region upon submersion in a $1 \mathrm{M} \mathrm{H}_{2} \mathrm{O}_{2}$ solution in aqueous ethyl acetate. Movie S6 shows the top-view of the composite while Movie S7 shows the side-view as gas formation arises due to the hydrogen peroxide decomposition reaction that is catalyzed by the Pt-NPs present in the irradiated region.

Supporting Movie S8. Composite Propulsion. The local gas evolution during the catalytic hydrogen peroxide decomposition reaction can be exploited to propel a sample of the Pt-NP composite across the surface of the aqueous ethyl acetate solution containing $1 \mathrm{M} \mathrm{H}_{2} \mathrm{O}_{2}$. The sample of MSP 2 was compression-molded for $1 \mathrm{~h}$ at $120^{\circ} \mathrm{C}$ with a pressure of 3 tons and subsequently exposed to UV light ( $1 \mathrm{~h} ; 320-390 \mathrm{~nm} ; 1000 \mathrm{~mW} \mathrm{~cm}{ }^{-2}$ ) through a photomask with a pin-hole at the short edge of the triangle-shaped specimen. 


\section{Experimental Part}

\subsection{Materials and Methods}

Chemical Analytics. NMR spectroscopy was carried out at $297.2 \mathrm{~K}$ on Bruker Avance III 400 or 300 spectrometers at frequencies of 400 or $300 \mathrm{MHz}$, respectively, for ${ }^{1} \mathrm{H}$ nuclei and 101 or $75 \mathrm{MHz}$, respectively, for ${ }^{13} \mathrm{C}$ nuclei in either $\mathrm{CDCl}_{3}$ or $\mathrm{CD}_{2} \mathrm{Cl}_{2}$. Spectra were calibrated to the residual solvent peak of $\mathrm{CDCl}_{3}$ (7.26 ppm ${ }^{1} \mathrm{H}$ NMR; $77.16 \mathrm{ppm}{ }^{13} \mathrm{C}$ NMR) or $\mathrm{CD}_{2} \mathrm{Cl}_{2}$ (5.32 ppm ${ }^{1} \mathrm{H}$ NMR; 53.84 ppm ${ }^{13} \mathrm{C}$ NMR), chemical shifts $(\delta)$ are expressed in parts per million (ppm) relative to tetramethylsilane $\left({ }^{1} \mathrm{H}\right.$ NMR and ${ }^{13} \mathrm{C}$ NMR), and coupling constant are given in Hz (multiplicity: $s=\operatorname{singlet}, d=$ doublet, $d d=$ double doublet, $t=$ triplet, $m=$ multiplet). ${ }^{195} \mathrm{Pt}(86 \mathrm{MHz}) \mathrm{NMR}$ spectra were recorded as service measurements by the Analytical Service of the Chemistry Department of the University of Fribourg on a Bruker Avance III 500 $\mathrm{MHz}$ spectrometer at $223.0 \mathrm{~K}$ in $\mathrm{CD}_{2} \mathrm{Cl}_{2}$ and calibrated to the signal of external sodium hexachloroplatinate(IV). Matrix assisted laser desorption/ionization (MALDI) time-of-flight (TOF) mass spectrometry was performed on a Bruker UltrafleXtreme MALDI-TOF with a trans-2-[3-(4-tert-butylphenyl)-2-methyl-2-propenylidene]malononitrile (DCTB) matrix as service measurements by the Analytical Services of the Chemistry Department of the University of Fribourg. High resolution electron ionization mass spectrometry (EI-MS) measurements were carried out as service measurements by the Molecular and Biomolecular Analysis Service (MoBiAS) of ETH Zurich on a Thermo scientific Q Exactive GC Orbitrap with a direct probe. Fourier-transform infrared spectroscopy (FTIR) was measured on a PerkinElmer Spectrum 65 FTIR spectrometer. Size exclusion chromatography (SEC) analyses were carried out at room temperature with a GPC Agilent Technologies 1200 series instrument equipped with multiangle laser light scattering (MALLS) detector and THF as the eluent at a flow rate of $1 \mathrm{~mL} \cdot \mathrm{min}^{-1}$.

UV-vis Spectroscopy and Spectrophotometric Titrations. UV-vis absorption spectroscopy was performed on a Shimadzu UV-2401 PC spectrophotometer with quartz glass cuvettes from Hellma with a path length of $1 \mathrm{~cm}$. Spectrophotometric titrations were carried out with solutions of either the model ligand 1-hexyloxy-4-phenylethynyl benzene $3\left(c\left(\mathrm{CHCl}_{3}\right)=30 \mu \mathrm{mol} \cdot \mathrm{L}^{-1}\right)$ or the diphenylacetylene terminated poly(ethylene-co-butylene) $1\left(c\left(\mathrm{CHCl}_{3}\right)=15 \mu \mathrm{mol} \cdot \mathrm{L}^{-1}\right)$. To the solution of the respective ligand, aliquots $(3 \mu \mathrm{L})$ of a solution containing $\mathrm{Pt}^{0}(\text { styrene })_{3}\left(c\left(\mathrm{CHCl}_{3}\right)=1.12 \mathrm{mmol} \cdot \mathrm{L}^{-1}\right)$ were added. After each addition of an aliquot of the $\mathrm{Pt}^{0}$ (styrene) $)_{3}$ solution, the mixture was stirred for $30 \mathrm{~s}$ for equilibration, and the UV spectra were subsequently recorded. The formation of the Pt0-ligand complexes was followed after addition of each aliquot of the $\mathrm{Pt}^{0}$ (styrene) $)_{3}$ solution by analysis of the absorption intensity at the characteristic wavelength associated with the metal-ligand charge transfer band at $330 \mathrm{~nm}$. 
Thermal Characterization. Differential scanning calorimetry (DSC) measurements were carried out on a Mettler Toledo DSC1 Star system operating under a nitrogen atmosphere with $40 \mu \mathrm{L}$ alumina pans and heating and cooling rates of $10^{\circ} \mathrm{C} \cdot \mathrm{min}^{-1}$ in the temperature range between $-80{ }^{\circ} \mathrm{C}$ and $250{ }^{\circ} \mathrm{C}$. Unless otherwise indicated, a sample mass of ca. $5 \mathrm{mg}$ was employed. The midpoint of the step change in the heat capacity is reported as the glass transition temperature $\left(T_{\mathrm{g}}\right)$ and the melting temperature $\left(T_{\mathrm{m}}\right)$ is reported based on the minimum of the major endothermic melting peak. Thermogravimetric analysis (TGA) were performed in a in a PerkinElmer TGA 4000 under air atmosphere with $40 \mu \mathrm{L}$ alumina pans and in the range of 25 to $600{ }^{\circ} \mathrm{C}$ at a rate of $10^{\circ} \mathrm{C} \cdot \mathrm{min}^{-1}$. Unless otherwise indicated, a sample mass of ca. $8 \mathrm{mg}$ was employed. Samples featuring $\mathrm{Pt}^{0}$ complexes were measured with a heating rate of $1{ }^{\circ} \mathrm{C} \cdot \mathrm{min}^{-1}$.

X-Ray Scattering. Small angle X-ray scattering (SAXS) was performed with a NanoMax-IQ camera (Rigaku Innovative Technologies, Auburn Hills, MI, USA). The camera was equipped with a Cu target sealed tube source (MicroMax 003 microfocus, Rigaku) and the scattering data were recorded by a Pilatus100 K detector (Dectris). Powder X-ray scattering experiments were performed with a Powder XRD Rigaku Ultima IV setup.

Optical Microscopy. Optical microscopy images were acquired with an Olympus BX51 microscope equipped with a DP72 digital camera.

Mechanical Characterization. Tensile tests were performed in a TA Instruments DMA Q 800 at $25{ }^{\circ} \mathrm{C}$ with a strain rate of $5 \% \cdot \mathrm{min}^{-1}$ using rectangular samples of the following approximate dimensions: $15 \times 3$ x $0.2 \mathrm{~mm}$ (length/width/thickness). Data are reported as averages of 3 independent measurements. The provided Young's moduli were calculated from the slope in the linear region of the stress strain curve (tangent modulus at a stress of $0.025 \mathrm{MPa}$ ).

Transmission Electron Microscopy. Samples for scanning transition electron microscopy (STEM) were prepared by spin-coating solutions of MSP 2 or Pt ${ }^{0}$ complex 4 on an ultra-thin carbon support grid. Grids were then heated in the DSC under $\mathrm{N}_{2}$ atmosphere. Samples for STEM after UV irradiation were prepared by microtoming of bulk MSP 2 after exposure to UV irradiation. High-angle annular dark-field (HAADF) STEM images and EDX spectrum images were acquired using an aberration-corrected (double Cs-corrected) Thermo Scientific Titan Themis 60-300, equipped with a high brightness Schottky X-FEG gun, a Super-X EDX system comprising four silicon drift detectors, and Velox acquisition software. HAADF-STEM images and EDXS data were acquired with an acceleration voltage of $200 \mathrm{kV}$ and beam currents of $150 \mathrm{pA}$ and $500 \mathrm{pA}$, respectively. Bright-field electron micrographs of the Pt particles obtained after heating of $\mathrm{Pt}^{0}$ complex 4 were recorded on a FEI Tecnai Spirit_(Hillsboro, Oregon, USA) at $120 \mathrm{kV}$ equipped with a 4k Eagle CCD camera (Thermo Scientific, formerly FEI). 
Particle Size Analysis. The analysis of transmission electron microscopy images for the size distribution of Pt-cluster and Pt-nanoparticle sizes was performed with the Fiji distribution of the ImageJ image processing software. The contrast and brightness of the TEM micrographs was adjusted and the background was subtracted. The images were subsequently subjected to a classification and segmentation by a threshold analysis with the Trainable Weka Segmentation plugin. The Pt-clusters and Pt nanoparticles were manually defined and separated in repeated segmentation steps with straight and free-hand lines from the background. The resulting images were then converted into 8-bit files, a size threshold was applied ( $0.25 \mathrm{~nm}$-infinity; circularity of $0-1)$, and the size distribution of the particles was determined.

Conductivity Measurements. Voltammetry measurements were performed with a Bio-Logic SP-300 potentiostat using stainless steel Swagelok cells. Samples were sandwiched between two stainless steel discs in a through-plane configuration. Typical settings were a voltage between $0-10 \mathrm{~V}$ with a scan rate of $50 \mathrm{mV} \mathrm{s}^{-1}$ at room temperature. In-air samples were assembled on the lab bench in ambient conditions, while dry samples were vacuum dried in a Binder vacuum oven overnight at $70{ }^{\circ} \mathrm{C}$ along with all Swaglok parts, and assembled inside an inert argon atmosphere in a glovebox $\left(<0.01 \mathrm{ppm} \mathrm{O}_{2}\right.$ and $\left.\mathrm{H}_{2} \mathrm{O}\right)$.

Catalysis Measurements. The volume of oxygen formed during the catalytic decomposition reaction of hydrogen peroxide was calculated by volumetric measurements (see Figure S37 for details). The hydrogen peroxide $(1 \mathrm{M})$ solution in aqueous ethyl acetate was placed in the round bottom flask together with the nanocomposite and the overpressure of formed produced oxygen gas displaced water through a stainless-steel cannula into a graduated cylinder. The amount of displaced water was measured over time to determine the rate of the oxygen formation for different nanocomposite samples.

A closed $100 \mathrm{~mL}$ pressure-equalizing dropping funnel filled with $100 \mathrm{~mL}$ of water was placed over a 50 $\mathrm{mL}$ round bottom flask containing $50 \mathrm{~mL}$ of a $1 \mathrm{M} \mathrm{H}_{2} \mathrm{O}_{2}$ aqueous ethyl acetate solution and the setup was closed with a septum. An empty $100 \mathrm{~mL}$ graduated cylinder was placed higher than the pressure-equalizing dropping funnel and connected via a stainless-steel cannula. The cannula was completely submerged in the water and the difference in height between both the dropping funnel and the graduated cylinder was set to $18 \mathrm{~cm}$. The catalytic activity of square shaped films of MSP 2 (5 to $7 \mathrm{mg}$ ) that were heated for 1,6 , or $24 \mathrm{~h}$ at $200{ }^{\circ} \mathrm{C}$ were then tested by measuring the volume of water displaced to the graduated cylinder per milligram of MSP 2 over the course of $1 \mathrm{~h}$. 


\subsection{Synthetic Procedures and Analytical Data}

Materials and General Procedures. Unless otherwise noted, all reactions were carried out in dried Schlenk glassware in an inert nitrogen atmosphere. Dichloromethane (DCM), ethyl acetate, hexane, diethyl ether, and methanol were purchased as analytical grade from either Sigma-Aldrich, Honeywell, or Fluka and used without further purification. Anhydrous dimethyl formamide (DMF) and toluene were purchased from Sigma-Aldrich. 4-Iodophenol (99\%, Aldrich), phenylacetylene (98\%, Aldrich), pyridine (ACS reagent, $\geq 99.0 \%$, Sigma-Aldrich), potassium carbonate (99.995\%, Aldrich), hydrochloric acid (ACS reagent, 37\%, Sigma-Aldrich) triphenylphosphine (99\% ReagentPlus ${ }^{\circledR}$, Sigma-Aldrich), cooper(I) iodide (98\%, Sigma-Aldrich) bis(triphenylphosphine) palladium(II) dichloride (98\%, Sigma-Aldrich), platinum(II) chloride (99.9\%, Aldrich), $p$-toluenesulfonyl chloride ( $\geq 98 \%$, Sigma Aldrich), and triphenylsilane (97\%, Aldrich) were used as received. Hydroxyl terminated poly(ethylene-co-butylene) of a number-average molecular weight $\left(M_{\mathrm{n}}\right)$ of $3100 \mathrm{~g} \mathrm{~mol}^{-1}$ (functionalization degree 1.9) was kindly donated by Cray Valley Specialty Chemicals under the trade name Krasol HLBH-P 3000. Styrene (99.9\%, Aldrich) was distilled once prior to use. Triethylamine ( $\geq 99.5 \%$, Aldrich) was dried over $\mathrm{CaH}_{2}$ and distilled once prior to use. 4-Phenylethylene phenol was synthesized following a procedure adapted from the literature ${ }^{2}$. A styrene solution of $\mathrm{Pt}^{0}(\text { styrene })_{3}\left(2.19 \times 10^{-2} \mathrm{M}\right)$ was prepared following a reported procedure ${ }^{3,4}$. Thin layer chromatography (TLC) was performed on TLC plates from Merck (Silica gel 60 F254). UV-light (254 or $365 \mathrm{~nm}$ ) or potassium permanganate were used for detection. Column chromatography was conducted on Geduran silica gel Si 60 from Merck $(40-60 \mu \mathrm{m})$.

Protocol for the Synthesis and Isolation of Pt-Nanoparticles from Pt0-Complex 4. The $\operatorname{bis}\left(\eta^{2}\right.$-(1-hexyloxy-4-phenylethynyl-benzene)) $\mathrm{Pt} 04$ complex (40 $\mathrm{mg}$ ) was placed in a round bottom flask and under an inert $\mathrm{N}_{2}$ atmosphere and heated to $120^{\circ} \mathrm{C}$ for $16 \mathrm{~h}$. The resulting black material was dissolved in toluene $(20 \mathrm{~mL})$, the solution centrifuged at $8000 \mathrm{rpm}$ for $15 \mathrm{~min}$, and the supernatant was removed. Toluene $(20 \mathrm{~mL})$ was added to solid residue, the mixture was centrifuged at $5000 \mathrm{rpm}$ for $10 \mathrm{~min}$, the supernatant was removed, and this sequence was repeated once with hexane $(20 \mathrm{~mL})$. After removal of the supernatant hexane with a syringe, the black precipitate was dried at room temperature. The resulting precipitate was suspended in $3 \mathrm{~mL}$ of milli- $\mathrm{Q}$ water by sonication in an ultrasound bath and $5 \mu \mathrm{L}$ of the solution was deposited on a carbon coated copper TEM grid.

Protocol for the Preparation of MSP 2 and the Formation of Nanocomposites. The macromonomer $1\left(75.16 \mathrm{mg}\right.$ ) was added to a vial, dissolved in $0.75 \mathrm{~mL}$ of a $\mathrm{Pt}^{0}$ (styrene) ${ }_{3}(c$ (styrene) $=0.023 \mathrm{M})$ solution, and stirred for $1 \mathrm{~h}$ to ensure successful ligand exchange. After stirring, the mixture was cast onto a polytetrafluoroethylene (PTFE) substrate and dried under ambient conditions for $24 \mathrm{~h}$. After drying, a sample of the tacky film was dissolved in $\mathrm{CDCl}_{3}$ and the complete ligand exchange was confirmed by ${ }^{1} \mathrm{H}-\mathrm{NMR}$ spectroscopy. The formation of the nanocomposites was carried out by heating samples of MSP 2 to a temperature of $120^{\circ} \mathrm{C}$ or higher. Films of the nanocomposite of uniform thickness were prepared by compression molding samples of MSP 2 in between PTFE sheets in a Carver CE Press at $120^{\circ} \mathrm{C}$ for $1 \mathrm{~h}$ with 
a pressure of 3 tons. Heating of samples of the nanocomposite to temperatures above $120^{\circ} \mathrm{C}$ was carried out in a vacuum oven under an inert nitrogen atmosphere.

Protocol for Spin Coating and Heating of Samples for TEM Measurements. Macromonomer 1 (15.59 $\mathrm{mg}$ ) was added to a vial, dissolved in $0.159 \mathrm{~mL}$ of a $\mathrm{Pt}^{0}$ (styrene) $)_{3}(c$ (styrene $\left.)=0.023 \mathrm{M}\right)$ solution, and the mixture was stirred for $1 \mathrm{~h}$ to ensure successful ligand exchange. For spin coating, a TEM grid was placed on a microscopy glass slide substrate on the spin coater (Spincoater Model P6700, Specialty Coating Systems, Inc.) and $3 \mu \mathrm{L}$ of the solution was deposited. The TEM grid was then spun using the following program:

1. $200 \mathrm{rpm}$ for $15 \mathrm{~s}$,

2. $2000 \mathrm{rpm}$ for $15 \mathrm{~s}$,

3.- $3100 \mathrm{rpm}$ for $1 \mathrm{~s}$.

This protocol was used for the deposition of samples on TEM grids and all samples were subsequently heated to different temperatures in the DSC under an inert nitrogen atmosphere.

\section{Synthesis of bis-diphenylacetylene terminated telechelic poly(ethylene-co-butylene) 1.}

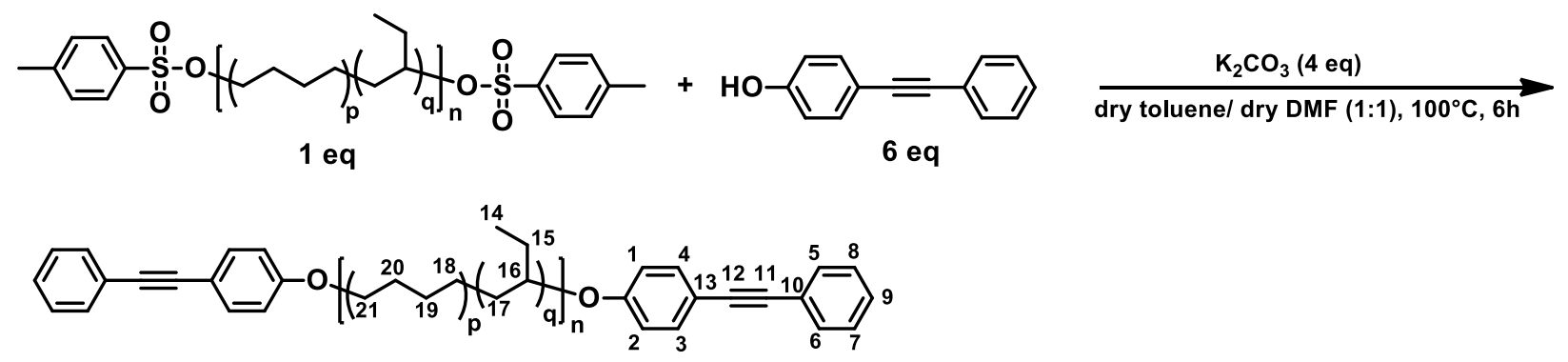

Tosylated poly(ethylene-co-butylene) (1.08 g, $0.25 \mathrm{mmol}, 1 \mathrm{eq}.), \quad 4$-(phenylethynyl)phenol (0.29 g, $1.5 \mathrm{mmol}, 6 \mathrm{eq}$.), and potassium carbonate (130 mg, $1 \mathrm{mmol}, 4$ eq.) were added to a round-bottom flask. After degassing in vacuo for $10 \mathrm{~min}$, the mixture was placed under a nitrogen atmosphere, anhydrous toluene (12 mL) as well as anhydrous DMF (12 mL) were added, and the stirred mixture was heated to $105^{\circ} \mathrm{C}$ for $6 \mathrm{~h}$. Then, the mixture was precipitated in methanol $(100 \mathrm{~mL})$, re-dissolved in hexane $(75 \mathrm{~mL})$, and precipitated again in methanol $(100 \mathrm{~mL})$ after concentration of the mixture under vacuo. After decanting the supernatant, the solid residue was rinsed with water, dissolved in hexane (75 $\mathrm{mL})$, and transferred to a separatory funnel. The organic phase was washed once with saturated $\mathrm{NaCl}$ solution, dried over $\mathrm{Na}_{2} \mathrm{SO}_{4}$, and the solvent was removed in vacuo. The solid was then passed over a plug of silica gel ( $<2 \mathrm{~cm}$ height) with hexane as eluent to obtain $1(850 \mathrm{mg}, 0.2 \mathrm{mmol}, 78 \%)$ as a sticky colorless solid. ${ }^{1} \mathrm{H}$ NMR (400 MHz, $\mathrm{CDCl}_{3}$ ): $\delta=7.51\left(\mathrm{dd}, J=7.6,2.0 \mathrm{~Hz}, \mathrm{CH} H^{5,6}, 2 \mathrm{H}\right), 7.45(\mathrm{~d}, J=8.8 \mathrm{~Hz}, \mathrm{CH} 3,4,2 \mathrm{H}), 7.39-7.28$ (m, $\left.\mathrm{CH}^{7-9}, 3 \mathrm{H}\right), 6.86\left(\mathrm{~d}, J=8.7 \mathrm{~Hz}, \mathrm{CH}^{1,2}, 2 \mathrm{H}\right), 3.98$ (q, $J=6.9 \mathrm{~Hz},-\mathrm{O}-\mathrm{CH}_{2}-$ ), 1.38-1.11 (m, $\left.\mathrm{CH}_{2}{ }^{15,17-21}\right), 0.92-$ $0.76\left(\mathrm{~m}, \mathrm{CH}^{16}, \mathrm{CH}_{3}{ }^{14}\right)$. MS (MALDI): calcd. mass for $\mathrm{C}_{232} \mathrm{H}_{426} \mathrm{O}_{12} \mathrm{Ag}\left([\mathrm{M}(p=0.37, q=0.63, n=51)+\mathrm{Ag}]^{+}\right)$ 3353.2; found 3353.3. 


\section{Synthesis of 1-hexyloxy-4-phenylethynyl benzene ligand 3.}

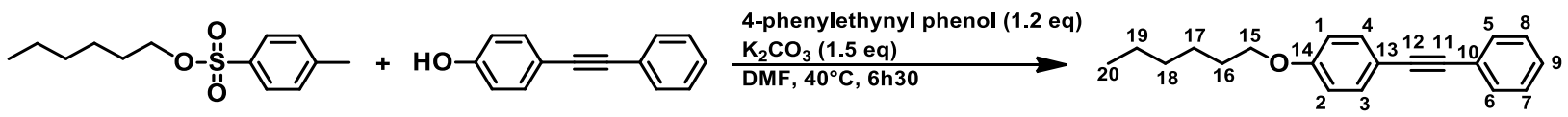

Toluene 4-sulfonic acid hexyl ester (500 mg, $1.95 \mathrm{mmol}, 1.0$ eq.), 4-(phenylethynyl)phenol (454 mg, $2.34 \mathrm{mmol}, 1.2 \mathrm{eq}$.), and potassium carbonate ( $404 \mathrm{mg}, 2.92 \mathrm{mmol}, 1.5 \mathrm{eq}$.$) were dissolved in DMF (20 mL)$ and the mixture was heated to $40^{\circ} \mathrm{C}$ for $8 \mathrm{~h}$. Ethyl acetate $(60 \mathrm{~mL})$ was added, the organic phase was washed twice with water $(80 \mathrm{~mL})$, once with saturated $\mathrm{NaCl}$ solution, dried over $\mathrm{Na}_{2} \mathrm{SO}_{4}$, and the solvent was removed in vacuo. Purification of the crude mixture by column chromatography (silica gel, hexane/ethyl acetate 20:1) afforded 3 (461 mg, $1.65 \mathrm{mmol}, 85 \%$ ) as a yellow solid. ${ }^{1} \mathrm{H}$ NMR (400 MHz, $\left.\mathrm{CDCl}_{3}\right): \delta=7.52-7.49\left(\mathrm{~m}, \mathrm{CH}{ }^{5,6}, 2 \mathrm{H}\right), 7.45\left(\mathrm{~d}, \mathrm{~J}=8.7 \mathrm{~Hz}, \mathrm{CH} H^{3,4}, 2 \mathrm{H}\right), 7.37-7.27\left(\mathrm{~m}, \mathrm{CH}^{7-9}, 3 \mathrm{H}\right), 6.86(\mathrm{~d}, \mathrm{~J}=$ $\left.8.7 \mathrm{~Hz}, \mathrm{CH}{ }^{1,2}, 2 \mathrm{H}\right), 3.97\left(\mathrm{t}, J=6.6 \mathrm{~Hz},-\mathrm{O}-\mathrm{CH}_{2}{ }^{15}, 2 \mathrm{H}\right), 1.85-1.72\left(\mathrm{~m}, \mathrm{CH}_{2}{ }^{19}, 2 \mathrm{H}\right), 1.51-1.40\left(\mathrm{~m}, \mathrm{CH}_{2}{ }^{16}, 2 \mathrm{H}\right)$, 1.41-1.28 (m, $\left.\mathrm{CH}_{2}{ }^{17,18}, 4 \mathrm{H}\right), 0.91\left(\mathrm{t}, J=7.0 \mathrm{~Hz}, \mathrm{CH}_{3}{ }^{20}, 3 \mathrm{H}\right) .{ }^{13} \mathrm{C} \mathrm{NMR}\left(91 \mathrm{MHz}, \mathrm{CDCl}_{3}\right): \delta=159.4\left(\mathrm{C}^{14}\right), 133.2$ (C ${ }^{3,4}$ ), 131.6 ( $\left.\mathrm{C}^{5,6}\right), 128.4\left(\mathrm{C}^{9}\right), 128.0\left(\mathrm{C}^{7,8}\right), 123.8\left(\mathrm{C}^{10}\right), 115.2\left(\mathrm{C}^{13}\right), 114.6\left(\mathrm{C}^{1,2}\right), 89.6\left(\mathrm{C}^{12}\right), 88.1\left(\mathrm{C}^{11}\right), 68.2$ (C15), 31.7 (C18), 29.3 (C16), 25.8 (C17), 22.7 (C19), 14.2 (C20). HRMS (EI): calcd. for $\mathrm{C}_{20} \mathrm{H}_{22} \mathrm{O}\left([\mathrm{M}-\mathrm{H}]^{-}\right)$: 278.16652; found 278.16673 .

Synthesis of bis( $\eta^{2}$-(1-hexyloxy-4-phenylethynyl-benzene) $) \mathrm{Pt}^{0}$ complex 4.

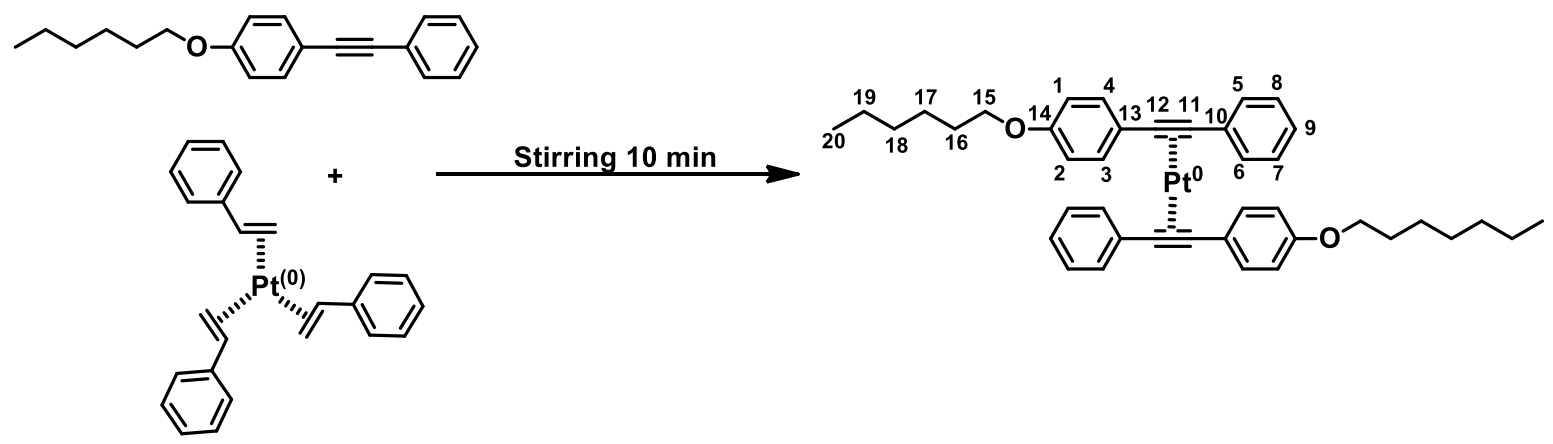

1-Hexyloxy-4-phenylethynyl benzene 3 (127 mg, $0.46 \mathrm{mmol}, 4$ eq.) was dissolved in $\mathrm{Pt}^{0}(\text { styrene })_{3}(5 \mathrm{~mL}$, $0.12 \mathrm{mmol}, 1$ eq.). The mixture was stirred for $10 \mathrm{~min}$ and the solvent was removed in vacuo. Then, column chromatography (silica gel, pentane/ $\mathrm{CHCl}_{3} 10: 1$ to $1: 1$ ) was performed and the solvents were removed in vacuo, to obtain an oil that was dissolved in petroleum ether $(1 \mathrm{~mL})$. The mixture was cooled to $-23{ }^{\circ} \mathrm{C}$ for 24-48 $\mathrm{h}$ and the resulting precipitate was collected and washed with cold pentane to obtain 4 (59 $\mathrm{mg}$, $0.079 \mathrm{mmol}, 69 \%$ ) as a white solid. ${ }^{1} \mathrm{H}$ NMR (400 MHz, $\mathrm{CDCl}_{3}$ ): $\delta=7.89$ (dd, $J=8.2,1.4 \mathrm{~Hz}, \mathrm{CH}$,6, $2 \mathrm{H}$ ), 7.85 (d, $\left.J=8.8 \mathrm{~Hz}, \mathrm{CH}^{3,4}, 2 \mathrm{H}\right), 7.41-7.29\left(\mathrm{~m}, \mathrm{CH}^{7-9}, 3 \mathrm{H}\right), 6.91\left(\mathrm{~d}, J=8.8 \mathrm{~Hz}, \mathrm{CH}{ }^{1,2}, 2 \mathrm{H}\right), 4.00\left(\mathrm{t}, J=6.6 \mathrm{~Hz},-0-\mathrm{CH}_{2}{ }^{15}\right.$, 2H), 1.86-1.72 (m, $\left.\mathrm{CH}_{2}{ }^{19}, 2 \mathrm{H}\right), 1.50-1.41\left(\mathrm{~m}, \mathrm{CH}_{2}{ }^{16}, 2 \mathrm{H}\right), 1.40-1.29\left(\mathrm{~m}, \mathrm{CH}_{2}{ }^{17,18}, 4 \mathrm{H}\right), 0.91(\mathrm{t}, J=7.1 \mathrm{~Hz}$, $\left.\mathrm{CH}_{3}{ }^{20}, 3 \mathrm{H}\right) .{ }^{13} \mathrm{C}$ NMR $\left(75 \mathrm{MHz}, \mathrm{CDCl}_{3}\right) \delta=160.40\left(\mathrm{C}^{14}\right), 132.63\left(\mathrm{C}^{3,4}\right), 130.83\left(\mathrm{C}^{5,6}\right), 129.10\left(\mathrm{C}^{9}\right), 128.74\left(\mathrm{C}^{7,8}\right)$, 125.62 (C $\left.{ }^{12}\right), 125.09\left(\mathrm{C}^{11}\right), 123.91\left(\mathrm{C}^{10}\right), 117.25\left(\mathrm{C}^{13}\right), 114.83\left(\mathrm{C}^{1,2}\right), 68.34\left(\mathrm{C}^{15}\right), 31.73\left(\mathrm{C}^{18}\right), 29.31\left(\mathrm{C}^{16}\right)$, $25.84\left(\mathrm{C}^{17}\right), 22.74\left(\mathrm{C}^{19}\right), 14.18\left(\mathrm{C}^{20}\right) .{ }^{195} \mathrm{Pt}$ NMR (86 MHz, $\mathrm{CD}_{2} \mathrm{Cl}_{2}$ ): $\delta=-3552.21(\mathrm{~s})$. 


\section{Synthesis of 4-(phenylethynyl)phenol.}

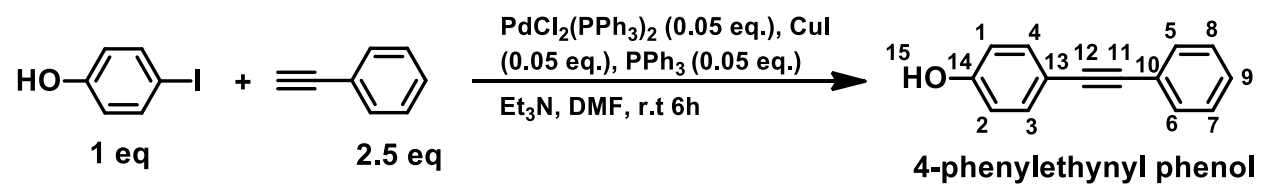

4-Iodophenol ( $2.0 \mathrm{~g}, 9.1 \mathrm{mmol}, 1$ eq.) and phenylacetylene ( $2.32 \mathrm{~g}, 22.7 \mathrm{mmol}, 2.5 \mathrm{eq}$.$) were added to$ anhydrous DMF (13 mL) and distilled triethylamine (26 mL), triphenyl phosphine (119 $\mathrm{mg}, 0.045 \mathrm{mmol}$, 0.05 eq.), and $\mathrm{PdCl}_{2}\left(\mathrm{PPh}_{3}\right)_{2}$ (319 mg, $0.045 \mathrm{mmol}, 0.05$ eq.) were consecutively added. The reaction mixture was purged with a flow of nitrogen for $30 \mathrm{~min}$, copper(I) iodide (86 mg, $0.045 \mathrm{mmol}, 0.1$ eq.) was added, the mixture was again purged with nitrogen for $10 \mathrm{~min}$, and left stirring at room temperature for $6 \mathrm{~h}$. The mixture was adjusted to $\mathrm{pH} 2$ by addition of $2 \mathrm{~m} \mathrm{HCl}$ and subsequently extracted three times with ethyl acetate $(40 \mathrm{~mL})$. The combined organic layers were washed once with saturated $\mathrm{NaCl}$ solution, dried over $\mathrm{Na}_{2} \mathrm{SO}_{4}$, and the solvent was removed in vacuo. Purification by column chromatography (silica gel, hexane/ethyl acetate 10:1) afforded 4-(phenylethynyl)phenol (2 g, $7.2 \mathrm{mmol}, 80 \%$ ) as a nacre/yellow solid. ${ }^{1} \mathrm{H}$ NMR (400 MHz, $\mathrm{CDCl}_{3}$ ): $\delta=7.51\left(\mathrm{~d}, \mathrm{~J}=7.8 \mathrm{~Hz}, \mathrm{CH}^{5,6}, 2 \mathrm{H}\right), 7.43\left(\mathrm{~d}, \mathrm{~J}=8.5 \mathrm{~Hz}, \mathrm{CH}^{3,4}, 2 \mathrm{H}\right.$ ), 7.37-7.28 $\left(\mathrm{m}, \mathrm{C} H^{7-9}, 3 \mathrm{H}\right), 6.81\left(\mathrm{~d}, \mathrm{~J}=8.5 \mathrm{~Hz}, \mathrm{CH}^{1,2}, 2 \mathrm{H}\right), 4.99(\mathrm{~s}, \mathrm{OH}, 1 \mathrm{H}) .{ }^{13} \mathrm{C}$ NMR $\left(101 \mathrm{MHz}, \mathrm{CDCl}_{3}\right): \delta=155.9\left(C^{14}\right)$, $133.6\left(C^{3,4}\right), 131.8\left(C^{5,6}\right), 128.7\left(C^{9}\right), 128.3\left(C^{7,8}\right), 123.9\left(C^{10}\right), 116.1\left(C^{13}\right), 115.7\left(C^{1,2}\right), 89.5\left(C^{12}\right), 88.3\left(C^{11}\right)$. HRMS (EI): calcd. for $\mathrm{C}_{14} \mathrm{H}_{10} \mathrm{O}\left([\mathrm{M}-\mathrm{H}]^{-}\right)$: 194.07261; found 194.07262.

\section{Synthesis of toluene 4-sulfonic acid hexyl ester.}

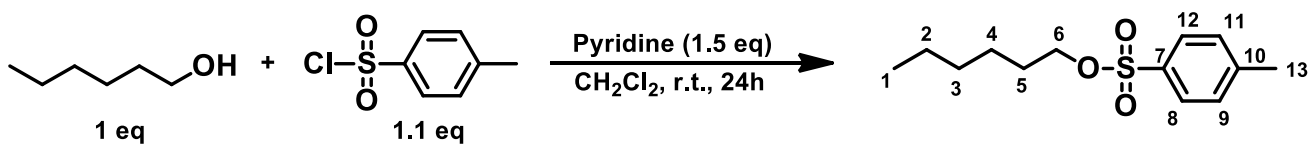

1-Hexanol (2.0 g, $19.6 \mathrm{mmol}, 1.0$ eq.) and $p$-toluenesulfonyl chloride (4.08 g, $21.6 \mathrm{mmol}, 1.1 \mathrm{eq}$.) were dissolved in dichloromethane $(80 \mathrm{~mL})$, the solution was cooled to $0{ }^{\circ} \mathrm{C}$, pyridine $(2.37 \mathrm{~mL}, 29.41 \mathrm{mmol}$, $1.5 \mathrm{eq)}$ was added dropwise, and the mixture was stirred for $24 \mathrm{~h}$ at room temperature. The mixture was adjusted to $\mathrm{pH} 2$ by addition of $2 \mathrm{~m} \mathrm{HCl}$ and subsequently extracted two times with DCM (40 mL). The combined organic layers were washed once with water, once with saturated $\mathrm{NaCl}$ solution, dried over $\mathrm{Na}_{2} \mathrm{SO}_{4}$, and the solvent was evaporated in vacuo. The crude mixture was purified by column chromatography (silica gel, hexane/diethyl ether 20:1) to afford toluene 4-sulfonic acid hexyl ester (4 g, $15.62 \mathrm{mmol}, 79 \%)$ as a colorless liquid. ${ }^{1} \mathrm{H}$ NMR (400 $\left.\mathrm{MHz}, \mathrm{CDCl}_{3}\right): \delta=7.79(\mathrm{~d}, J=8.3 \mathrm{~Hz}, \mathrm{CH}, 12,2 \mathrm{H}), 7.34$ (d, $\left.J=8.1 \mathrm{~Hz}, \mathrm{CH}^{9,11}, 2 \mathrm{H}\right), 4.02\left(\mathrm{t}, J=6.5 \mathrm{~Hz}, \mathrm{CH}_{2}{ }^{6}, 2 \mathrm{H}\right), 2.45\left(\mathrm{~s}, \mathrm{CH}_{3}{ }^{13}, 3 \mathrm{H}\right), 1.68-1.58\left(\mathrm{~m}, \mathrm{CH}_{2}{ }^{5}, 2 \mathrm{H}\right), 1.35-$ $1.13\left(\mathrm{~m}, \mathrm{CH}_{2}{ }^{2-4}, 6 \mathrm{H}\right), 0.85\left(\mathrm{t}, J=6.9 \mathrm{~Hz}, \mathrm{CH}_{3}{ }^{13}, 3 \mathrm{H}\right) .{ }^{13} \mathrm{C}$ NMR $\left(101 \mathrm{MHz}, \mathrm{CDCl}_{3}\right): \delta=144.7\left(C^{10}\right), 133.2\left(C^{7}\right)$, $129.9\left(C^{9,11}\right), 127.9\left(C^{8,12}\right), 70.8\left(C^{6}\right), 31.1\left(C^{3}\right), 28.8\left(C^{5}\right), 25.0\left(C^{4}\right), 22.4\left(C^{2}\right), 21.6\left(C^{13}\right), 13.9\left(C^{1}\right)$. 


\section{Synthesis of $\mathrm{PtCl}_{2}$ (styrene) $)_{2}$.}

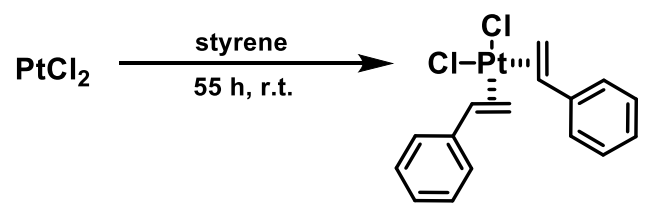

The preparation of $\mathrm{Pt}^{0}(\text { styrene })_{3}$ was adapted from a previously reported procedure (2): Platinum(II) chloride (100 mg, $0.38 \mathrm{mmol}$ ) was added to freshly distilled styrene $(4,1 \mathrm{~mL}, 36 \mathrm{mmol})$ and the reaction mixture was stirred at room temperature for $55 \mathrm{~h}$. The brown mixture was filtered through a fritted glass filter (porosity grade 3) and consecutively washed with toluene and pentane. Traces of pentane were removed by subjecting the solid to a continuous flow of nitrogen for $15 \mathrm{~min}$ and $\mathrm{Pt}^{\mathrm{II}} \mathrm{Cl}_{2}$ (styrene) (stas $_{2}$ obtained (112 mg, $0.22 \mathrm{mmol}, 59 \%$ ) as a green powder. ${ }^{95} \mathrm{Pt}-\mathrm{NMR}\left(86 \mathrm{MHz}, \mathrm{CD}_{2} \mathrm{Cl}_{2}\right.$ ): $\delta=-3159.93$ (isomer 1), -3281.11 (isomer 2).

\section{Synthesis of $\mathrm{Pt}^{0}(\text { styrene })_{3}$.}
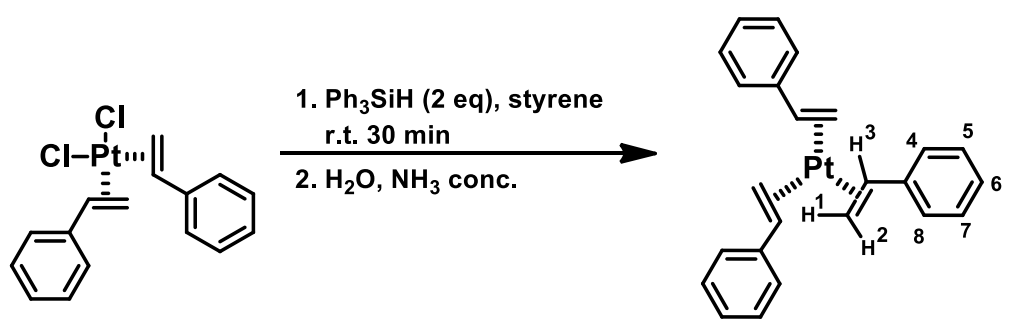

The preparation of $\mathrm{Pt}^{0}(\text { styrene })_{3}$ was adapted from a previously reported procedure (3): $\mathrm{Pt}^{\mathrm{II}} \mathrm{Cl}_{2}(\text { styrene })_{2}$ (230 mg, $0.45 \mathrm{mmol}, 1$ eq.) and triphenylsilane (238 mg, $0.91 \mathrm{mmol}, 2 \mathrm{eq}$.) were added to freshly distilled styrene (12 mL, $104 \mathrm{mmol}$, ca. 230 eq.) and the reaction mixture was stirred for $30 \mathrm{~min}$. Then, water (9.5 mL) and conc. ammonia (2.5 mL, 35w\%, $45 \mathrm{mmol}, 100$ eq.) were added and stirring was resumed for 75 min during which phase separation was observed. In cases phase separation had not occurred, more water $(9.5 \mathrm{~mL})$ was added to break the emulsion. The organic phase was subsequently separated and water $(9.5 \mathrm{~mL})$ was again added the stirring was continued for $20 \mathrm{~min}$. The organic phase was separated, and passed over pipettes of $0.5 \mathrm{~cm}$ diameter filled with dry silica (Geduran silica gel Si 60) with a height of $5.5 \mathrm{~cm} .2 \mathrm{~mL}$ of organic solution were used per pipette and additional distilled styrene (1.5-2 mL) was added to wash each pipette, affording a yellow $\mathrm{Pt}^{0}$ (styrene) $)_{3}$ solution $\left(c=1.7-2.2 \mu \mathrm{mol} \mathrm{L} \mathrm{L}^{-1}\right.$; as determined for each batch by UV-Vis titration). ${ }^{195} \mathrm{Pt} \mathrm{NMR}$ (86 $\mathrm{MHz}, \mathrm{CD}_{2} \mathrm{Cl}_{2}$ ): $\delta=-5909.78$ (isomer 1), -5919.05 (isomer 2).

\section{Synthesis of telechelic bis( $p$-toluenesulfonyl ester)-functionalized poly(ethylene-co-butylene).}

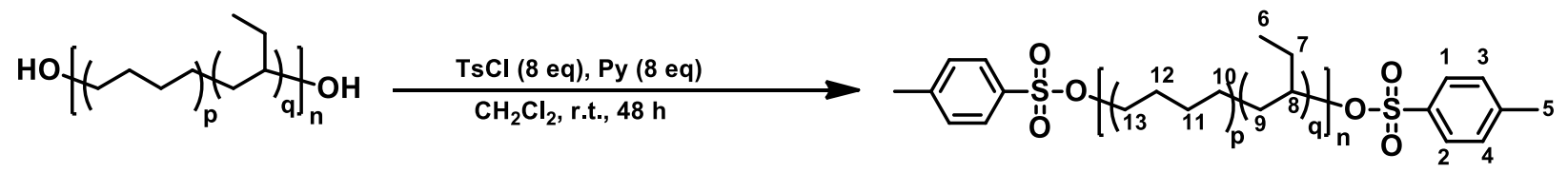

The preparation of bis( $p$-toluenesulfonyl ester)-functionalized poly(ethylene-co-butylene) was carried out according to a previously reported procedure ${ }^{5}$ : Hydroxyl terminated poly(ethylene-co-butylene) (Krasol 
HLBH-P 3000, 4.0 g, 1.03 mmol, 1.0 eq.) and p-toluenesulfonyl chloride (1.96 g, 10.32 mmol, 10 eq.) were placed in a round-bottom flask and degassed in vacuo for $10 \mathrm{~min}$. The flask was placed under a nitrogen atmosphere, DCM (40 mL) was added, and the mixture was stirred at room temperature until a solution was obtained. Pyridine (1.7 mL, $20.65 \mathrm{mmol}, 20$ eq.) was added dropwise and the solution was stirred for $24 \mathrm{~h}$ at room temperature. Then, the solution was concentrated in vacuo to ca. $10 \mathrm{~mL}$ and precipitated into methanol (300 mL). The supernatant was decanted, the residue was dissolved in hexane (ca. $100 \mathrm{~mL}$ ), and again precipitated into methanol $(300 \mathrm{~mL})$. The supernatant was decanted, the solid residue was rinsed with water $(50 \mathrm{~mL})$, dissolved in hexane $(100 \mathrm{~mL})$, and the solution was transferred to a separatory funnel. The organic phase was washed once with saturated $\mathrm{NaCl}$ solution, dried over $\mathrm{Na}_{2} \mathrm{SO}_{4}$, and the solvent was evaporated in vacuo. The solid was then passed over a plug of silica gel $(<2 \mathrm{~cm}$ height, hexane to hexane/ethyl acetate 1:1) to yield telechelic bis( $p$-toluenesulfonyl ester)-functionalized poly(ethylene-co-butylene) (3.3 g, $0.97 \mathrm{mmol}, 73 \%) .{ }^{1} \mathrm{H}$ NMR (400 MHz, $\left.\mathrm{CDCl}_{3}\right): \delta=7.8\left(\mathrm{~d}, J=8.2 \mathrm{~Hz}, \mathrm{CH}^{1,2}\right.$, $4 \mathrm{H}), 7.35\left(\mathrm{~d}, J=17.2 \mathrm{~Hz}, \mathrm{CH}^{3,4}, 4 \mathrm{H}\right), 4.08-3.99\left(\mathrm{dt}, J=13.3,6.8 \mathrm{~Hz},-\mathrm{O}-\mathrm{CH}_{2^{-}}, 4 \mathrm{H}\right), 2.45\left(\mathrm{~s}, \mathrm{CH}_{3}{ }^{5}, 6 \mathrm{H}\right), 1.25(\mathrm{~m}$, $\left.\mathrm{CH}_{2}{ }^{7,9-13}, 382 \mathrm{H}\right), 0.83\left(\mathrm{~m}, \mathrm{CH}{ }^{6,8}, 128 \mathrm{H}\right)$. 


\section{NMR Spectra}

${ }^{1} \mathrm{H}-\mathrm{NMR}$ spectrum $\left(\mathrm{CDCl}_{3}, 400 \mathrm{MHz}\right)$ of $\mathbf{1}$.

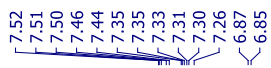

뭅ํํำ

|ن
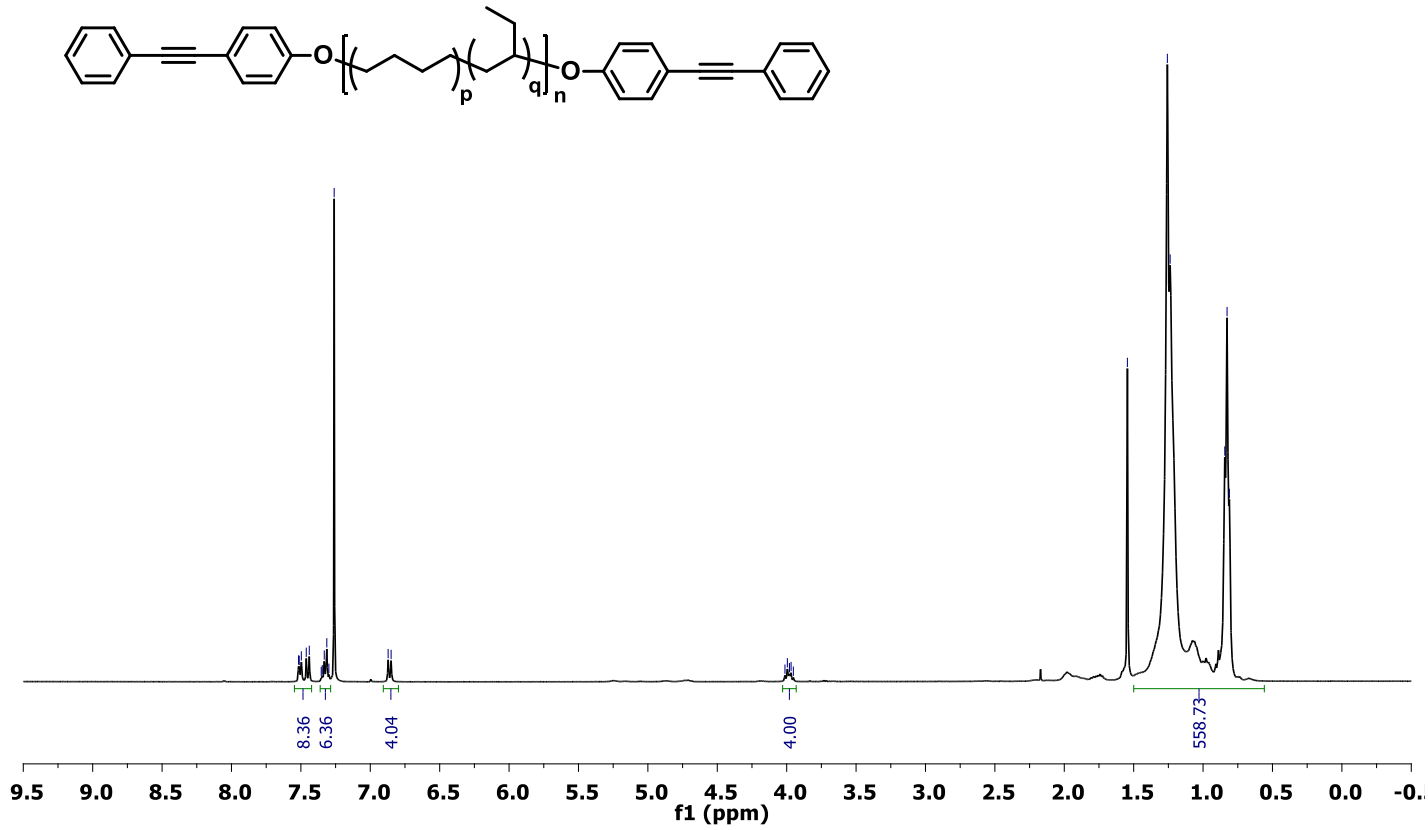

${ }^{1} \mathrm{H}-\mathrm{NMR}$ spectrum $\left(\mathrm{CDCl}_{3}, 400 \mathrm{MHz}\right)$ of MSP 2.

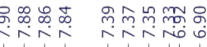

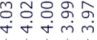

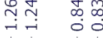
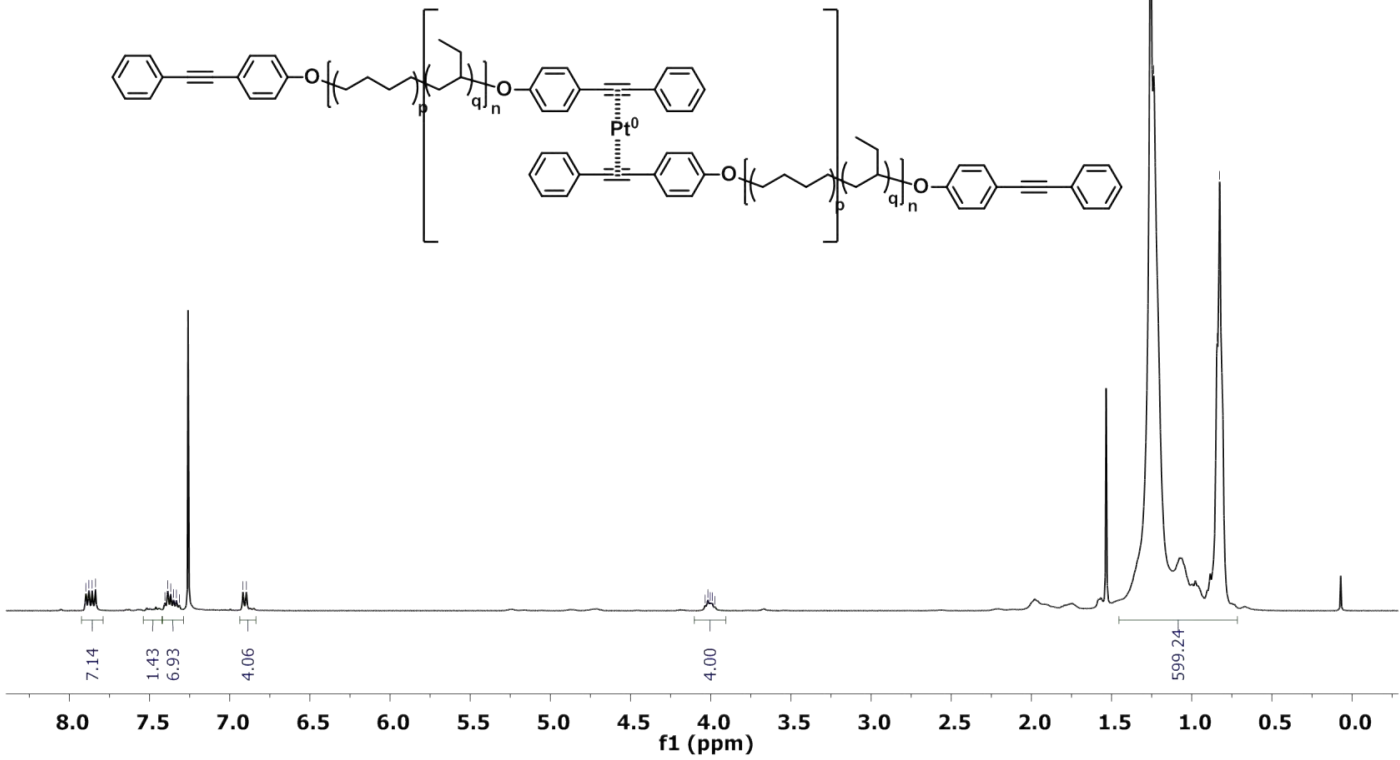
${ }^{1} \mathrm{H}$ NMR spectrum $\left(\mathrm{CDCl}_{3}, 400 \mathrm{MHz}\right)$ of 3.

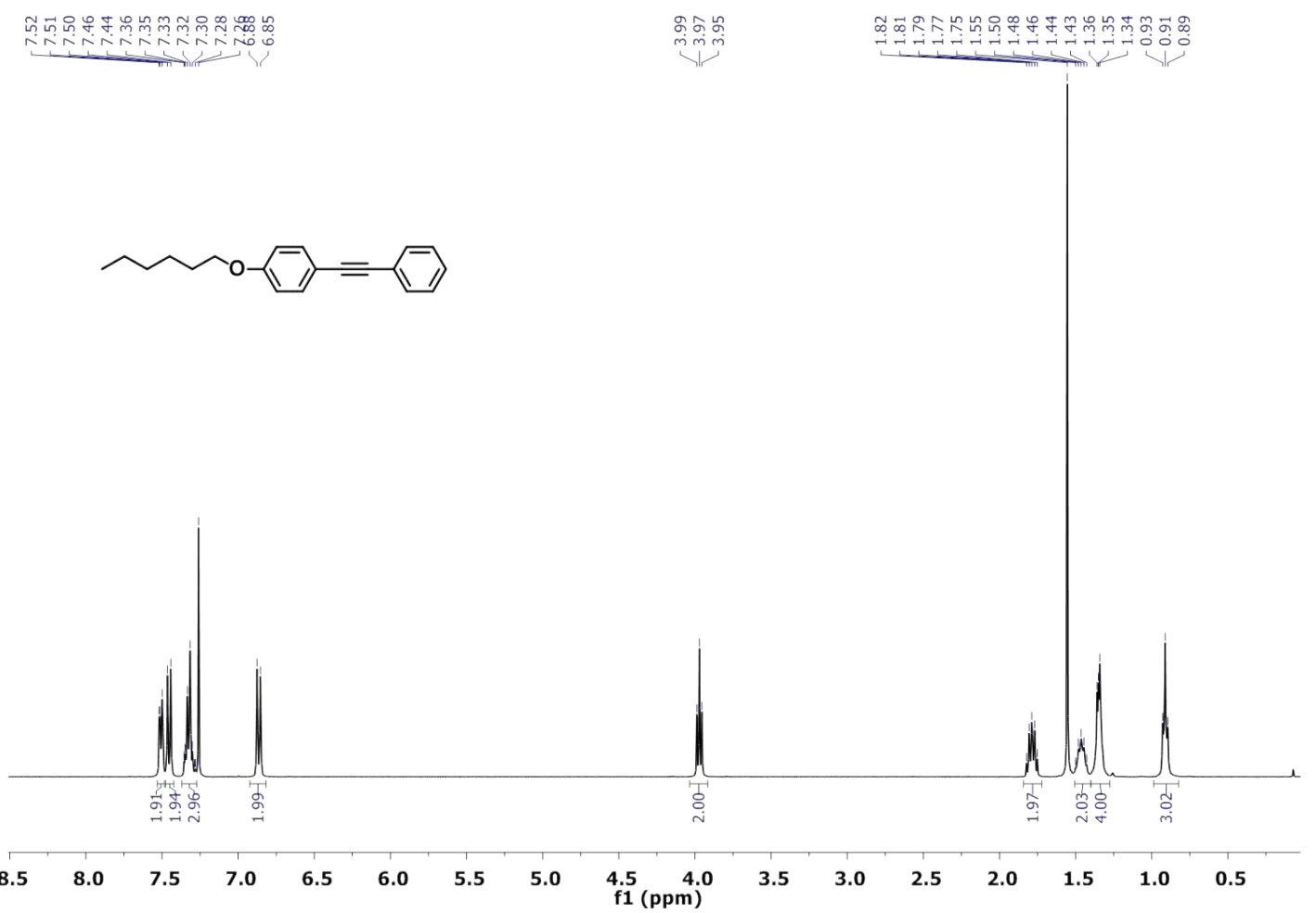

${ }^{13} \mathrm{C}$ NMR spectrum $\left(\mathrm{CDCl}_{3}, 101 \mathrm{MHz}\right)$ of 3.

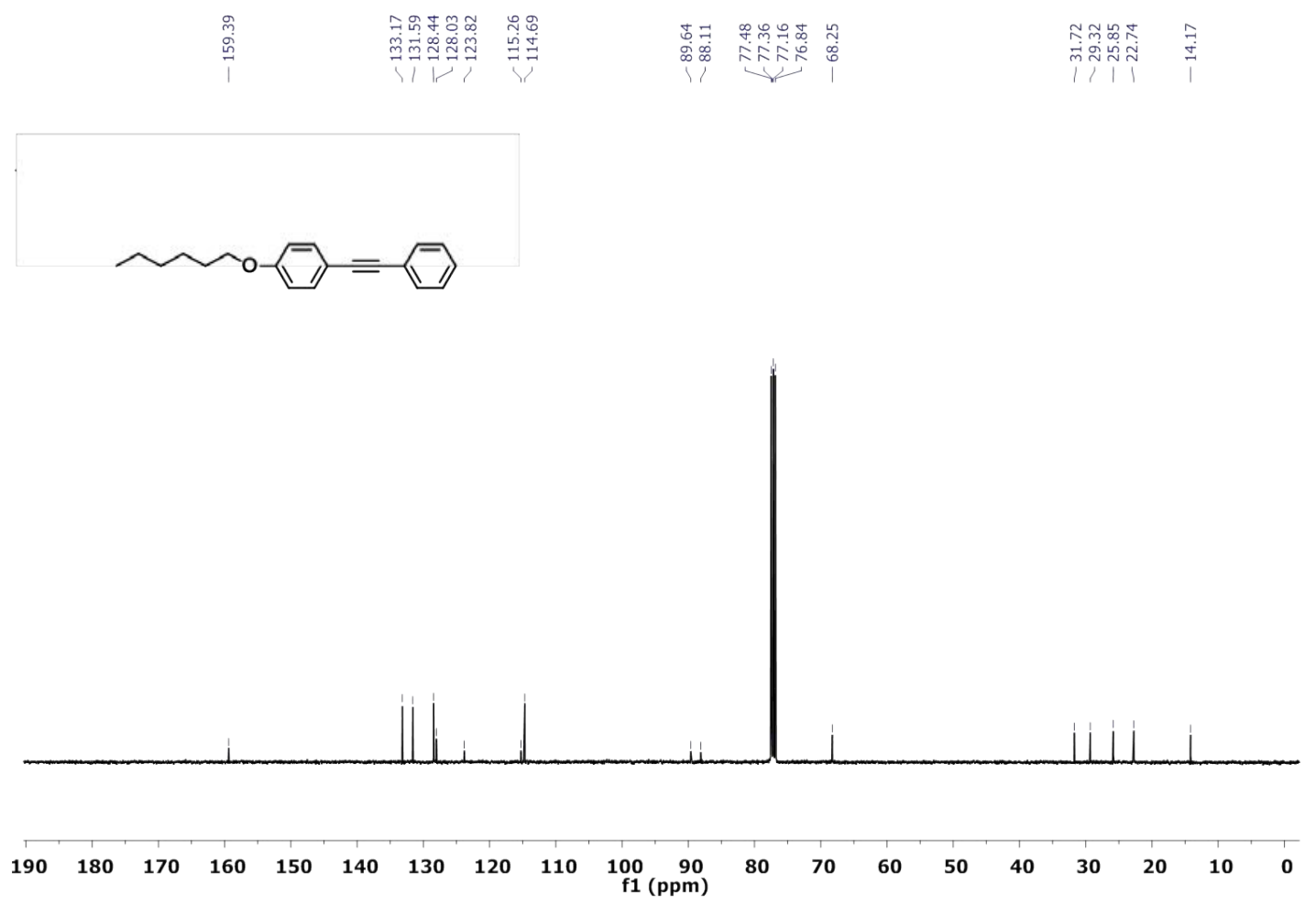


${ }^{1} \mathrm{H}$ NMR spectrum $\left(\mathrm{CDCl}_{3}, 400 \mathrm{MHz}\right)$ of 4 .

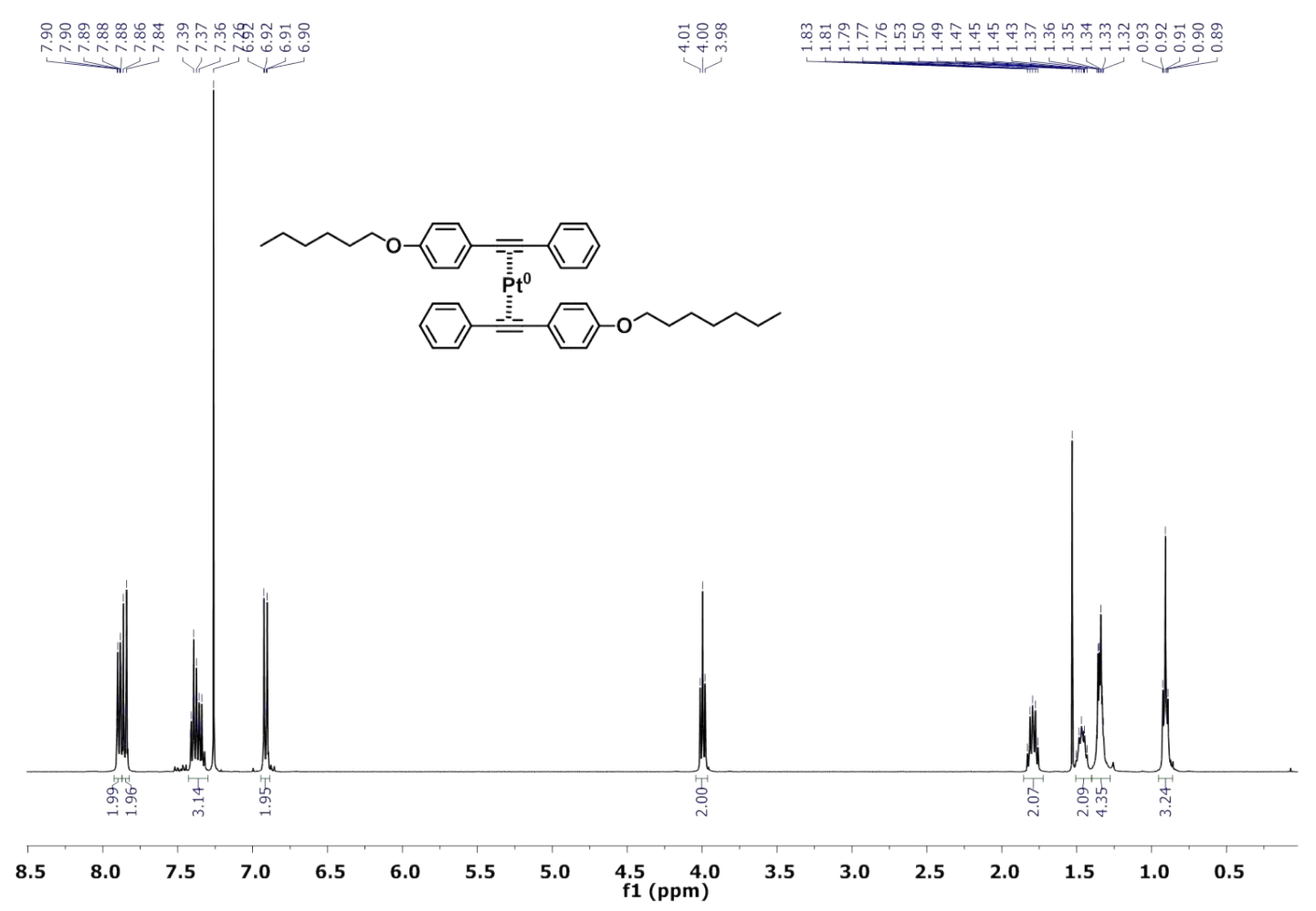

${ }^{13} \mathrm{C}$ NMR spectrum $\left(\mathrm{CDCl}_{3}, 101 \mathrm{MHz}\right)$ of 4 .

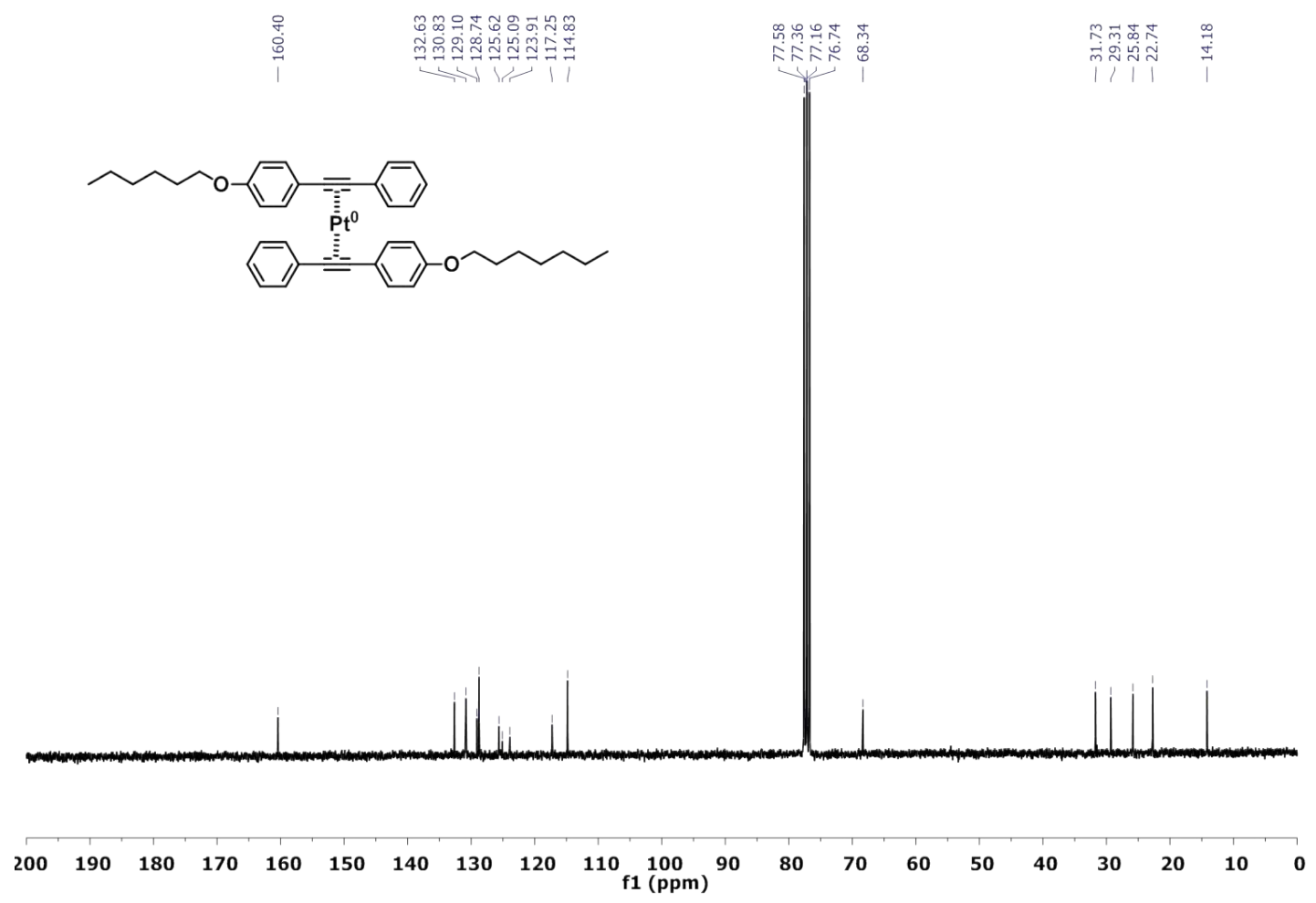


${ }^{13} \mathrm{C}(\mathrm{APT}) \mathrm{NMR}$ spectrum $\left(\mathrm{CDCl}_{3}, 101 \mathrm{MHz}\right)$ of 4 .

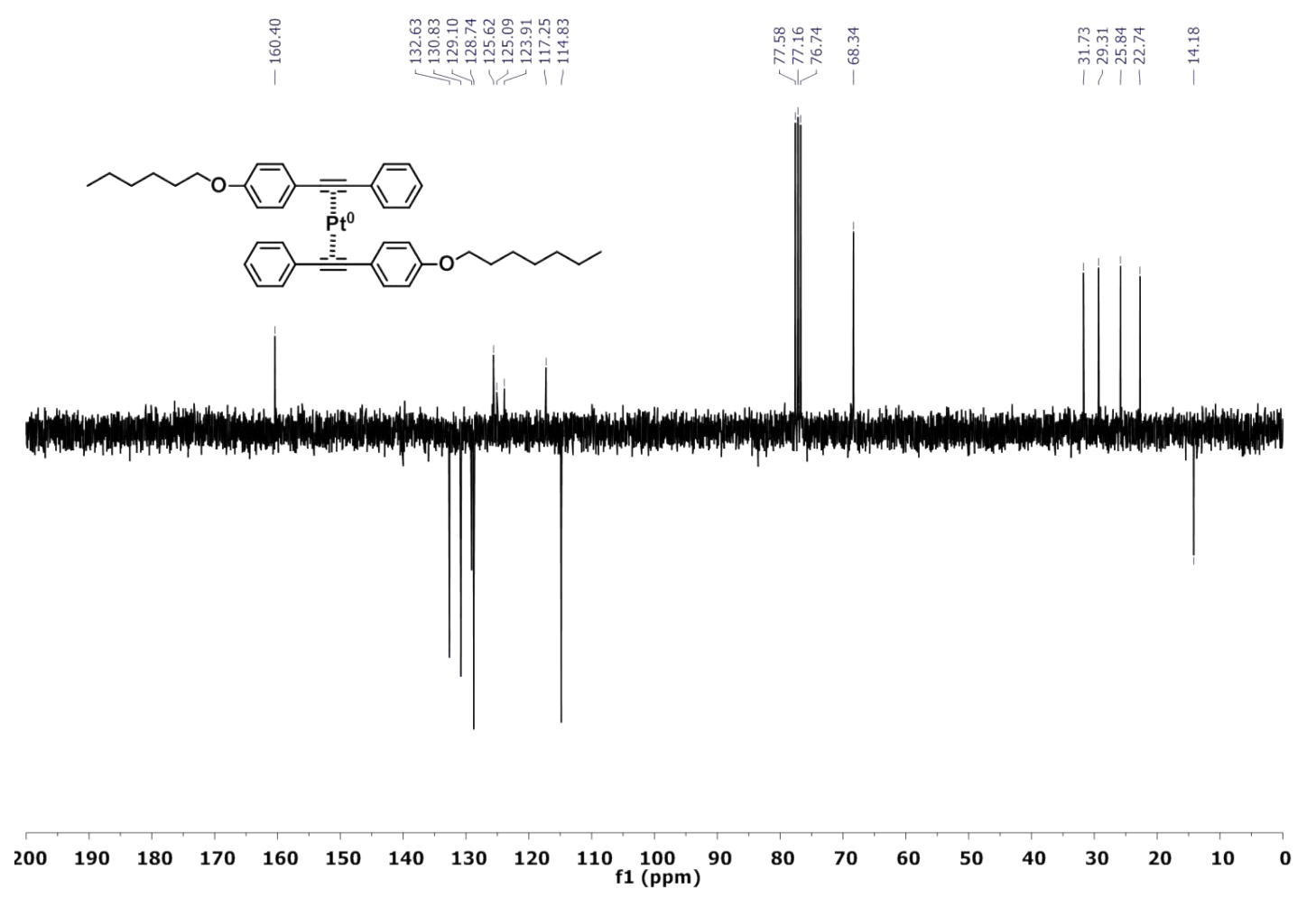

195 Pt NMR spectrum $\left(\mathrm{CD}_{2} \mathrm{Cl}_{2}, 86 \mathrm{MHz}\right)$ of 4 .
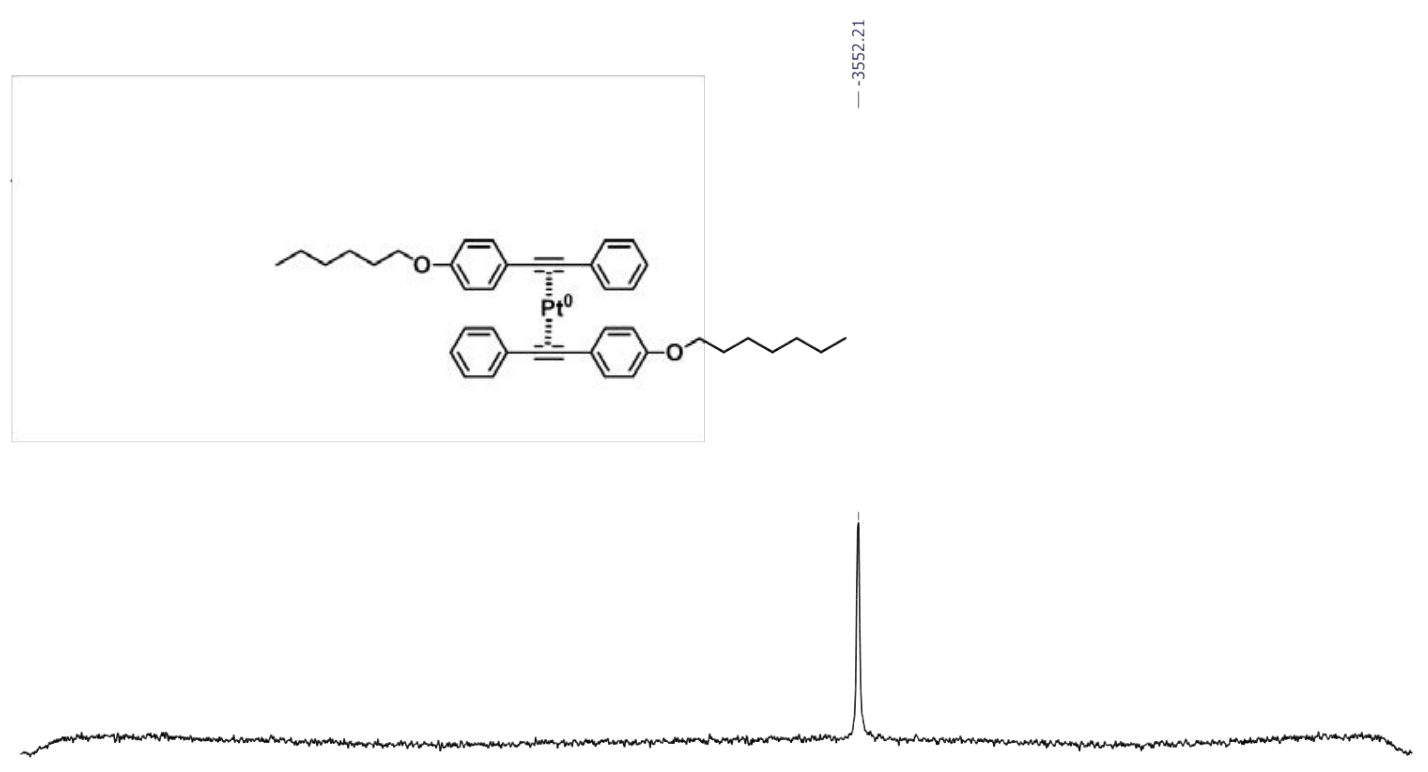

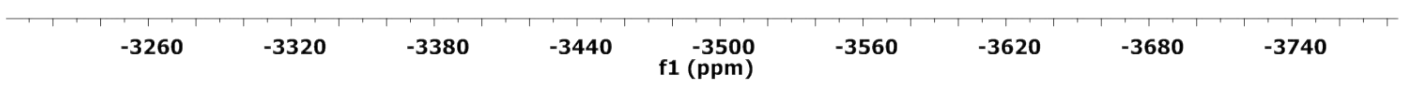


${ }^{1} \mathrm{H}$ NMR spectrum $\left(\mathrm{CDCl}_{3}, 400 \mathrm{MHz}\right)$ of 4-phenylethynyl-phenol.
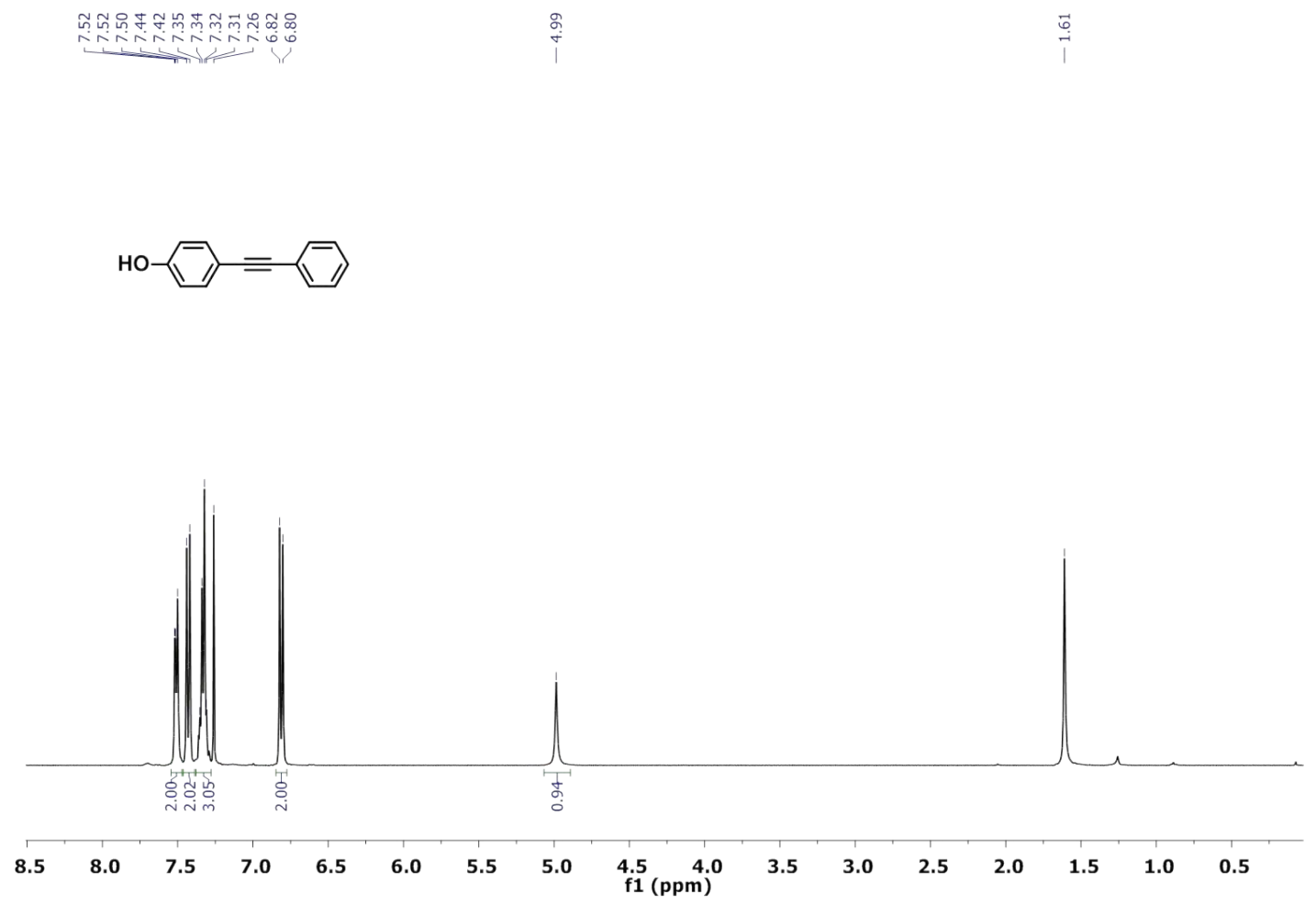

${ }^{13} \mathrm{C}$ NMR spectrum $\left(\mathrm{CDCl}_{3}, 101 \mathrm{MHz}\right)$ of 4-phenylethynyl-phenol.

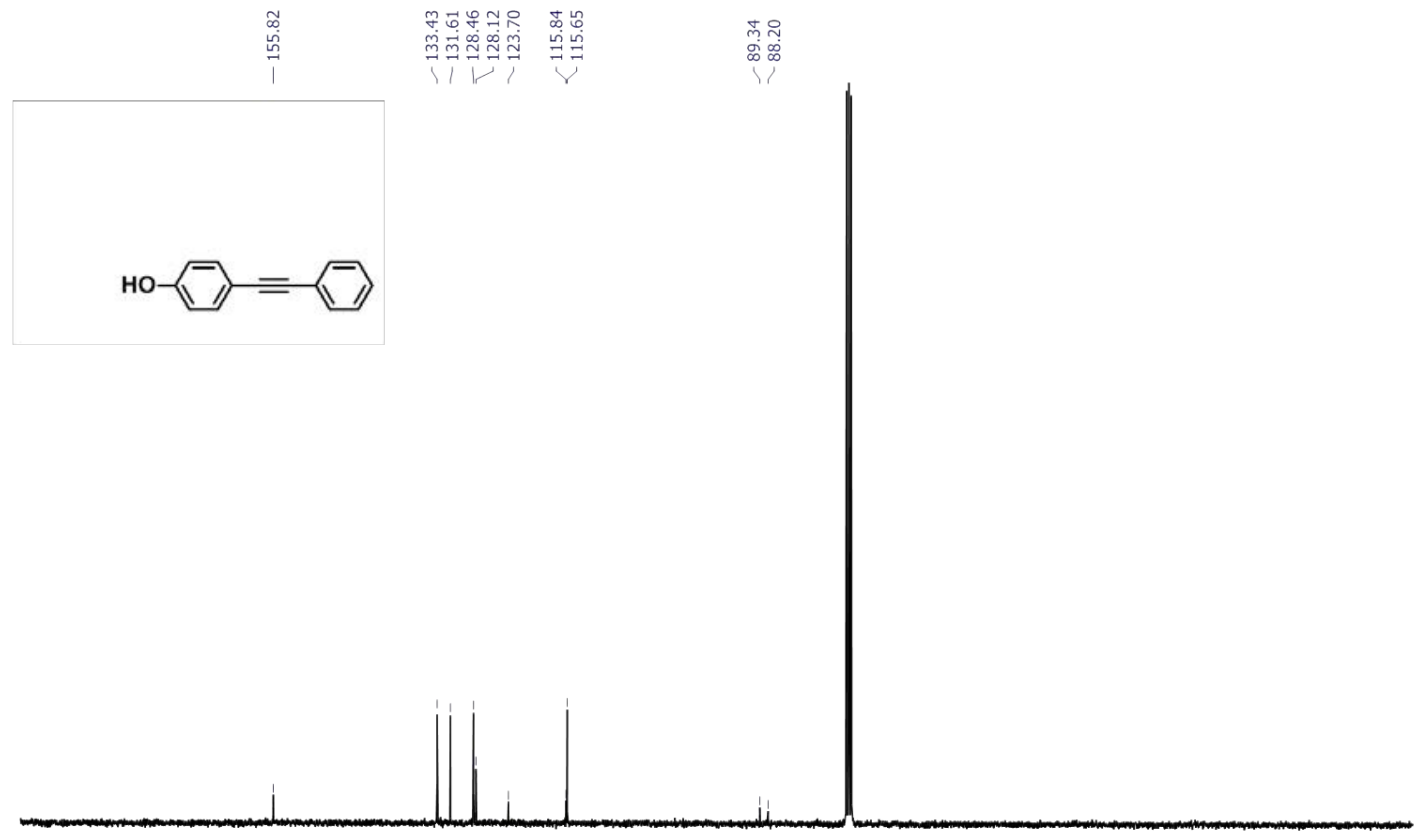

190

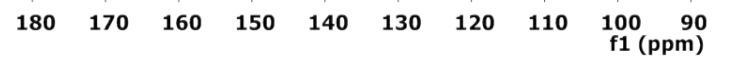

100
f1

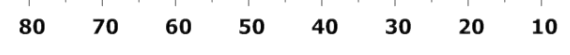


${ }^{1} \mathrm{H}$ NMR spectrum $\left(\mathrm{CDCl}_{3}, 400 \mathrm{MHz}\right)$ of toluene 4-sulfonic acid hexyl ester.
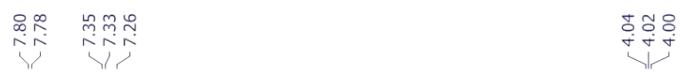

告.
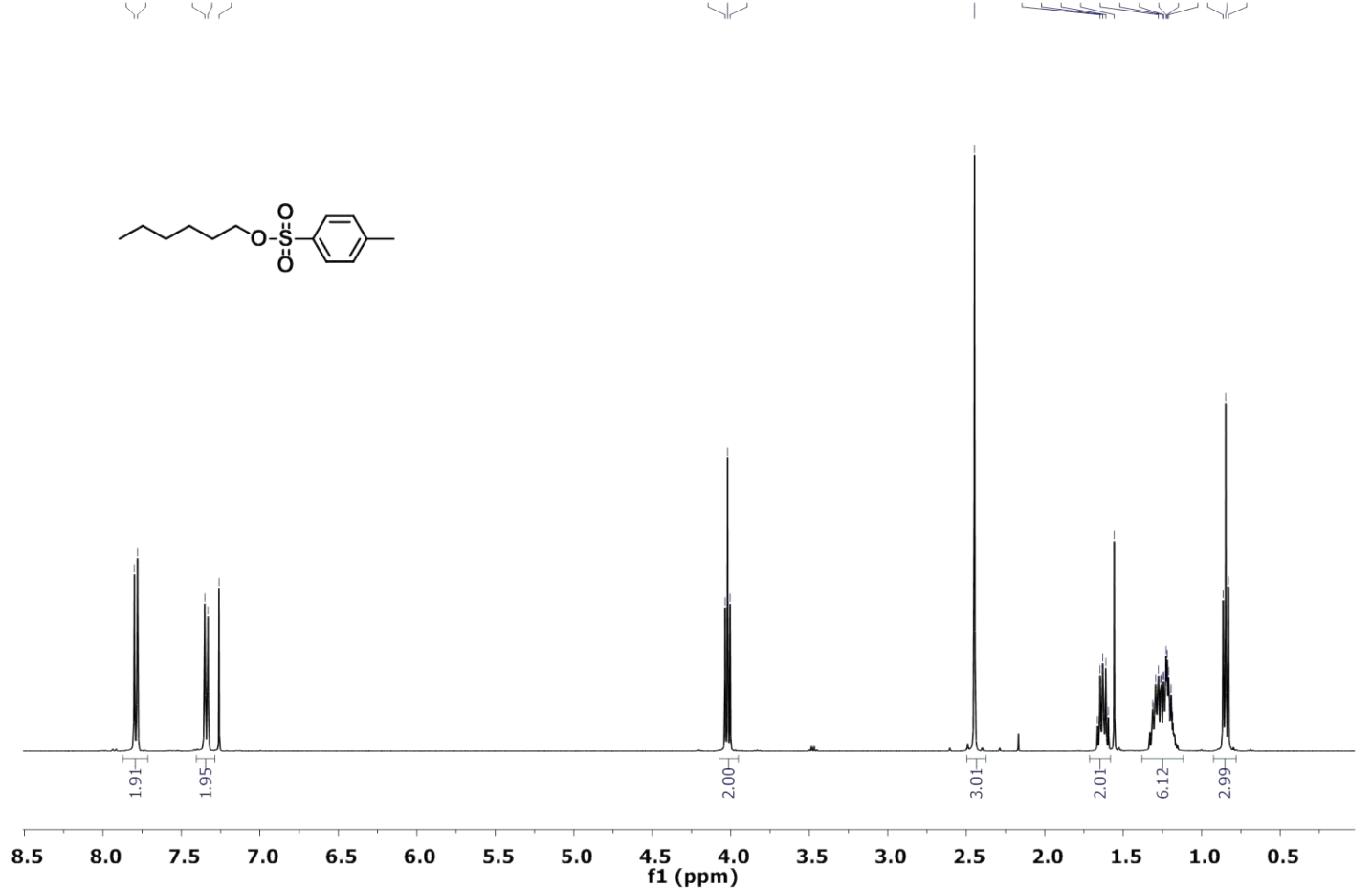

${ }^{13} \mathrm{C}$ NMR spectrum $\left(\mathrm{CDCl}_{3}, 101 \mathrm{MHz}\right)$ of toluene 4-sulfonic acid hexyl ester.
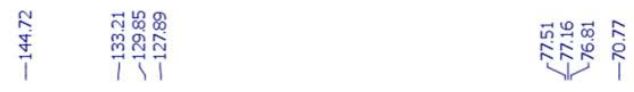

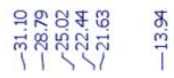

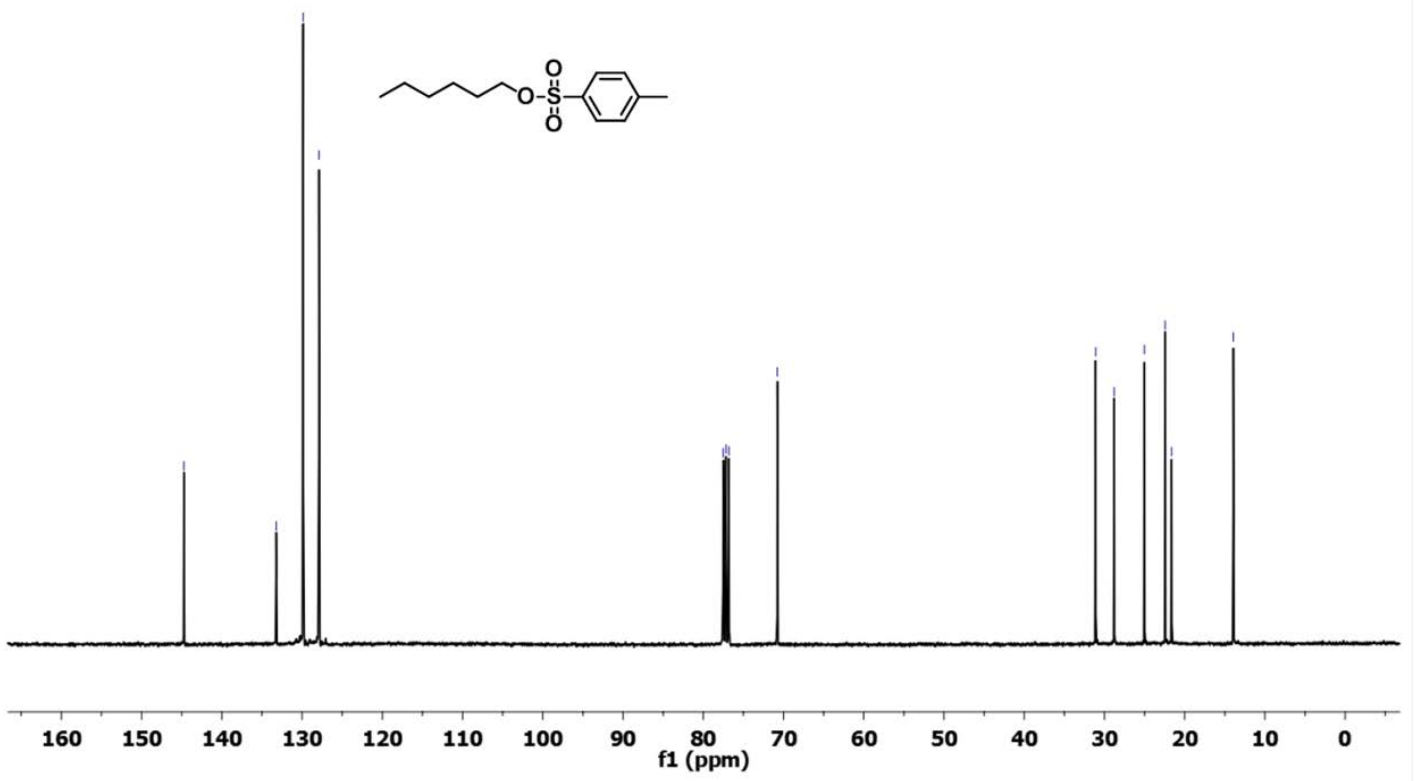


195Pt NMR spectrum $\left(\mathrm{CD}_{2} \mathrm{Cl}_{2}, 86 \mathrm{MHz}\right)$ of $\mathrm{PtCl}_{2}$ (styrene) 2 .

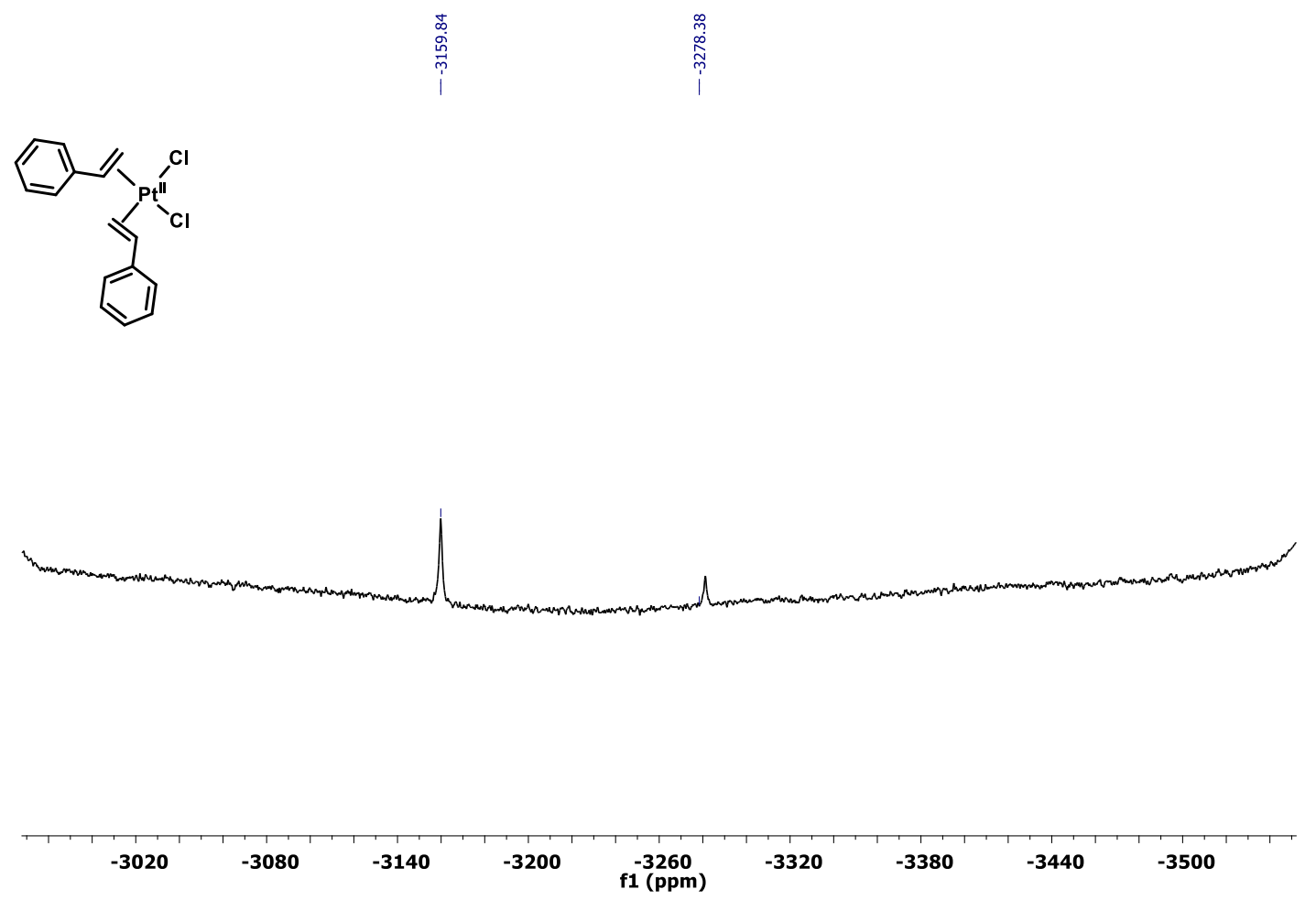

${ }_{195} \mathrm{Pt}$ NMR spectrum $\left(\mathrm{CD}_{2} \mathrm{Cl}_{2}, 86 \mathrm{MHz}\right)$ of $\mathrm{Pt}(0)$ (styrene) $)_{3}$.
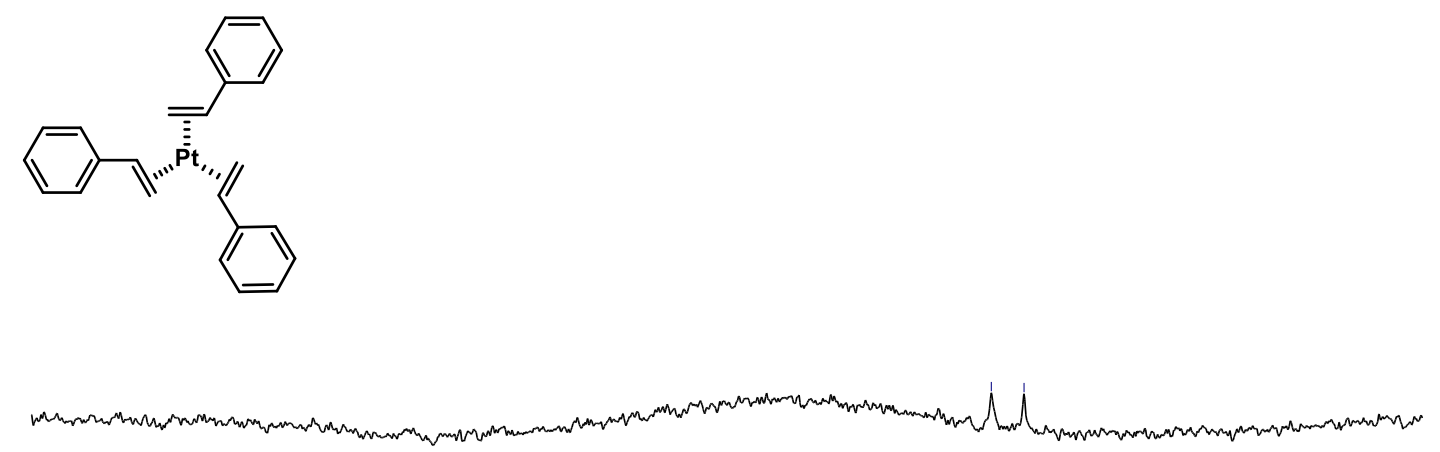

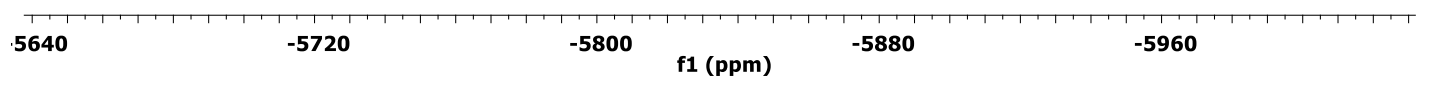


${ }^{1} \mathrm{H}-\mathrm{NMR}$ spectrum $\left(\mathrm{CDCl}_{3}, 400 \mathrm{MHz}\right)$ of hydroxyl terminated poly(ethylene-co-butylene).

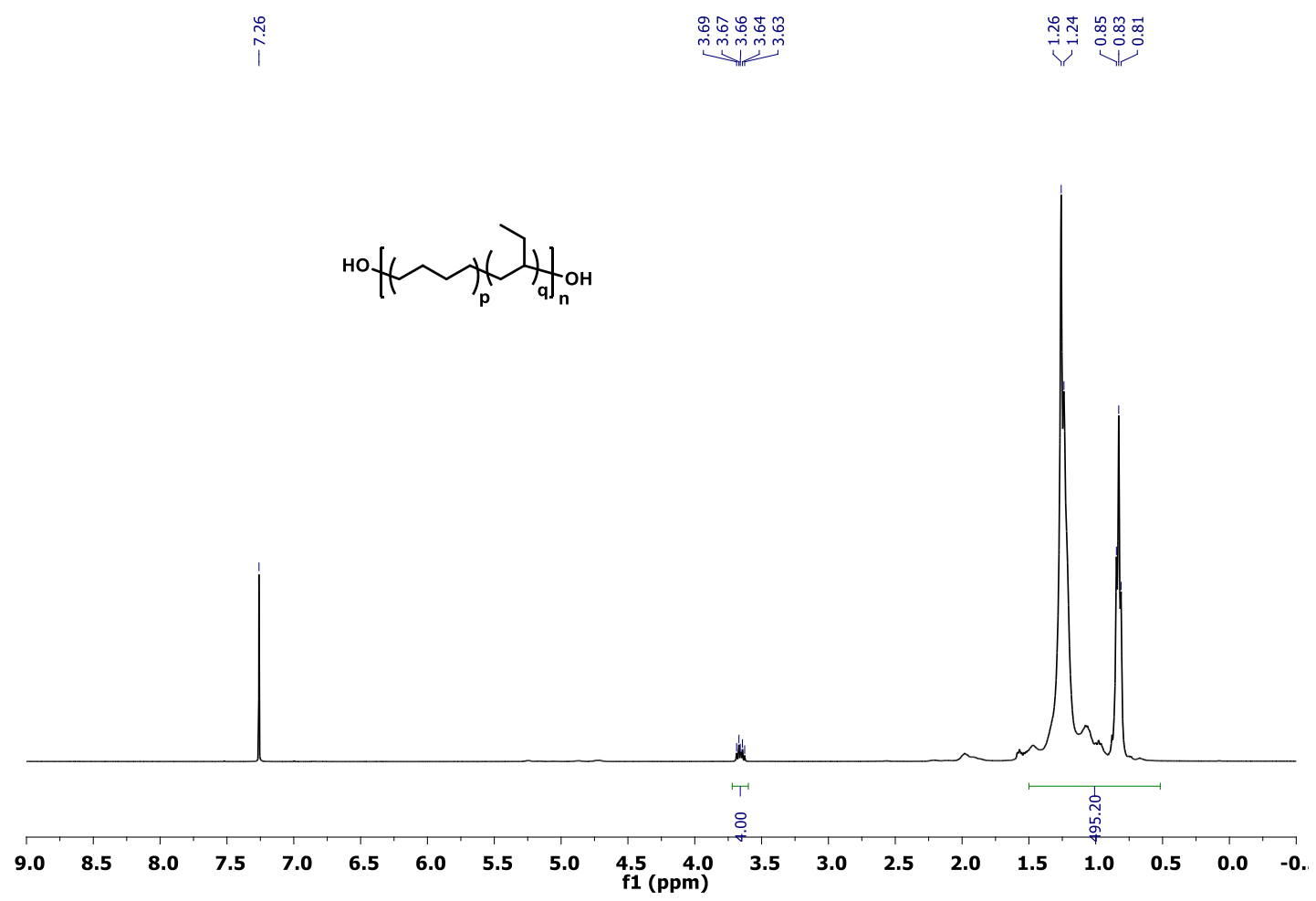

${ }^{1} \mathrm{H}-\mathrm{NMR}$ spectrum $\left(\mathrm{CDCl}_{3}, 400 \mathrm{MHz}\right)$ of tosylated poly(ethylene-co-butylene).

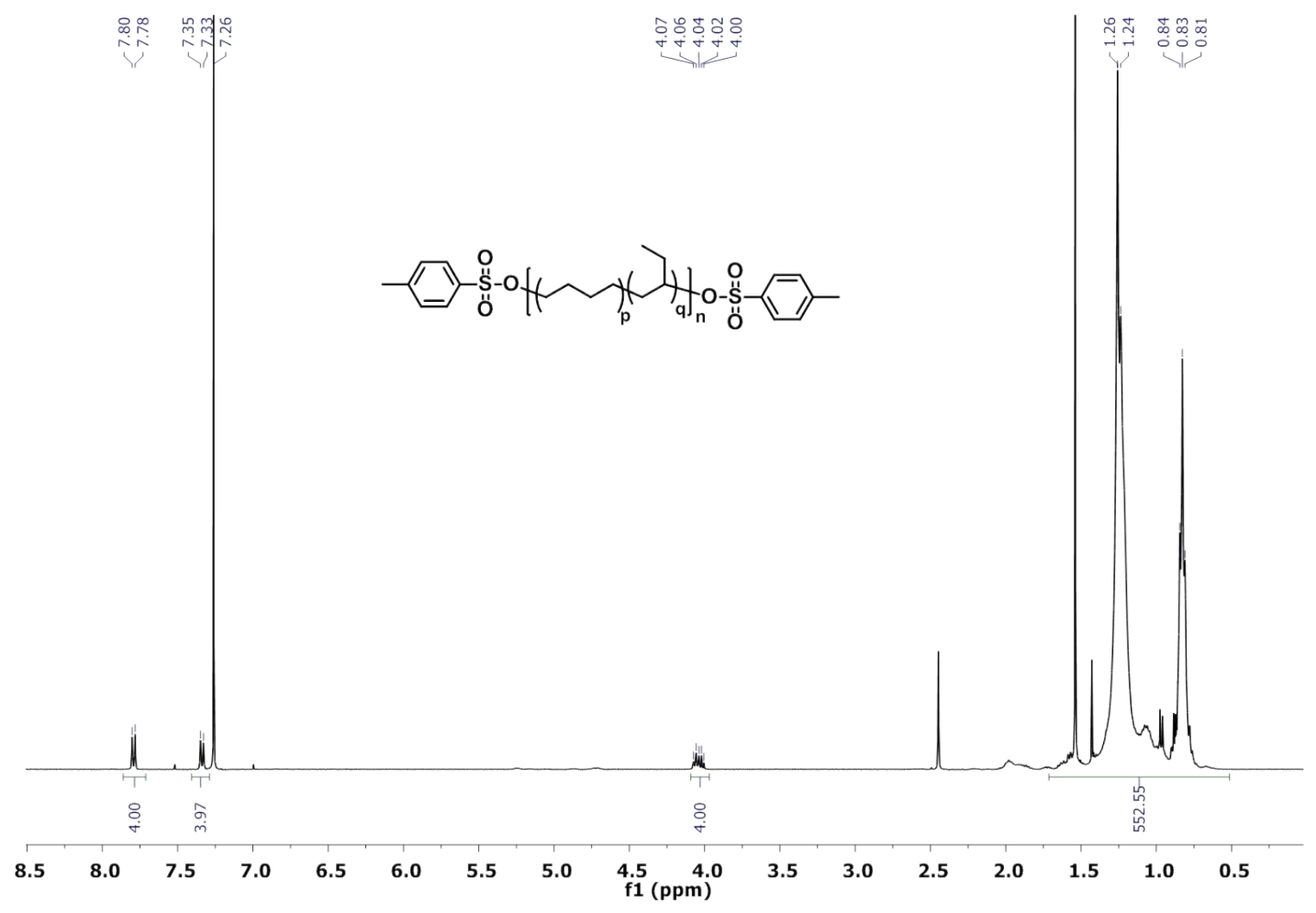




\section{References}

(1) Boita, J.; Nicolao, L.; Alves, M. C. M.; Morais, J. Observing Pt Nanoparticle Formation at the Atomic Level During Polyol Synthesis. Phys. Chem. Chem. Phys. 2014, 16 (33), 17640-17648.

(2) Jim, C. K. W.; Lam, J. W. Y.; Leung, C. W. T.; Qin, A.; Mahtab, F.; Tang, B. Z. Helical and Luminescent Disubstituted Polyacetylenes: Synthesis, Helicity, and Light Emission of Poly(Diphenylacetylene)S Bearing Chiral Menthyl Pendant Groups. Macromolecules 2011, 44 (8), 2427-2437.

(3) Caseri, W.; Pregosin, P. S. Hydrosilylation Chemistry and Catalysis with Cis- $\mathrm{PtCl}_{2}\left(\mathrm{PhCH}_{2} \mathrm{CH}_{2}\right)_{2}$. Organometallics 1988, 7 (6), 1373-1380.

(4) Albinati, A.; Caseri, W. R.; Pregosin, P. S. Hydrosilylation with Platinum Complexes. Preparation, Low-Temperature NMR Spectra, and X-Ray Crystal Structure of the Novel Bis-Olefin Catalyst Cis- $\mathrm{PtCl}_{2}\left(\mathrm{PhCH}: \mathrm{CH}_{2}\right)_{2}$. Organometallics 1987, 6 (4), 788-793.

(5) Montero de Espinosa, L.; Balog, S.; Weder, C. Isophthalic Acid-Pyridine H-Bonding: Simplicity in the Design of Mechanically Robust Phase-Segregated Supramolecular Polymers. ACS Macro Lett. 2014, 3 (6), 540-543. 